\title{
WILEY-VCH
}

\section{New Strategies for Defect Passivation in High-Efficiency Perovskite Solar Cells}

Seckin Akin, Neha Arora*, Shaik M. Zakeeruddin, Michael Grätzel, Richard H. Friend, M. Ibrahim Dar*

Dr. N. Arora, Dr. M. I. Dar, Prof. R. H. Friend

Cavendish Laboratory, Department of Physics, University of Cambridge, JJ Thomson

Avenue, Cambridge CB3 OHE, UK

E-mail: id338@cam.ac.uk, na498@cam.ac.uk

Dr. S. Akin, Dr. S. M. Zakerruddin, Prof. M. Grätzel

Laboratory of Photonics and Interfaces, Department of Chemistry and Chemical Engineering, École Polytechnique Fédérale de Lausanne, Lausanne CH-1015, Switzerland

Dr. S. Akin

Department of Metallurgical and Materials Engineering, Karamanoglu Mehmetbey

University, 70100, Karaman, Turkey

Keywords: (perovskite solar cells, defects, passivation, efficiency, mixed-cation-halide, 2D$3 \mathrm{D}$, engineering, stability)

Lead halide perovskite solar cells (PSCs) now show excellent efficiencies and encouraging levels of stability. Further improvements in performance require better control of electronhole recombination processes associated with trap states. Such trap states are considered to be associated with vacancies and defects at crystallite surfaces. We consider here how these traps can be mitigated by improving the quality of the perovskite layer and interfaces in fully assembled device configurations. In this review, we discuss most recent design strategies reported in the literature, that have been explored to tune grain orientation, to passivate defects, and to improve charge-carrier lifetimes. Specifically, we discuss advances made with single-cation, mixed-cation, and mixed-halide, and three-dimensional/two-dimensional(3D/2D) bilayer based light absorbers. We focus on interfacial, compositional, and band alignment engineering with their consequent effects on the open-circuit voltage, power conversion efficiency, and stability. 


\section{WILEY-VCH}

\section{Introduction}

The impetus to commercialize lead-halide perovskite solar cells (PSCs) as next-generation solar cells arises from their simple and facile solution-processibility. ${ }^{[1,2,3,4,5]}$ In addition, their desired optoelectronic properties such as high absorption coefficient with long carrier diffusion lengths have promoted the research domain targeting low-cost and high-efficiency solar cells. ${ }^{[6,7,8,9]}$ Initially, Miyasaka and co-workers reported breakthrough research on liquid electrolyte based PSCs with power conversion efficiency $(P C E)$ of $3.8 \%$ in $2008 .{ }^{[10]}$ Subsequently, higher PCEs were obtained while employing spiro-OMeTAD, a solid-state hole conductor in PSCs. ${ }^{[4,6]}$ All-solid-state PSCs also revealed that the generation of freecharges inside the bulk of the perovskite absorber layer. Since then, the PSC research field has expanded dramatically with PCEs exceeding $25 \% \cdot{ }^{[11]}$ One of the important aspects of improving the $P C E$ of PSCs is to minimize non-radiative recombination processes and preclude the carrier quenching both within the photoactive layer and at the interfaces while simultaneously promoting balanced charge transport and collection. ${ }^{[12,13,14,15]}$

Although it is difficult to know the nature of defects and to differentiate defects located at the surface and grain boundaries (GBs), their formation could be finely controlled by controlling the growth and morphology of the perovskite films and other structures. ${ }^{[16,17,18]}$ In addition, the compositional engineering of these $\mathrm{ABX}_{3}$ compounds, which allows tailoring of the bandgap, could be explored to improve the optoelectronic properties with great rationality to simultaneously increase the efficiency and stability of PSCs. Recently, many advances in the compositional (cation and/or anion) engineering including the partial substitution of formamidinium $\left(\mathrm{FA}^{+}\right)$cation and $\mathrm{I}^{-}$, respectively, with methylammonium $\left(\mathrm{MA}^{+}\right)$and $\mathrm{Br}^{-}$have been made to enhance both performance and stability. ${ }^{[19,20]}$ In addition, both organic and inorganic cations like cesium $\left(\mathrm{Cs}^{+}\right)$, rubidium $\left(\mathrm{Rb}^{+}\right)$, potassium $\left(\mathrm{K}^{+}\right)$, sodium 


\section{WILEY-VCH}

$\left(\mathrm{Na}^{+}\right)$, silver $\left(\mathrm{Ag}^{+}\right)$, guanidinium $\left(\mathrm{Gua}^{+}\right)$have been explored into the perovskite films to enhance the photovoltage ( $V O C$ ) of PSCs. ${ }^{[21,22,23,24]}$

The mitigation of instability issues, which get aggravated in the presence of traps, is one of the main challenges that PSCs technology is facing currently. Therefore, it has become imperative to passivate defects located at the surface and GBs. ${ }^{[25,26]}$ Towards this end, various strategies such as interface engineering via surface passivation and charge compensation by using metal oxides, additive engineering approach, which was employed to enlarge the dimensions of perovskite grains, and to increase the crystallinity, and small molecules, or polymers etc. have been developed for the stabilization of crystal phase and defect management in PSCs. ${ }^{[27,28,29]}$ More recently, the application of 2D Ruddlesden-Popper layered perovskites $\left.\left(\mathrm{RNH}_{3}\right)_{2}(\mathrm{~A})_{\mathrm{n}-1} \mathrm{BX} 3 \mathrm{n}+1\right),(n=1,2,3,4, \ldots \infty)$ (where $n$ is the number of layers and $\mathrm{RNH}_{3}$ are large alkyl ammonium cations) have been proposed as stable alternatives to $3 \mathrm{D}$ perovskites because of their superior hydrophobicity and thermostability. ${ }^{[1,30,31]}$ However, the PSCs employing 2D perovskites as the active layer display relatively poor performances primarily due to the anisotropic transport properties, which are intrinsically associated with the layered structure. Interestingly, in conjugation with the 3D perovskites, both efficiency and stability can be synergistically improved mainly due to the passivation of interfacial GBs in a 3D/2D bilayer configuration. ${ }^{[1]}$ Such a bilayer architecture also minimizes the issues associated with the hygroscopic nature of the 3D-perovskite material and sensitivity towards high temperature, which can induce the degradation of the interfaces and rapidly decrease the photovoltaic performances within a short period of operation. The graded combination of 2D/3D can also hinder the ionic-motion and mitigate the parasitic interfacial charge-carrier recombination. ${ }^{[32]}$ 


\section{WILEY-VCH}

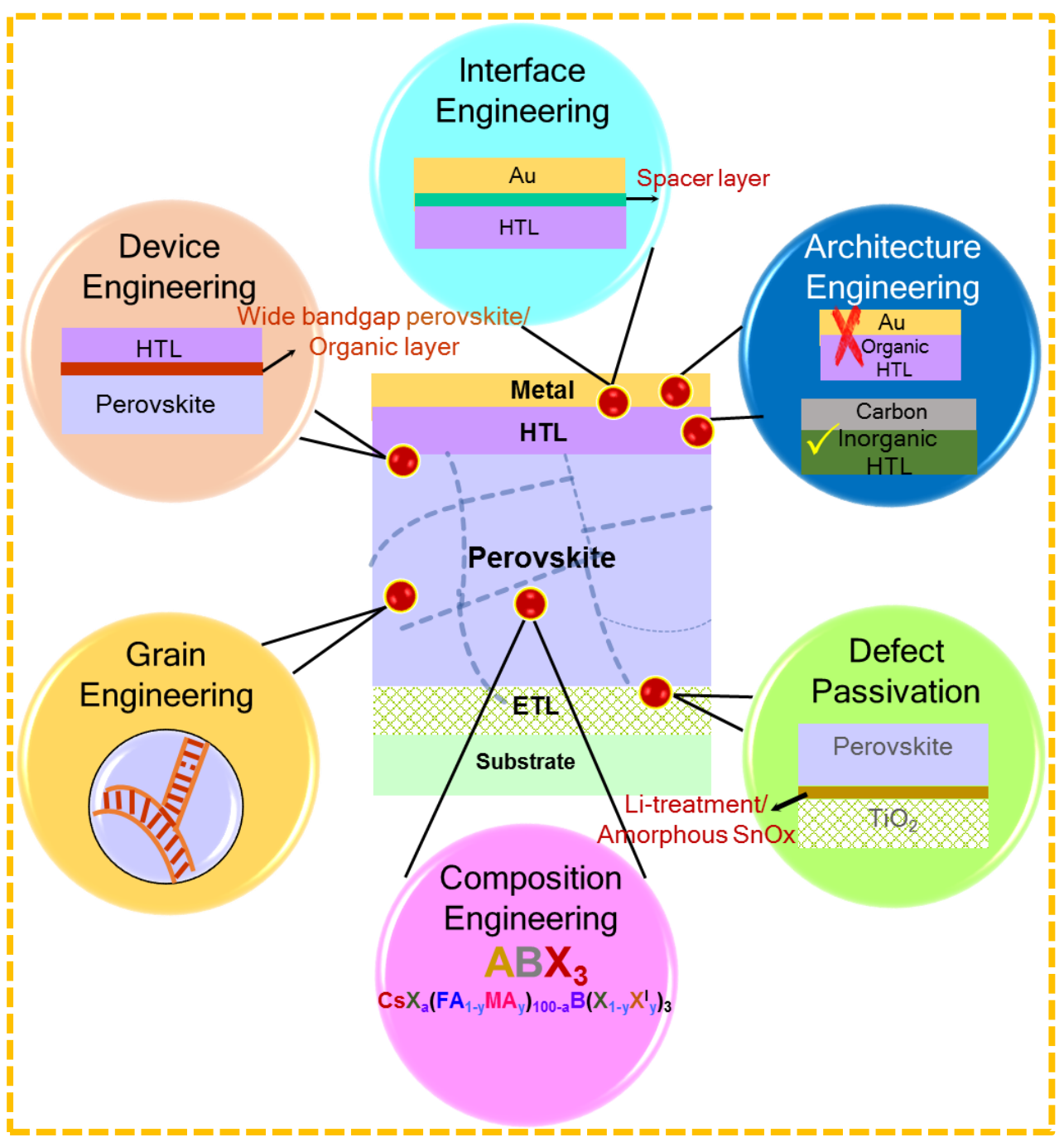

Figure 1. Schematic illustration of different passivation strategies for high-efficiency perovskite solar cells.

In this review, we provide an overview of the recent progress on the strategies adopted to passivate defects to realize high-efficiency PSCs (Figure 1). Firstly, we aim to highlight the routes that have been successfully explored to control the non-radiative recombination and enhance the photovoltage of PSCs. Specifically, most recent reports on PSCs based on singlecation to mixed-cation and/or mixed- halide to the $3 \mathrm{D} / 2 \mathrm{D}$ perovskite system will be discussed. The next section illustrates the stability of the PSCs based on these systems probed under illumination, humid conditions and thermal stress. Finally, the last section will provide the perspectives about this enticing scientific domain, i.e., defect passivation in PSCs. 


\section{WILEY-VCH}

\section{Single cation-based perovskites}

In the last decade, PSCs has become a promising and emerging technology with certified efficiency exceeding 25\%, ${ }^{[11]}$ This photovoltaic technology began with PSCs involving singlecation based light absorber with an efficiency of 3.8\% ${ }^{[10]}$ The forthcoming sections highlight recent reports showing that the approaches including composition-additive, charge transport layers, interface, and device architecture engineering are critical to the performance of these single cation-based PSCs.

\subsection{Composition-additive engineering in single cation perovskites}

A high-quality perovskite film with low-amount of grain boundaries and fewer trap states in the bulk and/or at the interfaces is necessary to obtain good performance. Compositionadditive engineering is one of the most efficient strategies to obtain perovskite films with high crystallinity, smooth surfaces, and large grains, which reduce the grain boundaries and trap states. In this section, composition-additive engineering approaches for single-cation perovskite absorber are discussed.

Carmano et al. fabricated the n-i-p-type mesoporous PSCs based on a nonstoichiometric $\mathrm{PbI}_{2}$ : MAI ratio $(x: 1$, being $x \geq 1)$ in the perovskite precursor solution. ${ }^{[33]}$ The obtained results demonstrated that the unreacted $\mathrm{PbI}_{2}$ enhances the crystallinity of the perovskite film due to the stronger interfacial coupling at the interface and promotes the electron transfer from perovskite to $\mathrm{TiO}_{2}$ layer owing to better band alignment. As a result of these remarkable properties, an improvement in the $F F$ and $V O C$ (as high as $1.11 \mathrm{~V}$ ) was acquired, boosting the averaged $P C E$ from $16.2 \%$ to values close to $18 \%$, with a champion efficiency of $>19 \%$. It is worth mentioning that the concept of using excess $\mathrm{PbI}_{2}$ renders the use of precursors containing a stoichiometric ratio of $\mathrm{PbI}$ : MAI undesired, as was commonly believed in the PSC field. In some cases, different methodologies were introduced to induce rapid crystallization of the perovskite structures with a slight excess of $\mathrm{PbI}_{2}$. For example, 


\section{WILEY-VCH}

laser irradiation was explored to obtain homogeneous and dense-grained $\mathrm{MAPbI}_{3}$ films. ${ }^{[34]}$ The advantage of laser irradiation is to produce a thermal gradient, which was found to be beneficial for the formation of the desired amount of $\mathrm{PbI}_{2}$ on the surface of $\mathrm{CH}_{3} \mathrm{NH}_{3} \mathrm{PbI}_{3}$ perovskite film. Consequently, the parasitic recombination occurring at the interface decreased due to self-passivation, minimizing the voltage loss to $0.41 \mathrm{~V}$.

New molecules were also designed to passivate the defects (defect-healing), which greatly improved the efficiency and stability of PSCs. Zheng et al. reported a study to passivate the ionic defects at the surfaces and grain boundaries of $\mathrm{MAPbI}_{3}$ perovskite films by using quaternary ammonium halides (QAHs), i.e., $N R_{4}^{+} X^{-}(R$ is an alkyl or aryl group and $X$ is halide). ${ }^{[35]}$ In addition to a significant reduction in the trap-state density, an improvement in the charge carrier lifetime was also observed in the presence of choline chloride-based passivation layer as shown in Figure 2a. As a result of successful passivation of ionic defects, the $V_{O C}$ of the p-i-n-architecture based planar devices increased from $1.04 \mathrm{~V}$ to $1.15 \mathrm{~V}$ with a significant enhancement in PCE (17.1\% to $20.0 \%)$ and hysteresis-free behavior. In addition, the defect healing approach enhanced the ambient stability of the perovskite films. The larger Voc yielded by the devices involving choline chloride QAHs was attributed to their zwitterionic structure and to the additional passivation effects of the halide ions (Figure $\mathbf{2 b}$ ). Another interesting aspect related to additive engineering approach is to achieve high-quality perovskite absorber films. For example, Wu et al. demonstrated that the addition of a small amount of $\mathrm{H}_{2} \mathrm{O}$ into $\mathrm{PbI} / \mathrm{DMF}$ makes a homogenous precursor solution for depositing highquality $\mathrm{PbI}_{2}$ film in a two-step method. ${ }^{[36]}$ Apparently, moisture can assist the grain growth of the perovskite film to improve the charge-carrier lifetime and carrier mobility. ${ }^{[37]}$ In this study, highly pure, smooth, crystalline and oriented perovskite films were deposited on PEDOT:PSS surface. The $\mathrm{PbI}_{2}$ film involving $2 \mathrm{wt} \%$ water exhibited the smoothest and 


\section{WILEY-VCH}

densely packed films composed of large grains. The inverted-type champion PSC showed a remarkable $F F$ of 0.85 , resulting in a $P C E$ of $18 \%$ with a $V O C$ of $1.03 \mathrm{~V}$.

Recently Han et al. developed an additive-based room temperature process to obtain high-quality $\mathrm{MAPbI}_{3}$ films with micron-sized grains ( $\left.>2 \mu \mathrm{m}\right)$, employing a simple lowvacuum process. ${ }^{[38]}$ Authors used methylammonium thiocyanate (MASCN) as an additive and achieved microsecond-range carrier lifetimes and highly crystalline perovskite films at room temperature. As a result of these excellent film characteristics, the best PCE of $18.22 \%$ (average $16.92 \%$ ) with low hysteresis and respectable environmental stability under the standard illumination was realized, whereas the control device (without additive) demonstrated only $2.04 \% P C E$ with $J_{S C}$ of $8.78 \mathrm{~mA} \mathrm{~cm}^{-2}, V O C$ of $0.638 \mathrm{~V}$ and $F F$ of 0.36 , under similar conditions. Such an improvement in the photovoltaic parameters was explained on the basis of increased grain size and improved crystallinity of perovskite films. The additive-based mechanism was proposed and verified by Tindall-effect tests and DLS measurements. The coordination of $\mathrm{SCN}^{-}$with $\mathrm{Pb}^{2+}$ facilitates enlargement of the precursor aggregates up to microscale before spin coating which arranges in an ordered fashion on the substrates during the film deposition. The solvent and volatile $\mathrm{SCN}^{-}$were removed by applying low-vacuum as depicted in Figure 2c.

Very recently, Zhou et al. employed the imidazole sulfonate zwitterion, 4-(1Himidazol-3-ium-3-yl) butane-1-sulfonate (IMS), as a bifunctional additive in an n-i-p planar $\mathrm{MAPbI}_{3}$ based type PSCs. ${ }^{[39]}$ It was reported that this additive not merely arranges the crystal orientation but also passivates the trap states of $\mathrm{MAPbI}_{3}$ perovskite film especially the iodine vacancy. The effect of bi-functional IMS additive observed due to coordination between sulfonate moiety of IMS and $\mathrm{Pb}^{2+}$ ion as well as electrostatic interaction between imidazole of IMS and $\mathrm{I}^{-}$ion of perovskite (Figure 2d). As a result, the PCE and $V o c$ increased from $18.77 \%$ and $1.10 \mathrm{~V}$ to $20.84 \%$ and $1.14 \mathrm{~V}$, respectively, while hysteresis decreased in the 


\section{WILEY-VCH}

presence of $0.5 \mathrm{wt} \%$ IMS doping. For a $1.2 \mathrm{wt} \%$ IMS doping ratio, a $V_{O C}$ of $1.208 \mathrm{~V}$ was achieved, and this was claimed to be the highest $V_{O C}$ for $\mathrm{MAPbI}_{3}$ employing n-i-p structured planar PSCs.

A record $V O C$ of $1.26 \mathrm{~V}$ has been demonstrated for planar solar cells with inverted architecture based on smooth $\mathrm{MAPbI}_{3}$ perovskite films with large grains. ${ }^{[40]}$ The perovskite films were obtained after employing the combination of lead acetate $\left(\mathrm{PbAc}_{2}\right)$ and lead chloride $\left(\mathrm{PbCl}_{2}\right)$ precursors and optimizing the contact layers. In addition, exceptionally long photoluminescence lifetimes, which translated into a magnificent $P C E$ of $\sim 20.7 \%$ were reported.

In addition to the molecular doping, the introduction of metal ions in the perovskite structure is another promising approach to address the main critical concerns of PSCs. Towards this end, various monovalent cations including $\mathrm{Na}^{+}, \mathrm{Ag}^{+}, \mathrm{Cu}^{+}$were introduced in the $\mathrm{MAPbI}_{3}$ films to improve the optoelectronic properties of MAPbI 3 structures, ${ }^{[41,42]}$ which consequently increased the photovoltaic performance of the resulting devices. The role of other inorganic cations such as $\mathrm{Cs}^{+}$and $\mathrm{Rb}^{+}$was also investigated in various perovskite compositions and the insights gained through various structural, thermal and spectroscopic studies amply established the absence of $\mathrm{Rb}^{+}$whereas, under similar conditions, a certain amount of $\mathrm{Cs}^{+}$was found to be occupying the A-site in 3D perovskite. ${ }^{[43]}$ In another interesting study, $\mathrm{Pb}$ metal in $\mathrm{MAPbI}_{3}$ perovskite films was substituted by nine different alternative divalent metal species such as $\mathrm{Co}, \mathrm{Cu}, \mathrm{Fe}, \mathrm{Mg}, \mathrm{Mn}, \mathrm{Ni}, \mathrm{Sn}, \mathrm{Sr}, \mathrm{Zn}$ to screen the tolerance of perovskite film towards extrinsic homovalent metal species and its impact on the photovoltaic performance of inverted-type $\mathrm{MAPbI}_{3} \mathrm{PSCs}{ }^{[4]}$ It was proven that the $\mathrm{MAPbI}_{3}$ film shows a much higher tolerance without any performance loss in comparison to crystalline silicon when less than $3 \%$ of the $\mathrm{Pb}^{2+}$ ions were replaced. This compositional engineering approach also showed that not only well-known $\mathrm{Sn}^{2+}$ but also $\mathrm{Co}^{2+}$ can replace $\mathrm{Pb}^{2+}$ from the 


\section{WILEY-VCH}

perovskite lattice as revealed by the crystallographic analysis. By using the optimum molar ratio of $63 \mathrm{~Pb}: 1 \mathrm{Co}$, the best $P C E$ of $17.2 \%$ with an improved $V O C$ (from $0.96 \mathrm{~V}$ for the baseline to $1.05 \mathrm{~V}$ for $63 \mathrm{~Pb}: 1 \mathrm{Co}$ and to $1.08 \mathrm{~V}$ for $31 \mathrm{~Pb}: 1 \mathrm{Co}$ ratio) over the standard MAPbI3. The $\sim 120 \mathrm{mV}$ increase in $V O C$ was attributed to the ability of $\mathrm{Co}^{2+}$ to shift the Fermi level and valence band edge of the perovskite material into a more favourable energetic alignment with HTL. Apparently, the obtained results showed that transition metal substitution could provide a new dimension for tuning the electronic and crystallographic properties of perovskite films while maintaining high photovoltaic performance.

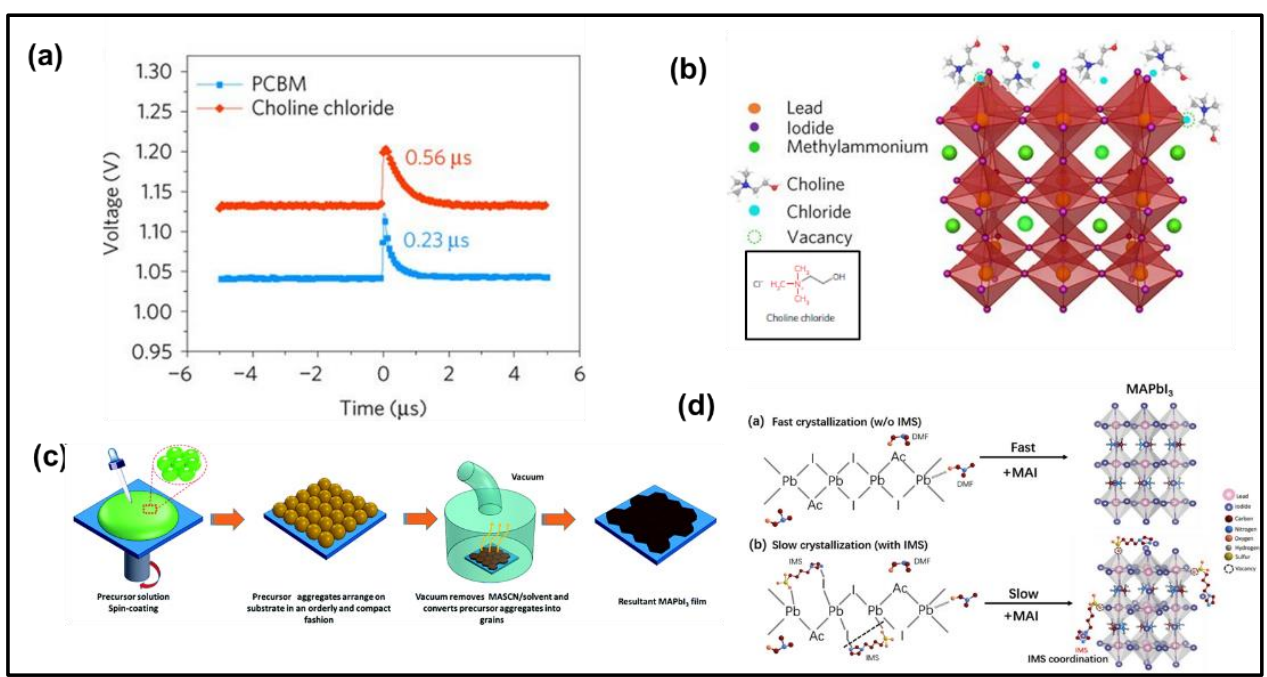

Figure 2. a) Charge carrier lifetime curves of control and choline chloride-treated devices, estimated from transient photovoltage measurement under open-circuit conditions. Reproduced with permission. [35] Copyright 2017, Nature Publishing Group. b) Schematic illustration of quaternary ammonium halides assembled on the defect sites (the red and blue symbols represent the $\mathrm{N}$ and $\mathrm{O}$ atoms of the choline chloride molecule, respectively). Reproduced with permission.[35] Copyright 2017, Nature Publishing Group. c) Schematic flow diagram of the room-temperature process to deposit $\mathrm{MAPbI}_{3}$ films and proposed film formation mechanism. Reproduced with permission.[38] Copyright 2017, Royal Society of Chemistry. d) Proposed formation mechanisms of $\mathrm{MAPbI}_{3}$ perovskite structure a) without and b) with imidazole sulfonate zwitterion, 4-(1H-imidazol-3-ium-3-yl)butane-1-sulfonate (IMS), as a bifunctional additive. Reproduced with permission.[39] Copyright 2019, John Wiley \& Sons.

In this section, we have covered recent reports of photovoltage enhancement in singlecation based PSCs in the context of composition-additive engineering. Quiet versatile 


\section{WILEY-VCH}

methods have been discussed including defect healing, increase in grain size and introduction of metal ions in the perovskite absorber. In the following, the different methods for energy band-alignment and interface engineering resulting in the improvement of photovoltaic parameters will be discussed.

\subsection{ETL engineering in single cation perovskites}

The electron transport layers (ETLs) play an indispensable role in PSCs owing to their key electron extracting/transporting features. Although $\mathrm{TiO}_{2}$ is considered as the most promising ETL material for highly efficient PSCs, it needs to be modified using suitable approaches or replaced with better alternatives to combat the current challenges, i.e., low electron mobility, insufficient band-offset, and high sintering temperature. In this section, highly promising modification methods and alternative ETL materials are presented to illustrate the importance of ETL materials in the state-of-the-art PSCs based on the single-cation absorber.

The impact of magical $\mathrm{TiCl}_{4}$ treatment was unraveled using photothermal deflection spectroscopy (PDS), and results amply showed a decrease in the energetic disorder not merely in mesoporous $\mathrm{TiO}_{2}$ but also in $\mathrm{CH}_{3} \mathrm{NH}_{3} \mathrm{PbI}_{3}$ light absorber layer. ${ }^{[45]}$ Using [6,6]-phenyl-C61butyric acid (PCBA) monolayer modified compact $\mathrm{TiO}_{2}\left(\mathrm{c}-\mathrm{TiO}_{2}\right)$ substrates, high-quality $\mathrm{CH}_{3} \mathrm{NH}_{3} \mathrm{PbI}_{3}$ films were deposited for planar heterojunction PSCs. ${ }^{[46]}$ The PCBA interfacial layer reduced the hole recombination by acting as the hole blocking layer at the c$\mathrm{TiO}_{2} / \mathrm{CH}_{3} \mathrm{NH}_{3} \mathrm{PbI}_{3}$ interface and facilitating efficient electron extraction by the ETL. The formation of a chemical bond between c- $\mathrm{TiO}_{2}$ and the carboxyl group of PCBA as well as the low solubility of PCBA in perovskite solvent of N, N-dimethylformamide (DMF) helped to obtain pin-hole free perovskite films, resulting in significant enhancement of photovoltaic performance from $7.46 \%$ to $13.33 \%$. The best $P C E$ of $17.76 \%$ with an outstanding $V O C$ of $1.16 \mathrm{~V}$ was achieved by optimizing the perovskite thickness. 


\section{WILEY-VCH}

Miyasaka and co-workers developed a fully low-temperature-processed PSCs employing an ultrathin amorphous $\mathrm{TiO}_{\mathrm{x}}$ ETL in combination with brookite $\mathrm{TiO}_{2}$ prepared at $<150{ }^{\circ} \mathrm{C} .{ }^{[47]}$ The $\mathrm{TiO}_{\mathrm{x}} /$ brookite $\mathrm{TiO}_{2}$ bilayer ETL based PSCs demonstrated an excellent $P C E$ up to $21.6 \%$, supported by a remarkable $V O C$ and $F F$ of $1.18 \mathrm{~V}$ and 0.83 , respectively, as a result of well-matched band alignment with respect to brookite $\mathrm{TiO}_{2}$. The authors also examined $\mathrm{SnO}_{\mathrm{x}}$ as an alternative ETL to $\mathrm{TiO}_{\mathrm{x}}$ in combination with brookite $\mathrm{TiO}_{2}$. Although the $\mathrm{SnO}_{\mathrm{x}} /$ brookite $\mathrm{TiO}_{2}$ bilayer ETL based PSCs yielded $V_{O C}$ and $J_{S C}$ as high as $\mathrm{TiO}_{\mathrm{x}} /$ brookite $\mathrm{TiO}_{2}$ based PSCs, loss of $F F$ resulted in relatively lower $P C E$. The electron band edge potentials of ETLs and brookite $\mathrm{TiO}_{2}$ were evoked to explain the drop in $F F$, whereas more negative conduction band edge of $\mathrm{SnO}_{\mathrm{x}}$ exhibited an energy barrier for electron injection from brookite $\mathrm{TiO}_{2}$ into $\mathrm{SnO}_{x}$ layer.

In comparison to $\mathrm{TiO}_{2}$ and $\mathrm{SnO}_{2}, \mathrm{ZnO}$ exhibits more promising electron extraction ability owing to its superior electron mobility and more favourable band-offset. A simple strategy was developed to obtain planar PSCs at low-temperature by combining bi-functional self-assembled monolayer (SAM)-modified $\mathrm{ZnO}$ electron-accepting layers with sequentially prepared perovskite active layers. ${ }^{[48]}$ Highly polar molecules of bithiophene conjugated cyanoacrylic acid (T2CA) julolidine moiety conjugated cyanoacrylic acid (JTCA) were employed as the SAM as shown in Figure 3a. The JTCA-modified ZnO ETL based PSCs reached a $P C E$ of $18.82 \%$ with $V_{O C}$ of $1.13 \mathrm{~V}$, whereas the pristine ZnO ETL based PSC reached only $15.41 \%$ with $V O C$ of $1.06 \mathrm{~V}$. The trap state measurements showed a lower trap density in the JTCA (SAM)-modified device whereas the carrier mobility of the ITO-JTCA employing device was $50 \%$ higher $\left(0.61 \mathrm{~cm}^{2} \mathrm{~V}^{-1} \mathrm{~s}^{-1}\right)$ than that of bare ITO $\left(0.43 \mathrm{~cm}^{2} \mathrm{~V}^{-1} \mathrm{~s}^{-1}\right)$. A large enhancement in the $V_{O C}$ from $0.962 \mathrm{~V}$ to $1.135 \mathrm{~V}$ and $P C E$ from $14.15 \%$ to $19.14 \%$ was reported for PEDOT:PSS HTL based inverted type $\mathrm{MAPbI}_{3}$ based PSCs by employing two-dimensional (2D) materials such as graphene oxide (GO) at PEDOT: PSS/perovskite 


\section{WILEY-VCH}

interface and $\mathrm{MoS}_{2}$ at PCBM/Ag interface. ${ }^{[49]}$ The $V O C$ was further improved to $1.176 \mathrm{~V}$ when the perovskite structure was doped with $\mathrm{Br}^{-}\left(\mathrm{MAPbI}_{2.5} \mathrm{Br} 0.5\right)$. In addition to enhanced ohmic contact, which facilitates the rapid transfer of the electrons across the $\mathrm{MoS}_{2} / \mathrm{Ag}$ interface, $\mathrm{MoS}_{2}$ layer also showed a hole blocking potential to decrease the recombination at the interface near the cathode. The combination of energy level matching at the contact interface and the electronic and chemical properties of the $2 \mathrm{D}$ materials resulted in the improvement of photovoltaic parameters. The enhancement in the device stability was also reported in the presence of interlayers due to the blocking of the ion diffusion at the PEDOT: PSS/perovskite and PCBM/Ag interfaces.

More recently, a hydrophobic fullerene derivative, [6,6]-phenyl-C61-butyric acidN,N-dimethyl-3-(2-thienyl)propanam ester (PCBB-S-N) containing a functional sulphur atom and $\mathrm{C}_{60}$ was synthesized and employed as an intermediary layer on PCBM ETL to heal the defect states in PSCs (Figure 3b). ${ }^{[50]}$ The resulting planar p-i-n $\mathrm{MAPbI}_{3} \mathrm{PSCs}$ exhibited much-improved PCE of over $21 \%$ relative to bare PCBM ETL-based control device (PCE $17.41 \%$ ), and also showed excellent moisture and thermal stability. The enhanced VOC of 70 $\mathrm{mV}$ was attributed to the slightly increased LUMO energy level of PCBB-S-N and passivation of antisite defects by the pendent thiophene moieties, while higher $F F$ and $J_{S C}$ values were explained on the basis of formation of compact and homogeneous PCBB-S-N film contributing to its electronic contact with the cathode.

\subsection{HTL engineering in single cation perovskites}

Despite playing a key role in PSCs, the high cost of spiro-OMeTAD is an issue. Moreover, spiro-OMeTAD can easily provoke the degradation of perovskite structure upon thermal stress and at perceived humidity levels owing to its amorphous and highly hygroscopic nature. The following section introduces the alternative HTL materials and an outline of current 


\section{WILEY-VCH}

routes, which were employed to enhance the photovoltaic performance of the devices based on $\mathrm{MAPbI}_{3}$ absorber.

Bi et al. investigated the grain growth of $\mathrm{MAPbI}_{3}$ perovskite for efficient inverted-type PSCs as a function of wetting-ability of HTLs. ${ }^{[51]}$ To study the effect of the wetting-ability, $\mathrm{MAPbI}_{3}$ film were deposited on different wetting and non-wetting polymer substrates such as polyvinyl alcohol (PVA), poly(3,4-ethylenedioxythiophene) polystyrene sulfonate (PEDOT: PSS), crosslinked $N 4, N 4$ '-bis(4-(6-((3-ethyloxetan-3-yl)methoxy)hexyl)phenyl)- $N 4, N 4$ 'diphenylbiphenyl-4,4'-diamine (c-OTPD), poly(bis(4-phenyl)(2,4,6-trimethylphenyl)amine) (PTAA), and poly $\left(N-9^{\prime}\right.$-heptadecanyl-2,7-carbazole-alt-5,5-(4',7'-di-2-thienyl-2', $1^{\prime}, 3^{\prime}$ benzothiadiazole)) (PCDTBT). The wetting capability of the different substrates was determined by contact angle measurement and the values of $10^{\circ}, 12^{\circ}, 79^{\circ}, 105^{\circ}$ and $108^{\circ}$ were obtained for PVA, PEDOT: PSS, c-OTPD, PTAA, and PCDTBT, respectively. SEM images indicated that the average $\mathrm{MAPbI}_{3}$ grain size (apparent) on c-OTPD $(480 \mathrm{~nm})$ is much larger than that on PEDOT: PSS $(230 \mathrm{~nm})$. This result indicates that a non-wetting surface can suppress the heterogeneous nucleation and facilitate grain boundary migration, resulting in low nucleation density and thus larger grain size. As a result of the reduced grain boundary area and dramatically improved crystallinity, a significant reduction in the charge recombination and charge trap density by $10-100$-fold was achieved.

Pham et al. presented highly efficient and humidity-resistant PSCs by using two new small molecule-based HTLs, i.e, anthanthrone (ANT) dye, namely, 4,10-bis(1,2dihydroacenaphthylen- 5-yl)-6,12-bis(octyloxy)-6,12-dihydronaphtho[7,8,1,2,3nopqr]tetraphene (ACE-ANT-ACE) and 4,4'-(6,12-bis(octyloxy)-6,12dihydronaphtho[7,8,1,2,3-nopqr]tetraphene- 4,10-diyl)bis( $N, N$-bis(4-methoxyphenyl)aniline) (TPA-ANT-TPA) (Figure 3c). ${ }^{[52]}$ After extensive optimization in device processing conditions, a PCE of $17.5 \%\left(J_{S C}=21.07 \mathrm{~mA} \mathrm{~cm}^{-2}, V_{O C}=1.03 \mathrm{~V}\right.$, and $\left.F F=0.80\right)$ was 


\section{WILEY-VCH}

achieved with negligible hysteresis for devices based on dopant-free TPA-ANT-TPA HTL whereas a slightly lower $P C E$ of $13.1 \%$ with $J_{S C}$ of $18.7 \mathrm{~mA} \mathrm{~cm}^{-2}, V_{O C}$ of $1.03 \mathrm{~V}$, and $F F$ of 0.67 was recorded for ACE-ANT-ACE based device. The doped spiro-OMeTAD HTL based device showed a $P C E$ of $16.8 \%$ with $J_{S C}$ of $21.09 \mathrm{~mA} \mathrm{~cm}^{-2}, V O C$ of $1.04 \mathrm{~V}$, and $F F$ of 0.77 . The difference in $J_{S C}$ values for devices based on new HTLs was explained on the basis of the shallower HOMO level of TPA-ANT-TPA that allowed an effective hole extraction. In addition to rapid quenching of PL for TPA-ANT-TPA HTL system, a close alignment of HOMO energy levels with minimal band offset demonstrated the great potential of corresponding HTL for designing highly efficient PSCs. Because of the hydrophilic nature of the corresponding HTLs, improved stability was reported as compared to hygroscopic LiTFSI doped spiro-OMeTAD.

\subsection{Interface engineering in single cation perovskites}

Interface engineering is also important to further increase efficiency by improving the charge collection and by reducing the parasitic charge-carrier recombination. The effects of interface engineering on the photovoltaic performance of $\mathrm{MAPbI}_{3}$ based PSCs is presented in the following section.

Wolff et al. carried out a systematic investigation of the energetics and the Voc losses in $\mathrm{MAPbI}_{3} \mathrm{PSCs}$ with different fullerene derivatives (PCBM, $\mathrm{C}_{60}$, and ICTA) employed in the ETL. ${ }^{[53]}$ The analysis of energetics and the $V_{O C}$ losses demonstrated that PCBM and $\mathrm{C}_{60}$ are not the ideal ETLs when targeting high VOC. The fabricated devices with ICTA, which has the lowest electron affinity, i.e., the highest LUMO level among the fullerenes tested in this study, exhibited the highest $V_{O C}$ while $\mathrm{C}_{60}$ with the lowest-lying LUMO level showed the lowest $V_{O C}($ Figure 3d). The insertion of an ultrathin layer of insulating polystyrene (PS) between the $\mathrm{MAPbI}_{3}$ and $\mathrm{C}_{60}$ increased the $V_{O C}$ by as much as $130 \mathrm{mV}$ (on average $120 \mathrm{mV}$ ), compared to the $\mathrm{C}_{60}$ based control device, while maintaining the $F F$ and $J_{S C}$ values. From the 


\section{WILEY-VCH}

electroluminescence (EL) measurement, a better EQEEL was found, indicating that nonradiative recombination of injected charge becomes progressively suppressed upon lifting the LUMO level, and it was further reduced by inserting the PS layer.

A low-temperature $\left(140{ }^{\circ} \mathrm{C}\right)$ processed $\mathrm{SnO}_{2}$ was employed as an ETL for $\mathrm{MAPbI}_{3}$

planar PSCs on a flexible PEN (polyethylenenaphthalate) substrate. ${ }^{[54]}$ A $\mathrm{C}_{60}$ pyrrolidine trisacid (CPTA) was used to modify the interface between $\mathrm{SnO}_{2}$ and $\mathrm{MAPbI}_{3}$ to significantly enhance the photovoltaic performance. This flexible PSC achieved a PCE of $18.36 \%$ under simulated AM1.5 sunlight and maintained $75 \%$ of its initial efficiency after 500 cycles of bending with a curvature radius of $5 \mathrm{~mm}$. The $\mathrm{PL}$ measurements of $\mathrm{MAPbI}_{3}$ film on $\mathrm{SnO}_{2}$ CPTA substrate showed a 6-fold weaker PL intensity than that of $\mathrm{MAPbI}_{3}$ on pristine $\mathrm{SnO}_{2}$, indicating the efficient extraction of electrons in the presence of CPTA.

In another interesting work, a new method of fabricating large-area flexible PSCs by inserting a conjugated polyelectrolyte interlayer (PTAA, PFNBr, and PTFTS) between the $\mathrm{MAPbI}_{3}$ and HTL (graphene oxide, GO) was described (Figure 3e). ${ }^{[5]}$ To investigate the wettability of interlayers on GO layer, the contact angles of perovskite precursor solutions on $\mathrm{GO} / \mathrm{PTAA}, \mathrm{GO} / \mathrm{PFNBr}$ and $\mathrm{GO} / \mathrm{PTFTS}$ of $78^{\circ}, 21^{\circ}$, and $44^{\circ}$, respectively, were determined, whereas the pristine GO provided a contact angle of $29^{\circ}$. Apparently, non-wetting surface facilities the growth of larger grains due to the dramatic suppression of heterogeneous nucleation. ${ }^{[51]}$ The resulting perovskite film on GO/PTAA showed no pin-holes with an average grain size of $800 \mathrm{~nm}$, whereas the average size of perovskite grains on GO/PTFTS was $\sim 550 \mathrm{~nm}$. For the best-performing GO-based device, a PCE of $14.91 \%$ with VOC of 1.05 V, was reported while a remarkable $P C E$ of $18.82 \%$ was achieved for PTFTS-modified GO HTL based devices. The GO/PTFTS (1.09 V) and GO/PTAA (1.07 V) based devices showed a higher built-in potential $\left(\mathrm{V}_{\mathrm{bi}}\right)$ than pristine $\mathrm{GO}$-based device $(0.99 \mathrm{~V})$, correlating with the $V_{O C}$ of the corresponding devices. 


\section{WILEY-VCH}

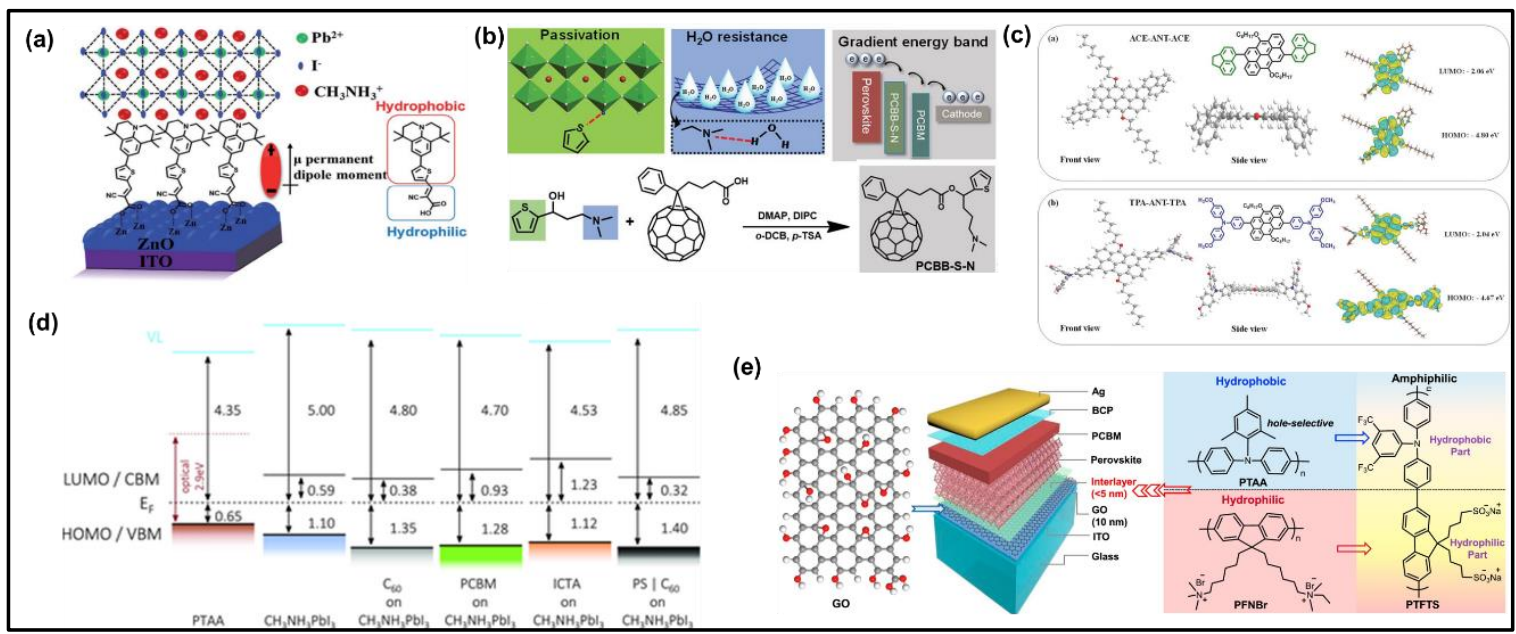

Figure 3. a) Schematic illustration of SAM-induced permanent dipole moment at the $\mathrm{ZnO}$ /perovskite interface. Reproduced with permission. [48] Copyright 2018, John Wiley \& Sons. b) Design and synthesis of PCBB-S-N, with a targeted therapy effect. Reproduced with permission.[50] Copyright 2019, John Wiley \& Sons. c) Chemical structures, geometrical configuration (front view and side view), and calculated isosurfaces and energy levels of HOMO and LUMO orbital surfaces of a) ACE-ANT-ACE and b) TPA-ANT-TPA, synthesized by classical Suzuki coupling. Reproduced with permission. [52] Copyright 2018, John Wiley \& Sons. d) Schematic energy-level diagram of the different layers relative to EF. Reproduced with permission. [53] Copyright 2017, John Wiley \& Sons. e) The inverted device architecture of planar-type PSCs and the chemical structures of GO and polymer interlayers. Reproduced with permission. [55] Copyright 2019, Elsevier.

\subsection{Other (Architecture) engineering in single cation perovskites}

Apart from the above-mentioned engineering strategies, architecture engineering is another promising way to achieve high VOC. Huang et al. designed a novel prismatic PSCs with light trapping configuration to mitigate the losses. ${ }^{[56]}$ In the current system, incident high-to-low energy photons were separately captured by four horizontally aligned $\mathrm{MAPbI}_{x} \mathrm{Br}_{3-\mathrm{x}}(\mathrm{x}=3,2$, 1, and 0) sub-cells with varied bandgaps. This approach generated a record $V O C$ of $5.3 \mathrm{~V}$ and a significant $P C E$ of $21.3 \%$, Basically, this new form of cell architecture minimized the thermodynamic losses and improved the photovoltages of PSCs by subsequently harvesting the incident photons with different energies using four different $\mathrm{MAPbI}_{\mathrm{x}} \mathrm{Br}$ 3-x sub-cells. As a result of subsequent harvesting of high-to-low energy photons, the corresponding sub-cells based on $\mathrm{MAPbBr}_{3}, \mathrm{MAPbIBr}_{2}, \mathrm{MAPbI}_{2} \mathrm{Br}$ and $\mathrm{MAPbI}_{3}$ absorber layers generated a $V_{O C}$ of 


\section{WILEY-VCH}

$1.54 \mathrm{~V}, 1.45 \mathrm{~V}, 1.25 \mathrm{~V}$ and $1.15 \mathrm{~V}$, respectively, yielding a record $V_{O C}$ of $5.3 \mathrm{~V}$. This study clearly demonstrates that the mitigation of thermodynamic loss and light trapping can be achieved by carefully designing the absorption of active layers to achieve a higher $V O C$ and PCE.

Overall, the highlighted reports in this section of the review show that despite the relatively poor device stability of single-cation iodide-based PSCs, an appropriate engineering approach can dramatically improve not only photovoltaic performance but also operational stability of resulting devices. From this perspective, it is clearly evident from the abovementioned studies that more efficient charge-transporting layers showing well-matched band alignment with perovskite can be obtained by doping and/or treatment strategies, whereas composition-additive engineering can be readily employed to form a high-quality perovskite layer with fewer trap states in the bulk and/or at the interfaces. Table 1 summarizes the recent progress on the photovoltaic performance of single-cation iodide-based PSCs.

Table 1. Voc and other photovoltaic parameters yielded by single-cation and iodide perovskite-based PSCs.

\begin{tabular}{|c|c|c|c|c|c|c|}
\hline Device configuration & $\begin{array}{l}\text { Voc } \\
\text { (V) }\end{array}$ & $\begin{array}{l}J s c \\
(\mathrm{~mA} \\
\left.\mathrm{cm}^{-2}\right)\end{array}$ & $F F$ & PCE (\%) & $\begin{array}{l}\text { Change in } \\
\text { Voc } \\
(\mathrm{mV})\end{array}$ & Ref. \\
\hline $\begin{array}{l}\mathrm{FTO} / \mathrm{c}-\mathrm{TiO}_{2} / \mathrm{mp}-\mathrm{TiO}_{2} / \text { Perovskite }+\mathrm{Pbl}_{2} / \text { Spiro- } \\
\text { OMeTAD/Au }\end{array}$ & 1.09 & 22.42 & 0.79 & 19.09 & +40 & [33] \\
\hline FTO/c-TiO $/$ /Perovskite/Spiro-OMeTAD/Au & 1.15 & 22.82 & 0.68 & 17.80 & +50 & [34] \\
\hline ITO/PTAA/Perovskite/Choline chloride/ $\mathrm{C}_{60} / \mathrm{BCP} / \mathrm{Cu}$ & 1.15 & 22.90 & 0.76 & 20.00 & +90 & [35] \\
\hline ITO/PEDOT:PSS/Perovskite + $\mathrm{H}_{2} \mathrm{O} / \mathrm{PCBM} / \mathrm{Ca} / \mathrm{Al}$ & 1.03 & 20.60 & 0.85 & 18.00 & +1020 & {$[36]$} \\
\hline $\mathrm{FTO} / \mathrm{c}-\mathrm{TiO}_{2} /$ Perovskite + MASCN/Spiro-OMeTAD/Au & 1.06 & 22.29 & 0.77 & 18.22 & +430 & [38] \\
\hline ITO/c-TiO $/$ /Perovskite + IMS/Spiro-OMeTAD/Au & 1.14 & 22.08 & 0.83 & 20.84 & +40 & [39] \\
\hline ITO/PTAA/Perovskite $+\mathrm{PbCl}_{2} / \mathrm{PCBM} / \mathrm{BCP} / \mathrm{Ag}$ & 1.26 & 20.70 & 0.80 & 20.70 & +15 & {$[40]$} \\
\hline ITO/Pedot:PSS/Perovskite + Co/PCBM/BCP/AI & 1.05 & 21.10 & 0.75 & 17.20 & +90 & {$[44]$} \\
\hline
\end{tabular}




\begin{tabular}{|c|c|c|c|c|c|c|}
\hline FTO/c-TiO $/$ /PCBA/Perovskite/Spiro-OMeTAD/Ag & 1.16 & 21.38 & 0.72 & 17.76 & +80 & {$[46]$} \\
\hline ITO/TiO ${ }_{x} /$ brookite $\mathrm{TiO}_{2} /$ Perovskite/Spiro-OMeTAD/Au & 1.18 & 21.86 & 0.83 & 21.60 & +40 & {$[47]$} \\
\hline ITO/JTCA-modified ZnO/Perovskite/Spiro-OMeTAD/Au & 1.13 & 21.72 & 0.76 & 18.82 & +70 & [48] \\
\hline ITO/Pedot:PSS/GO/Perovskite/PCBM/MoS $/$ /Ag & 1.14 & 22.83 & 0.74 & 19.14 & +70 & [49] \\
\hline ITO/PTAA/MAPbI $3 /$ PCBB-S-N/PCBM/AI & 1.12 & 23.83 & 0.79 & 21.08 & +70 & {$[50]$} \\
\hline ITO/PTAA/Perovskite/PCBM/ ${ }_{60} / \mathrm{Al}$ & 1.07 & 22.00 & 0.77 & 18.10 & +150 & [51] \\
\hline 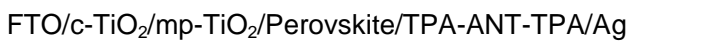 & 1.03 & 21.05 & 0.80 & 17.50 & -10 & [52] \\
\hline ITO/PTAA/Perovskite/PS/C $60 / \mathrm{Cu}$ & 1.16 & 22.30 & 0.75 & 19.42 & +130 & [53] \\
\hline ITO/CPTA-modified $\mathrm{SnO}_{2} /$ Perovskite/Spiro-OMeTAD/Au & 1.08 & 22.39 & 0.75 & 18.36 & +30 & {$[54]$} \\
\hline ITO/GO/PTFTS/Perovskite/PCBM/BCP/Ag & 1.10 & 20.89 & 0.82 & 18.82 & +50 & [55] \\
\hline FTO/c-TiO ${ }_{2} / \mathrm{mp}-\mathrm{TiO}_{2} /$ Perovskite/TPA-ANT-TPA/Ag & 1.03 & 21.05 & 0.80 & 17.50 & -10 & [52] \\
\hline ITO/PTAA/MAPbl $3+$ PCBB-OEG/PCBM/AI & 1.07 & 23.65 & 0.80 & 20.20 & +30 & [57] \\
\hline ITO/ZnO/PVP/Perovskite/Spiro-OMeTAD/MoO ${ }_{3} / \mathrm{Ag}$ & 1.07 & 19.97 & 0.56 & 14.12 & +70 & {$[58]$} \\
\hline FTO/NiO/Cul/Perovskite/PCBM/BCP/Ag & 1.07 & 20.60 & 0.69 & 15.26 & +50 & [59] \\
\hline
\end{tabular}

\section{Mixed cation and/or mixed halide-based perovskites}

The functionality and performance of the perovskite absorber layer are mainly dependent on the chemical composition. Although $\mathrm{MAPbI}_{3}$ perovskite material has been extensively used as a light-harnesser in device architecture, the best-performing devices use mixed cations and/or mixed halides perovskite absorber. The chemical modification of the X-site anions and A-site cations improved the optoelectronic properties and modulated the device efficiency. For instance, the introduction of formamidinium $\left(\mathrm{FA}^{+}\right)$cations into $\mathrm{MAPbI} 3$ structure led to the fabrication of $\mathrm{MA}_{0.6} \mathrm{FA}_{0.4} \mathrm{PbI}_{3}$ based PSCs yielding an efficiency up to $14.9 \%,{ }^{[60]}$ whereas the mixed-halide perovskite composition with the substitution of $10-15$ mol\% of iodide with bromide facilitated a fully solution-processed PSCs with a certified efficiency of $16.2 \%{ }^{[61]}$ The bandgap of mixed-halide perovskites can be effectively modulated by controlling the composition of incorporated halides, whereas the mixed-cation perovskites can make the halide redistribution thermodynamically unfavorable and consequently minimize the halide 


\section{WILEY-VCH}

segregation. The emerging compositions render these systems enormously appealing for designing of perovskite devices, displaying outstanding efficiency, long-term operational stability, and low process sensitivity. In the following section, we summarize the recent advances in the modification of $\mathrm{A}$-site and/or $\mathrm{X}$-site of the $\mathrm{ABX}_{3}$ perovskite structure (where $\mathrm{A}$ is an organic ammonium cation, $\mathrm{B}$ is $\mathrm{Pb}^{+2}$ or $\mathrm{Sn}^{+2}$, and $\mathrm{X}$ is a halide anion).

\subsection{Composition-additive engineering in mixed-cation and/or mixed-halide perovskites}

The overall efficiency and stability of PSCs are strongly dependent on the composition of the perovskite materials. In addition to enhanced device stability and other desirable optoelectronic properties, the mixed-halide perovskite compositions offer a great opportunity to optimize the spectral range by tuning the bandgap of the corresponding films. The incorporation of different types of halides into a crystal lattice also lead to radical changes in perovskite morphology, which can further improve the efficiency and stability of PSCs. Initially, the role of chloride remained a mystery, later studies including both electron microscopy-based analysis and bandgap studies clearly brought out that the presence of chloride can influence the growth, morphology and charge-carrier recombination without

altering the bandgap of $\mathrm{MAPbI}_{3}{ }^{[62]}$ In a similar direction, bromide was found to play a similar role, leading to significant improvement in PCE from $14 \%$ to $>16 \% .{ }^{[17,18,63,64]}$ Highlyefficient PSCs (certified PCE 16.2\%) were initially reported for mixed-halide based $\operatorname{MAPb}\left(\mathrm{I}_{1-\mathrm{x}} \mathrm{Br}_{\mathrm{x}}\right)_{3}(\mathrm{x}=0.1-0.15)$ perovskite absorbing layer using solvent engineering technique. ${ }^{[61]}$ A mixed solvent of $\gamma$-butyrolactone (GBL) and dimethylsulphoxide (DMSO) was used followed by a toluene drop-casting to obtain dense and fully covered perovskite films on the mesoporous $\mathrm{TiO}_{2}$ layer. It was shown that the formation of a stable $\mathrm{MAI}(\mathrm{Br})-$ $\mathrm{PbI}_{2}-\mathrm{DMSO}$ phase via an intercalation process during the application of a non-dissolving 


\section{WILEY-VCH}

solvent (toluene) was critical in retarding the rapid reaction between $\mathrm{MAI}(\mathrm{Br})$ and $\mathrm{PbI}(\mathrm{Br})_{2}$ which enabled the formation of a highly uniform and highly crystalline perovskite films.

Recently, Longo et al. fabricated fully vacuum-deposited mixed-halide methylammonium lead mixed-halide $\operatorname{MAPb}\left(\mathrm{Br}_{\mathrm{x}} \mathrm{I}_{1-\mathrm{x}}\right)_{3}(x=0.2$ and 0.5$)$ perovskite films with a bandgap of 1.72 and $1.87 \mathrm{eV} .^{[65]}$ The photoluminescence (PL) signal did not change under prolonged illumination at low $\mathrm{Br}^{-}$ratio, while halide segregation was observed at high $\mathrm{Br}^{-}$ concentrations similar to solution-processed perovskite films. The absorption onset of the obtained films showed a monotonic blue-shift with increasing $\mathrm{Br}^{-}$content. The $V_{O C}$ increased from $1.095 \mathrm{~V}$ to $1.119 \mathrm{~V}$ to $1.207 \mathrm{~V}$ for devices employing perovskite with the $\mathrm{Br}^{-}$the content of $x=0,0.2$, and 0.5, respectively (Figure 4a). The increase in VOC of the corresponding perovskite compositions was attributed to the widening of the bandgap.

The effect of thermal treatment on the intermediate state was also investigated for hydrobromic acid (HBr) assisted fast crystallization process of mixed-halide $\mathrm{MAPbI}_{3-\mathrm{x}} \mathrm{Cl}_{\mathrm{x}}$ based perovskite films. ${ }^{[66]}$ This approach helped to achieve rapid formation and crystallization of perovskite films after the annealing step. The enhancement in the device performance was attributed to the increased shunt resistance, lower leakage current, reduced series resistance, and stronger crystallization of the corresponding perovskite layer in the presence of $\mathrm{HBr}$ treatment.

In contrast to the thermally instable MA cation-based perovskites, inorganic halide perovskites such as cesium lead iodide $\left(\mathrm{CsPbI}_{3}\right)$ hold great promise due to their excellent thermal stability and ideal bandgap for tandem solar cell applications. However, the small size of $\mathrm{Cs}^{+}$cation increases the tolerance factor, and $\mathrm{CsPbI}_{3}$ rapidly degrades to non-photoactive $\delta$ phase (yellow phase) under ambient conditions. As mentioned above, the partial substitution of $\mathrm{I}^{-}$with $\mathrm{Br}^{-}$or sufficient treatment of $\mathrm{CsPbI}_{3}$ surface helps to stabilize the $\alpha$-phase of $\mathrm{CsPbI}_{3}$ to make efficient PSCs. Very recently, Wang et al. reported a study to mitigate the 


\section{WILEY-VCH}

effects of cracks and pinholes in the $\beta-\mathrm{CsPbI}_{3}$ perovskite layer by choline iodide $(\mathrm{CHI})$ treatment. ${ }^{[67]} \mathrm{CHI}$ treatment increased the charge-carrier lifetime and improved the energylevel alignment between the $\beta$ - $\mathrm{CsPb}_{3}$ and charge-transporting layers (Figure $\mathbf{4 b}$ and $\mathbf{4 c}$ ). Besides improving the energy-level alignment of the conduction band minimum between $\beta$ $\mathrm{CsPbI}_{3}$ and $\mathrm{TiO}_{2}$ by $120 \mathrm{meV}, \mathrm{CHI}$ treatment fills the pinhole. The PSCs employing CHItreated material achieved a stable efficiency reaching $18.4 \%$ (certified PCE of $18.3 \%$ ) recorded at $45 \pm 5^{\circ} \mathrm{C}$ under ambient conditions. As shown in Figure 4d, although the $J_{S C}$

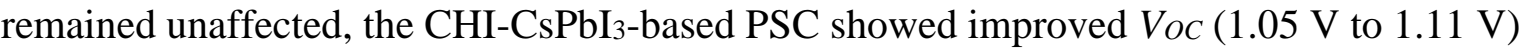
and $F F(0.72$ to 0.82$)$.

Similar to $\mathrm{CsPbI}_{3}$, formamidinium lead iodide $\left(\mathrm{FAPbI}_{3}\right)$ shows higher thermal stability than $\mathrm{MAPbI}_{3}$. In addition, $\mathrm{FAPbI}_{3}$ exhibits a narrower bandgap (as compared to $\mathrm{MAPbI}_{3}$ ), however, its structural instability remains a concern particularly in the presence of moisture. Reports show that such issues of yellow-phase formation ( $\delta-\mathrm{FAPbI}_{3}$, non-perovskite phase), halide segregation, undesired phase transition, degradation under moisture can be eliminated by using perovskites with mixed-cations compositions. For the first time, Pellet et al. introduced mixed-cation 3D perovskite, $(\mathrm{MA})_{x}(\mathrm{FA})_{1-\mathrm{x}} \mathrm{PbI}_{3}(\mathrm{x}=0-1)$ as an absorber layer in the mesoscopic PSCs. ${ }^{[60]}$ The mixed-cation perovskite with $\mathrm{MA}_{0.6} \mathrm{FA}_{0.4} \mathrm{PbI}_{3}$ composition showed the best photovoltaic performance, which was attributed to the enhanced harvesting and collection of red photons. The longer exciton lifetime explained the superior carriercollection efficiency of mixed-organic-cation perovskite. Wang et al. reported further improvement in the device performance of $\left(\mathrm{MA}_{1-x} \mathrm{FA}_{x} \mathrm{PbI}_{3}\right)$ by introducing a small amount of lead thiocyanate $\left(\mathrm{Pb}(\mathrm{SCN})_{2}\right)$ additive into mixed perovskite precursor solutions. ${ }^{[68]}$ The champion $\mathrm{MA}_{0.7} \mathrm{FA}_{0.3} \mathrm{PbI}_{3}$ PSCs with $3 \% \mathrm{~Pb}(\mathrm{SCN})_{2}$ additive showed $P C E$ of $20.10 \%$ with a $V_{O C}$ of $1.12 \mathrm{~V}$. The increase in $P C E$ was attributed to the enlarged grain size and prolonged charge carrier lifetimes revealed by time-resolved photoluminescence (TRPL) measurements. 


\section{WILEY-VCH}

The dependence of $V_{O C}$ on the light intensity presented a lower slope for $\mathrm{Pb}(\mathrm{SCN})_{2}$ incorporated perovskite-based devices, revealing a lower Shockley-Read-Hall recombination (trap-assisted recombination) in the corresponding devices.

Recently, a new method was described for fabricating gradient heterostructure of PSCs based on "intolerant" trivalent metal cations such as $\mathrm{Sb}^{3+}$, and $\mathrm{In}^{3+} \cdot{ }^{[69]} \mathrm{In}$ this study, mixedcation $\mathrm{Cs}_{0.1} \mathrm{FAA}_{0.9} \mathrm{PbI}_{3}$ perovskite structure was employed as the active layer due to its moderate Goldschmidt tolerant factor $(\tau=0.9)$ and excellent photoelectrical performance. ${ }^{[19,70]}$ Both the $\mathrm{Sb}^{3+}$ and $\mathrm{In}^{3+}$ do not dissolve homogeneously in the perovskite solution due to large difference in ionic sizes and electrostatic interaction between the dopants and the host $\mathrm{Pb}$ atoms as shown in Figure 4e. Therefore, a graded heterojunction was formed spontaneously. As a result, $\mathrm{Sb}^{3+}$ doped PSCs reached a stabilized PCE of $21.04 \%$ with an extraordinary $F F$ and $V O C$ of 0.84 and $1.10 \mathrm{~V}$, respectively. Both theoretical calculations and experimental observations specified optimized charge management as a result of the tailored band structure and interfacial electronic hybridization, promoting the charge separation and collection processes.

In order to tailor the band structure and electronic properties of perovskites, chemical modification realized by the substitution of $\mathrm{I}^{-}$with $\mathrm{Br}^{-}$as well as by the substitution of $\mathrm{MA}^{+}$ with different organic/inorganic cations have been applied as an efficient approach, resulting in colour variation, high stability, and $P C E$ modulation. Compositional engineering of mixedhalide and mixed-cation perovskite materials has been first reported by combining the unstable $\mathrm{FAPbI}_{3}$ with $\mathrm{MAPbBr}_{3}$ in $\left(\mathrm{FAPbI}_{3}\right)_{1-\mathrm{x}}\left(\mathrm{MAPbBr}_{3}\right)_{\mathrm{x}}{ }^{[71]}$. As shown in Figure 4f, simultaneous introduction of $15 \mathrm{~mol} \%$ of both $\mathrm{MA}^{+}$cations and $\mathrm{Br}^{-}$anions in $\mathrm{FAPbI}_{3}$ led to the stabilization of $\left(\mathrm{FAPbI}_{3}\right)_{0.85}\left(\mathrm{MAPbBr}_{3}\right)_{0.15}$ perovskite phase. The trend in $P C E$ as a function of $\mathrm{x}$ showed that $J_{S C}$ increased from $19.0 \mathrm{~mA} \mathrm{~cm}^{-2}($ at $\mathrm{x}=0.05)$ to a maximum value of $22 \mathrm{~mA} \mathrm{~cm}^{-2}$ (at $\mathrm{x}=0.15$ ); and then decreased to $20 \mathrm{~mA} \mathrm{~cm}^{-2}$ (at $\mathrm{x}=0.30$ ), whereas $V_{O C}$ 
increased from $1.0 \mathrm{~V}$ to $1.12 \mathrm{~V}$ with increasing $\mathrm{x}$. The incorporation of $\mathrm{MAPbBr}_{3}$ not merely stabilized $\mathrm{FAPbI}_{3}$ phase but also improved PCE more than $18 \%$ with negligible hysteresis.

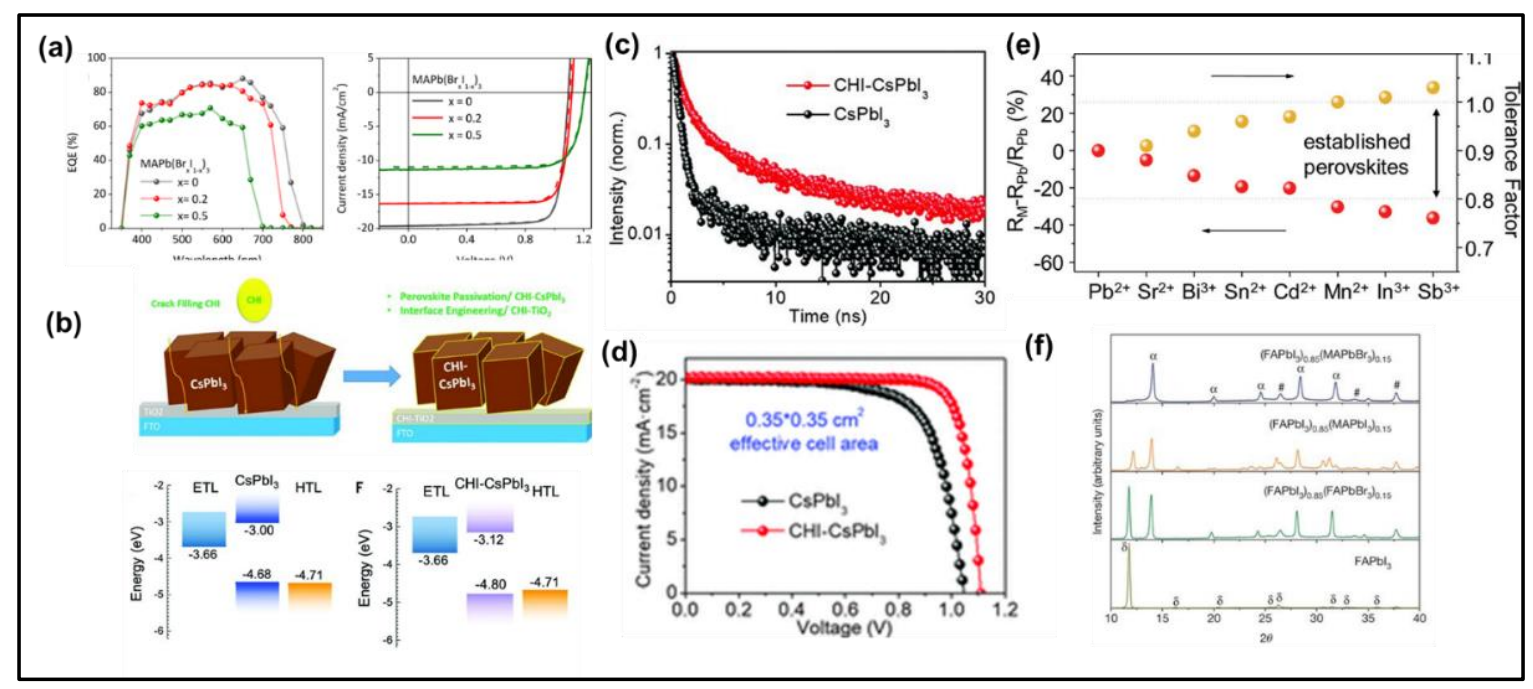

Figure 4. a) EQE spectra and $J-V$ curves of the annealed devices $\mathrm{MAPbI}_{3}$ (black), $\operatorname{MAPb}\left(\mathrm{Br}_{0.2} \mathrm{I}_{0.8}\right)_{3}$ (red), and $\mathrm{MAPb}\left(\mathrm{Br}_{0.5} \mathrm{I}_{0.5}\right)_{3}$ (green) (solid lines show forward scans, while dashed lines show reverse ones). Reproduced with permission.[65] Copyright 2018, American Chemical Society. b) Schematic illustration of crack-filling interface engineering and corresponding energy diagrams of the $\mathrm{CsPbI}_{3}$ and choline iodine (CHI)-CsPbI $\mathrm{Cilms}_{3}, \mathrm{CHI}$ treatment led to the improvement in the energy-level alignment of the conduction band minimum between $\beta-\mathrm{CsPbI}_{3}$ and $\mathrm{TiO}_{2}$. Reproduced with permission.[67] Copyright 2019, American Association for the Advancement of Science. c) TRPL decay curves of $\mathrm{CsPbI}_{3}$ and $\mathrm{CHI}-\mathrm{CsPbI}_{3}$ thin films. Reproduced with permission.[67] Copyright 2019, American Association for the Advancement of Science. d) $J$ - $V$ characteristics of the champion PSCs based on $\mathrm{CsPbI}_{3}$ and $\mathrm{CHI}-\mathrm{CsPbI}_{3}$ with $0.1-\mathrm{cm}^{2}$ effective cell area under simulated AM 1.5G solar illumination of $100 \mathrm{~mW} \mathrm{~cm} \mathrm{~cm}^{-2}$ in reverse scan. Reproduced with permission.[67] Copyright 2019, American Association for the Advancement of Science. e) $R_{\mathrm{M}}-R_{\mathrm{Pb}} / R_{\mathrm{Pb}}$ (yellow solid circles) and tolerance factor (red solid circles) of Cs $0.1 \mathrm{FA}_{0.9} \mathrm{MI}_{3}$ perovskites, $\mathrm{M}=\mathrm{Pb}^{2+}, \mathrm{Sr}^{2+}, \mathrm{Bi}^{3+}, \mathrm{Sn}^{2+}, \mathrm{Cd}^{2+}, \mathrm{Mn}^{2+}, \mathrm{In}^{3+}$, and $\mathrm{Sb}^{3+}$. Reproduced with permission.[69] Copyright 2019, John Wiley \& Sons. f) XRD patterns of solventengineering-processed $\mathrm{FAPbI}_{3},\left(\mathrm{FAPbI}_{3}\right)_{1-x}\left(\mathrm{MAPbI}_{3}\right)_{x},\left(\mathrm{FAPbI}_{3}\right)_{1-x}\left(\mathrm{FAPbBr}_{3}\right)_{x}$, and $\left(\mathrm{FAPbI}_{3}\right)_{1-x}\left(\mathrm{MAPbBr}_{3}\right)_{x}$ perovskite films (with $\left.x=0.15\right)$ on mesoporous- $\mathrm{TiO}_{2} /$ blocking$\mathrm{TiO}_{2} /$ FTO glass substrates. Reproduced with permission.[71] Copyright 2015, Nature Publishing Group.

Lead thiocyanate $\left(\mathrm{Pb}(\mathrm{SCN})_{2}\right)$ additive has also been used for the fabrication of mixedcation mixed-halide perovskite thin films. However, the formation of excessive lead iodide $\left(\mathrm{PbI}_{2}\right)$ is still a big challenge limiting the utilization of the $\mathrm{Pb}(\mathrm{SCN})_{2}$ additive. $\mathrm{Yu}$ et al. combined the chemical approach of additive-engineering strategy with the physical approach 


\section{WILEY-VCH}

of solvent annealing and reported the synergistic effects on the performance of PSCs employing wide-bandgap (bandgap of $1.75 \mathrm{eV}$ ) FA $\mathrm{F}_{0.8} \mathrm{Cs} 0.2 \mathrm{~Pb}\left(\mathrm{I}_{0.7} \mathrm{Br}_{0.3}\right)_{3}$ light-absorber. ${ }^{[72]}$ The authors demonstrated that the cooperation of $1.0 \mathrm{~mol} \% \mathrm{~Pb}(\mathrm{SCN})_{2}$ additive and solvent annealing can successfully facilitate the formation of large grains while avoiding the formation of excessive $\mathrm{PbI}_{2}$. As a result, the average $P C E$ increased from $13.44 \pm 0.48 \%$ to $17.68 \pm 0.36 \%$ owing to the great improvement in the $V_{O C}(80 \mathrm{mV})$.

Among the various film modification approaches, polymer-assisted crystal engineering has been found to be a robust method to increase the perovskite grain size. Bi et $a l$. reported the poly(methyl methacrylate) (PMMA)-templated nucleation and crystal growth of perovskite films. ${ }^{[73]}$ The PMMA polymer played the dual role of enabling fast heterogeneous nucleation and slowing down the perovskite crystal growth by forming an intermediate adduct with $\mathrm{PbI}_{2}$. As evidenced by the long PL lifetime, smooth and shiny perovskite films with excellent electronic quality were obtained. By using the (FAI) ${ }_{0.81}\left(\mathrm{PbI}_{2}\right)_{0.85}\left(\mathrm{MAPbBr}_{3}\right)_{0.15}$ perovskite absorber layer, a $P C E$ of $21.6 \%$ (a certified $P C E$ of $21.02 \%$ ) with $V O C$ of $1.14 \mathrm{~V}, F F$ of 0.78 , and $J_{S C}$ of $23.7 \mathrm{~mA} \mathrm{~cm}^{-2}$ was reported while the control devices showed a PCE of around 20\% (Figure 5a).

In a similar direction bis-analogue of PCBM (bis-PCBM) was utilized as a templating agent in antisolvent to obtain high electronic quality perovskite films with low-defect density ${ }^{[74]}$ It was reported that PCBM can fill the vacancies and grain boundaries on the perovskite surface and thus improve the crystallization of final perovskite film. The introduction of an electron-accepting PCBM into the $(\mathrm{FAI})_{0.81}\left(\mathrm{PbI}_{2}\right)_{0.85}(\mathrm{MABr})_{0.15}\left(\mathrm{PbBr}_{2}\right)_{0.15}$ film facilitated the slow electron extraction resulting in a $P C E$ of $20.8 \%$. The increase in $J_{S C}$ with PCBM was ascribed to the enhanced photoelectron transport, higher conductivity, and higher mobility whereas the origin of the improved $V O C$ was the reduction of spontaneous trap-assisted non-radiative recombination. 


\section{WILEY-VCH}

Although MA-FA based perovskite materials dramatically improved the photovoltaic performance of PSCs, these compositions are sensitive to the processing conditions because of their intrinsic structural and thermal instability issues. To overcome these issues, composition-additive engineering involving the mixing of MA/FA organic cations with small amounts of inorganic cations has been intensively investigated in recent years. High-quality perovskite films were obtained by incorporating a small amount of inorganic cesium (Cs) cation into the MA/FA composition. The obtained triple-cation $\mathrm{Cs}_{0.05}\left(\mathrm{MA}_{0.17} \mathrm{FA}_{0.83}\right)_{0.95} \mathrm{~Pb}\left(\mathrm{I}_{0.83} \mathrm{Br}_{0.17}\right)_{3}$ perovskite absorber yielded a stabilized $P C E$ exceeding $21 \%$ with a $V O C$ of $1.13 \mathrm{~V}$ and excellent operational stability (Figure 5b). ${ }^{[21]}$ In another study, small and oxidation-stable rubidium cations $\left(\mathrm{Rb}^{+}\right)$were explored to further improve the properties of perovskite material and the photovoltaic efficiency of resulting PSCs. ${ }^{[22]}$ Stabilized PCE of $21.6 \%$ with a $V O C$ of $1.19 \mathrm{~V}$ was obtained from PSCs based on RbCsMAFA perovskite composition containing $5 \% \mathrm{Rb}$ additive. The best device showed an outstanding $V_{O C}$ of $1.24 \mathrm{~V}$ with a loss in the potential of only $\sim 0.39 \mathrm{~V}$, implying negligible nonradiative recombination losses. The obtained electroluminescence of $3.8 \%$ further confirmed a strong suppression of nonradiative recombination in the RbCsMAFA device. The electrochemical characterization also brought out that the introduction of $\mathrm{Rb}^{+}$improves the interfacial charge transport characteristics in multiple-cation mixed-halide PSCs. ${ }^{[75,76]}$

Recently, in order to further boost the photovoltage of mixed-cation and mixed-halide based PSCs, guanidinium iodide (GuaI) was introduced into Cs0.05(MA0.17FA0.83) ${ }_{0.95} \mathrm{~Pb}\left(\mathrm{I}_{0.83} \mathrm{Br}_{0.17}\right)_{3}$ perovskite films. ${ }^{[77]} \mathrm{GuaI}$ led to the suppression of parasitic charge-carrier recombination and enabled fabrication of efficient PSCs (>20\% PCE) yielding reproducible $V_{O C}$ as high as $1.20 \mathrm{~V}$ (Figure 5c). The $70 \mathrm{mV}$ enhancement in $V_{O C}$ was ascribed to the reduced non-radiative recombination as revealed by time-resolved photoluminescence and electroluminescence measurements (Figure 5d). 

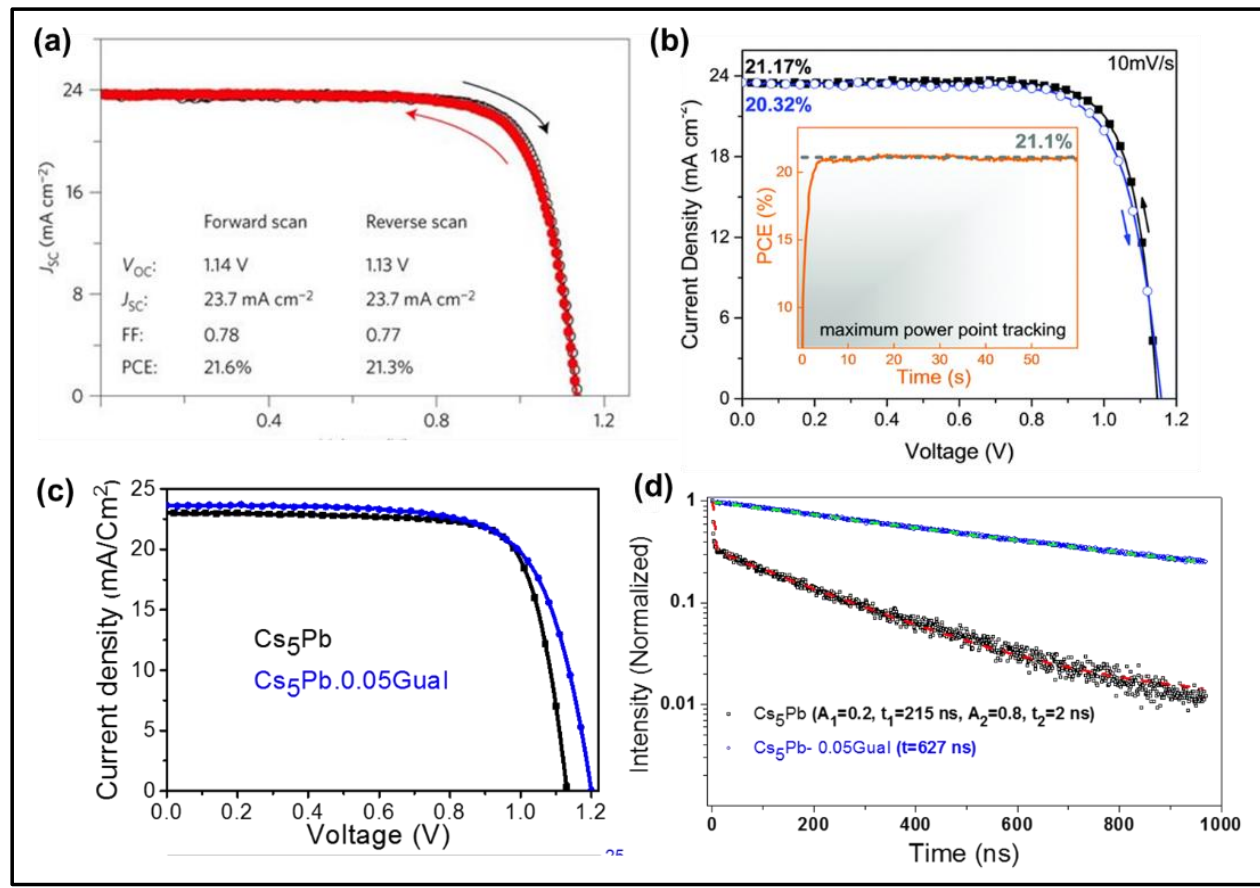

Figure 5. a) $J-V$ curves of the champion PSC prepared by polymer-templated nucleation and growth method displaying the best $P C E$ of $21.6 \%$ with a PMMA concentration $C_{\text {PMMA }}=$ $0.6 \mathrm{mg} \mathrm{ml}^{-1}$. Reproduced with permission.[73] Copyright 2016, Nature Publishing Group. b) $J-V$ and stability characteristics (for the best performing $\mathrm{Cs}_{5} \mathrm{M}$ device. The inset shows the power output under maximum power point tracking for $60 \mathrm{~s}$. Reproduced with permission.[21] Copyright 2016, Royal Society of Chemistry. c) $J-V$ curves of the best devices based on $\mathrm{Cs}_{5} \mathrm{~Pb}$ and $\mathrm{Cs}_{5} \mathrm{~Pb}_{0.05} \mathrm{GuaI}$ perovskite films, $5 \%$ GuaI to $\mathrm{Cs}_{5} \mathrm{~Pb}$ significantly improved the $V_{O C}$ from $1.13 \mathrm{~V}$ to $1.20 \mathrm{~V}$. Reproduced under the terms of the CC BY 4.0 license.[77] Copyright 2019, Science and Technology Review Publishing House (d) TRPL spectra of pure and GuaI containing perovskite films, charge carrier lifetime values of $215 \mathrm{~ns}$ and $627 \mathrm{~ns}$ were estimated, respectively, for the $\mathrm{Cs} 5 \mathrm{~Pb}$, and $\mathrm{Cs}_{5} \mathrm{~Pb}{ }_{0.05} \mathrm{GuaI}$ perovskite films. Reproduced under the terms of the CC BY 4.0 license.[77] Copyright 2019, Science and Technology Review Publishing House.

The suppression of defects resulting in an increase in the VOC has also been reported for halide-based additives. For example, Fu et al. introduced an additive-engineering strategy by adding formamidine acetate (FAAc) to the perovskite-precursor solution. ${ }^{[78]}$ The role of FAAc was explained on the basis of chemical reactions between FAAc and methylammonium iodide (MAI) which forms formamidinium iodide (FAI) and methylammonium acetate (MAAc). In this way, the number of $\mathrm{I}^{-}$vacancies could be reduced at the surface due to lower thermal stability of MAAc instead of MAI, leading to a reduced recombination rate in the resulting perovskite films. TRPL and thermogravimetric analysis (TGA) results confirmed the 


\section{WILEY-VCH}

stabilization of $\mathrm{I}^{-}$anions by $\mathrm{Ac}^{-}$anions. By using such an additive in

$\mathrm{Cs}_{0.05} \mathrm{FA}_{0.81} \mathrm{MA}_{0.14} \mathrm{~Pb}\left(\mathrm{I}_{2.55} \mathrm{Br}_{0.45}\right)$ based perovskite film, the $V_{O C}$ of $1.19 \mathrm{~V}$ was achieved with the best PCE of $21.9 \%$.

\subsection{ETL engineering in mixed cation and/or mixed halide perovskites}

One of the most important layers in obtaining the high $V_{O C}$ is the ETL, which facilitates the extraction and transport of electron as discussed in section 2.2. Therefore, a suitable energy level alignment and a trap-free surface are critical to achieving admissible PCE. ETL engineering is one of the most efficient ways to acquire a high-quality electron conductor with well-matched energy level and low trap-states and/or pin-holes. In this section, the remedial ETL engineering strategies employed for mixed-cation and/or mixed-halide based perovskite devices are discussed.

Zhou et al. reported the doping of $\mathrm{TiO}_{2} \mathrm{ETL}$ with yttrium $\left(\mathrm{Y}^{3+}\right)$ ions and modification of ITO substrate with poly-ethyleneimine ethoxylated (PEIE) to suppress the carrier recombination in the perovskite film and to facilitate the carrier injection into the carrier transport layers ${ }^{[79]}$. By PEIE modification, the work function of ITO was reduced from -4.6

$\mathrm{eV}$ to $-4.0 \mathrm{eV}$, whereas $\mathrm{Y}^{3+}$ doping increased the conduction band minimum (CBM) up to -4.0 $\mathrm{eV}$. As a result of these modifications, a PCE (only reverse scan) of $19.3 \%$ with $V O C$ of 1.15 $\mathrm{V}$, was achieved for $\mathrm{n}$-i-p-type PSCs in a planar configuration. The $110 \mathrm{mV}$ increase in $V_{O C}$ was mainly attributed to the reduced non-ideal space charge distribution as a result of balanced carrier transport. Notably, the PCE measured by a reverse scan can be highly overestimated owing to the large-hysteresis index. The anomalous hysteresis in PSCs can mainly be explained by the evoking the charge migration or accumulation at the perovskite/ETL interface. The enhancement in electrical properties and reduction in surface defects of ETL by suitable dopants can reduce the non-radiative recombination at the 


\section{WILEY-VCH}

perovskite/ETL interface and thereby properly alleviate the anomalous hysteresis behaviour of PSCs.

In an interesting study, a new mesoscopic architecture using Cs-doped $\mathrm{TiO}_{2}$ beads as electron selective contact was described. ${ }^{[80]}$ The enhancement of the contact area accessed by the perovskite light absorber and interface passivation between perovskite and $\mathrm{mp}-\mathrm{TiO}_{2}$ led to the fabrication of efficient quadruple-cation $\left(\mathrm{Rb} / \mathrm{Cs} / \mathrm{FA}_{0.95} \mathrm{MA}_{0.05}\right)$ perovskite-based PSCs with negligible hysteresis (Figure 6a). This substantially reduced hysteresis as compared to the bare $\mathrm{TiO}_{2}$, which was attributed to less charge accumulation at the perovskite/Cs-doped $\mathrm{TiO}_{2}$ interface. It was also demonstrated that Cs doping induces a shift of both oxygens (O) $1 \mathrm{~s}$ and titanium (Ti) $2 p$ peaks to lower energy, thereby decreasing oxygen vacancy which functions as an electron trap. This study obviously showed that a reduction in recombination rate is directly related to the increase in $V_{O C}$ of devices. Another electron selective contact that has gained considerable attention for enhancement of photovoltage is $\mathrm{SnO}_{2}$, which has a deeper conduction band and a suitable band alignment with the perovskite absorber. A lowtemperature atomic layer deposition (ALD) method was reported to fabricate compact and pin-hole free $\mathrm{SnO}_{2}$ ETL for their application in planar PSCs exhibiting a high performance (> $18 \%$ ) with high voltages up to $1.19 \mathrm{~V} \cdot{ }^{[81]}$ The low hysteresis is a result of suitable band alignment and good charge collection for $\mathrm{SnO}_{2}$ based devices, whereas, amorphous $\mathrm{TiO}_{2}$ based devices showed a strong hysteresis and a low $J_{S C}($ Figure 6b). The UPS and femtosecond TA measurements indicated a barrier-free charge transport across the perovskite/ $\mathrm{SnO}_{2}$ in contrast to the perovskite/ $\mathrm{TiO}_{2}$ interface. Recently, the suppression of hysteresis in planar-type PSCs was also reported using EDTA-complexed $\mathrm{SnO}_{2}$ ETL with a striking $P C E .^{[82]}$ EDTA-complexed $\mathrm{SnO}_{2}$ provided a well-matched Fermi level with the conduction band of mixed-cation $\mathrm{FA}_{0.95} \mathrm{Cs}_{0.05} \mathrm{PbI}_{3}$ perovskite structure, leading to a higher Voc. In addition, the electron mobility EDTA-complexed $\mathrm{SnO}_{2} \mathrm{ETL}$ was found to be three 


\section{WILEY-VCH}

times higher than that of the pristine $\mathrm{SnO}_{2}$. The record $P C E$ of corresponding PSCs based on EDTA-complexed $\mathrm{SnO}_{2}$ ETL was achieved to be $21.60 \%$ (certified as $21.52 \%$ by Newport) while pristine $\mathrm{SnO}_{2}$ ETL based device showed only a PCE of $18.93 \%$. As shown in (Figure 6c), the hysteresis in the EDTA-complexed $\mathrm{SnO}_{2}$ ETL based device drastically reduced because of the eliminated charge accumulation between perovskite and ETL interface. It was also reported that EDTA treatment made the $\mathrm{SnO}_{2}$ surface more hydrophilic, thus, decreasing the Gibbs free energy for heterogeneous nucleation, resulting in high-quality perovskite films.
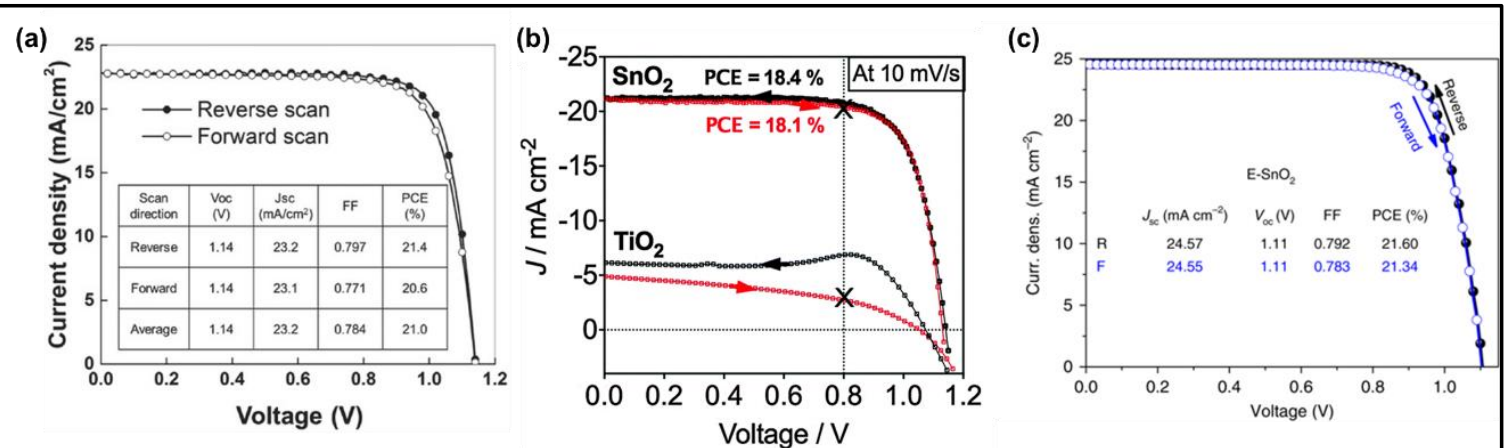

Figure 6. a) $J$ - $V$ curves of the top-performing devices prepared with $\mathrm{CsBr}$-doped $\mathrm{mp}^{-\mathrm{TiO}_{2}}$ as ETL. Reproduced with permission. [80] Copyright 2018, John Wiley \& Sons. b) $J$ - $V$ properties of $\mathrm{TiO}_{2}$ and $\mathrm{SnO}_{2}$-based planar $\left(\mathrm{FAPbI}_{3}\right)_{0.85}\left(\mathrm{MAPbBr}_{3}\right)_{0.15}$ devices backward scan (black curve) and reversed scan (red curve). Reproduced under the terms of the CC BY-NC 3.0 license.[81] Copyright 2015, Royal Society of Chemistry. c) $J$ - $V$ curves of the device using EDTAcomplexed $\mathrm{SnO}_{2} \mathrm{E}-\mathrm{SnO}_{2}$ as ETL in forward and reverse direction. Reproduced under the terms of the CC BY-NC 4.0 license.[82] Copyright 2018, Nature Publishing Group.

Gong et al. systematically investigated the band offset between ETL and $\left(\mathrm{FAPbI}_{3}\right)_{0.85}\left(\mathrm{MAPbBr}_{3}\right)_{0.15}$ perovskite absorber by tuning $\mathrm{F}$-doping level in gradient $\mathrm{SnO}_{2}$ based ETL. ${ }^{[83]}$ A reduction in the band offset was reported by the gradual substitution of $\mathrm{F}^{-}$ anions, resulting in a reduction in energy loss and a dramatic increase in VOC. By employing the bilayer ETLs, planar type PSCs reached to a PCE of $20.2 \%$ with a $V O C$ of $1.13 \mathrm{~V}$, while the control device showed a PCE of $16.3 \%$ with a $V O C$ of $1.03 \mathrm{~V}$. Compared to pristine $\mathrm{SnO}_{2}$ ETL, the bilayer ETL showed a lower surface roughness, higher electrical conductivity, and 


\section{WILEY-VCH}

upward-shifted Fermi level. More importantly, in addition to longer lifetime constant of bilayer ETL/perovskite ( $\sim 356.5 \mathrm{~ns})$ than that of pristine $\mathrm{SnO}_{2}$ ETL/perovskite ( $\left.198.7 \mathrm{~ns}\right)$; bilayer ETL exhibited better carrier collection and effectively suppressed the carrier recombination.

In a similar direction, a thin layer of $\mathrm{LiF}$ at the $\mathrm{SnO}_{2} /$ perovskite interlayer was introduced to fabricate high efficiency PSCs ${ }^{[84]}$ It was deduced that the LiF interlayer acts as a highly efficient interfacial passivation layer between $\mathrm{SnO}_{2} /$ perovskite interface without influencing the surface topography and crystal quality of perovskite films as well as light absorption ability of devices. In the presence of $1 \mathrm{~nm}$ thick LiF layer, the $V O C$ increased from $1.06 \mathrm{~V}$ to $1.16 \mathrm{~V}$, indicating that $\mathrm{LiF}$ suppressed the interfacial trap states between $\mathrm{SnO}_{2} /$ perovskite and reduced the interfacial (parasitic) charge recombination. The role of $\mathrm{Li}^{+}$ and $\mathrm{F}^{-}$was also investigated separately, by using the interlayer of $\mathrm{PbF}_{2}\left(\mathrm{~F}^{-}\right.$only) and LiTFSI ( $\mathrm{Li}^{+}$only) layers. It was found that a thin $\mathrm{PbF}_{2}$ modified $\mathrm{SnO}_{2}$ layer increased the $\mathrm{Voc}$ from 1.06 V to $1.14 \mathrm{~V}$, while LiTFSI did not change it. Therefore, the effect of $\mathrm{F}^{-}$ions was the key factor in $V O C$ improvement.

In addition to doping based modifications, the preparation of the ETL is also important to obtain efficient devices. A low-temperature solution-processed chemical bath deposition (CBD) method was described for Nb-doped $\mathrm{SnO}_{2}$ layers for almost hysteresis-free and highly efficient $\left(\mathrm{FAPbI}_{3}\right)_{0.85}(\mathrm{MAPbBr} 3)_{0.15}$ perovskite-based planar type PSCs. ${ }^{[85]}$ ETLs with an optimum Nb-doping (5 mol.\%) exhibited a lower series resistance, resulting in a higher FF (0.74 in average) and suppressed $J-V$ hysteresis. This approach generated a $V o c$ of $1.16 \mathrm{~V}$ and a significant $P C E$ of $20.47 \%$ for the device employing 5 mol.\% Nb-doped ETL. Such an improvement in $V O C$ was attributed to the reduced recombination at the interface due to the formation of defect-free and high-quality surface coverage. 


\section{WILEY-VCH}

\subsection{HTL engineering in mixed-cation and/or mixed-halide perovskites}

As described in Section 2.3. HTLs play a key role in extracting and transporting the photogenerated holes and in achieving an admissible photovoltaic performance. In addition to reasonable hole mobility and high electrical conductivity, HTL should meet requirements such as well-aligned energy levels, low-cost synthesis, and excellent thermal/photochemical stability. ${ }^{[86,87]}$ Towards this end, different strategies in HTL engineering, i.e. additives, molecular engineering, new materials, have been investigated. In the following section, some of the most representative reports regarding photovoltaic performance and stability of mixedcation mixed-halide PSCs will be discussed.

In spiro-OMeTAD based systems, the dopants play a key role in recombination dynamics to limit the $V_{O C}$ because they act as recombination centres at the HTL interface. The effect of dopant concentration of spiro-OMeTAD was examined on the recombination dynamics and it was found that the recombination is strongly dominated by the dopants and a VOC can significantly boost up to $1.23 \mathrm{~V}$ by reducing the Li-TFSI concentrations in spiroOMeTAD (Figure 7a). ${ }^{[88]}$ However, lower dopant concentrations also yielded a lower $F F$, resulting in a decrease in the overall $P C E$, showing that the dopant is indispensable in the case of spiro-OMeTAD owing to its low conductivity and hole mobility.

Other dopants have been also explored to enhance photovoltaic performance. Among the various alternates, $\mathrm{Zn}_{\text {-TFSI }}$ was successfully employed in spiro-OMeTAD as a $p$-type dopant by Seo et al., leading to improved hole mobility (from $3.78 \times 10^{-3} \mathrm{~cm}^{2} \mathrm{~V}^{-1} \mathrm{~s}^{-1}$ to $3.83 \times 10^{-2}$ $\mathrm{cm}^{2} \mathrm{~V}^{-1} \mathrm{~s}^{-1}$ ) and hole separation compared to the Li-TFSI. ${ }^{[89]}$ The device with Zn-TFSI2 exhibited an $80 \mathrm{mV}$ higher built-in voltage and a larger recombination resistance as compared to those based on Li-TFSI, leading to the striking increase in both the $V_{O C}$ and $F F$. Zn-TFSI 2 employing devices showed a stabilized $P C E$ of $22 \%$ with a $V_{O C}$ of $1.15 \mathrm{~V}$ owing to the downward shifting of the Fermi level of spiro-OMeTAD (Figure 7b). Furthermore, Zn-TFSI 2 


\section{WILEY-VCH}

employing devices presented an excellent photo-stability, showing even a $2 \%$ increase after $600 \mathrm{~h}$ light soaking. The remarkable photovoltaic performance was ascribed to the electronic properties of the Zn-TFSI2, whereas outstanding long-term stability was attributed to the static nature and higher electric-field strength of the $\mathrm{Zn}$ ions, inducing a strong electrostatic interaction within the spiro-OMeTAD matrix.

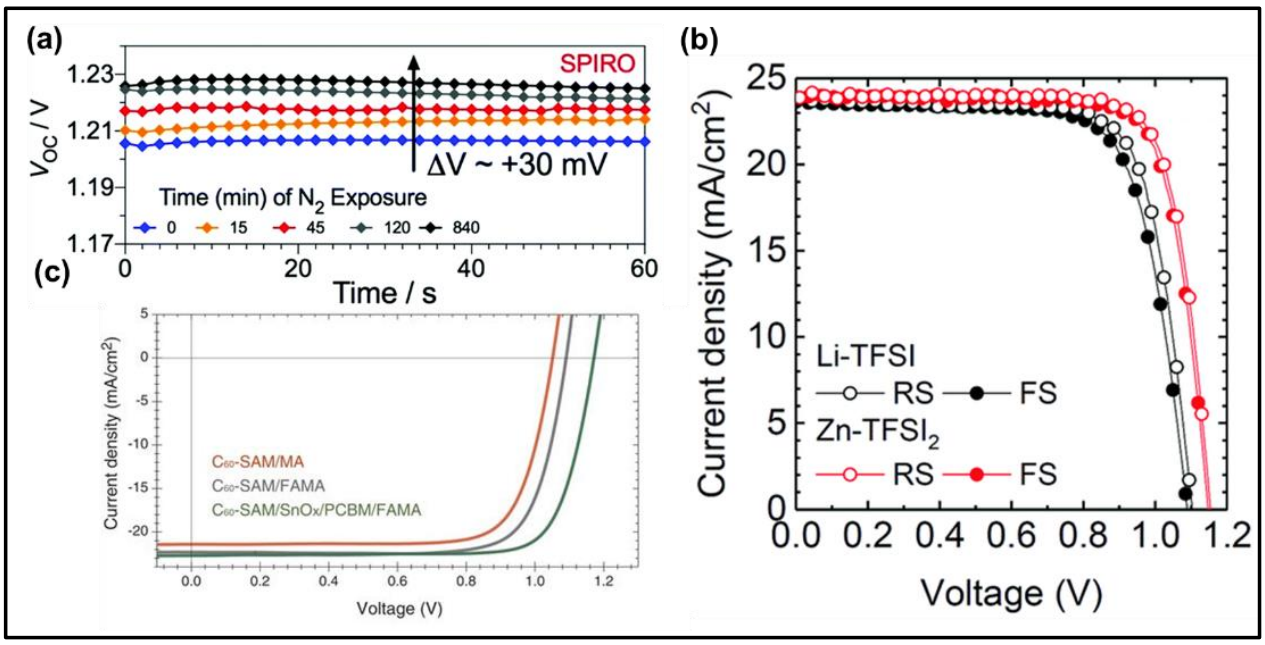

Figure 7. a) VoC vs. time with nitrogen exposure for best-performing devices using spiroOMeTAD as HTL. Reproduced with permission. [88] Copyright 2017, Royal Society of Chemistry. b) $J$ - $V$ curves of devices employing Li-TFSI or Zn-TFSI 2 as a dopant for spiroOMeTAD. Reproduced with permission.[89] Copyright 2018, Royal Society of Chemistry. c) $J-V$ curves of the maximized performance devices for MA perovskite using C60-SAM as ETL (orange curve) and PDCBT/Ta-WO $x$ as HTL, FAMA perovskite-based devices using $\mathrm{C}_{60}-$ SAM as ETL and PDCBT/Ta-WO $x$ as HTL (gray curve), and FAMA perovskite-based devices using $\mathrm{C}_{60}-\mathrm{SAM} / \mathrm{SnO}_{x} / \mathrm{PC}_{60} \mathrm{BM}$ as ETL and $\mathrm{PDCBT}^{\mathrm{T} a}-\mathrm{WO}_{x}$ as HTL (green curve). Reproduced with permission.[91] Copyright 2017, American Association for the Advancement of Science.

In addition to TFSI based dopants, different additives have been also explored to reduce the non-radiative recombination losses. The synthesis and utilization of adamantylammonium halides (ADAHX, $\mathrm{X}=\mathrm{Cl}^{-}, \mathrm{Br}^{-}, \mathrm{I}^{-}$) as a promising dopant in spiroOMeTAD was recently reported. ${ }^{[90]}$ Solid-state NMR spectroscopy showed a strong interaction between ADAHI and perovskite surface, resulting in highly efficient PSCs (22\%). The insertion of ADAHI dopant into spiro-OMeTAD increased the $V_{O C}$ by $145 \mathrm{mV}$ (from $1.10 \mathrm{~V}$ to $1.245 \mathrm{~V})$. The loss in the potential for the corresponding devices was reported to be 


\section{WILEY-VCH}

only $365 \mathrm{mV}$ with respect to the bandgap of $1.61 \mathrm{eV}$. The recombination behaviour at perovskite and HTL interface was investigated by electron beam-induced current (EBIC), which demonstrated a strong and uniform signal in the presence of ADAHI, indicating a lower recombination rate owing to the successful suppression of interfacial traps.

In addition to interfacial traps, the energy barriers between the HTL interfaces play a key role in minimizing the charge-carrier transport losses in PSCs. Bilayered HTLs are one of the best ways to decrease the energy barriers, which not only show a good selectivity but also a low-resistivity. Hou et al. reported tantalum-doped tungsten oxide $\left(\mathrm{Ta}^{-} \mathrm{WO}_{\mathrm{x}}\right)$ and a polythiophene derivative, poly[5,5'-bis(2-butyloctyl)-(2,2'-bithiophene)-4,4'-dicarboxylatealt-5,5'-2,2'-bithiophene] (PDCBT) conjugated polymer multilayers to reduce interfacial barrier and form quasi-ohmic contacts. ${ }^{[91]}$ By employing the perovskite composition of $\mathrm{FA}_{0.83} \mathrm{MA}_{0.17} \mathrm{~Pb}_{1.1} \mathrm{Br}_{0.50} \mathrm{I}_{2.80}$ and ionic dopant-free HTL, a $P C E$ of $21.2 \%$ with negligible hysteresis was achieved (Figure 7c). A thin coating of high conductive Ta-WOx film onto PDCBT showed a shift of $0.5 \mathrm{eV}$ in work function, implying much more effective charge transfer from the polymer to the metal oxides.

The concept of molecular engineering of the perovskite layer and HTL is crucial to increase the $V_{O C}$ and improve the performance of PSCs. In general, a higher Voc is obtained for HTMs with a higher oxidation potential. However, factors like intrinsic mobility of the HTM material, optimization of HTM molecular structure are equally important to enhance VOC. The introduction of an electron-withdrawing group such as fluorine with a high electronegativity to organic conjugated materials has been demonstrated as an efficient route to alleviate the charge transfer by controlling the energetic offset and improve the $V_{O C}$ values of polymer-based PSCs. For example, Kim et al. investigated the impact of fluorination on poly(triarylamine) (PTAA) polymers hole-transporting materials in $\left(\mathrm{FAPbI}_{3}\right)_{0.85}\left(\mathrm{MAPbBr}_{3}\right)_{0.15}$ based mesoporous n-i-p structure PSCs. ${ }^{[92]}$ The fluorination 


\section{WILEY-VCH}

successfully led to downshifting of the highest occupied molecular orbital (HOMO) level of PTAA derivatives $(-5.14 \mathrm{eV}$ to $-5.63 \mathrm{eV})$, leading to an increase in the $V_{O C}(1.10 \mathrm{~V}$ to 1.14 V) (Figure 8a and 8b). Space-charge-limited current (SCLC) measurements revealed hole mobility in the order of $10^{-5}$ while TRPL measurement showed a better charge extraction from perovskite compared with the reference PTAA HTL.

In a similar direction, fluorene-terminated HTL material ((N2,N2',N7,N7'-tetrakis(9,9dimethyl-9H-fluoren-2-yl)-N2,N2',N7,N7'-tetrakis(4-methoxyphenyl)-,9'-spirobi[fluorene]$2,2^{\prime}, 7,7^{\prime}$-tetraamine)) (abbreviated as DM) with a high glass transition temperature was synthesized for efficient $\left(\mathrm{FAPbI}_{3}\right)_{0.95}(\mathrm{MAPbBr})_{0.05}$ based PSCs. By using obtained material, $P C E$ of $22.9 \%$ with certified efficiencies of $22.6 \%$ for small-area $\left(\sim 0.094 \mathrm{~cm}^{2}\right)$ devices and $20.9 \%$ for large-area $\left(\sim 1 \mathrm{~cm}^{2}\right)$ was demonstrated (Figure 8c). ${ }^{[93]}$ The obtained VOC of $1.14 \mathrm{~V}$ was ascribed to the slightly higher oxidation potential of DM HTL, leading to better energylevel matching with the perovskite as shown in (Figure 8d). HTL engineering strategies have also been applied for inverted device architecture in order to further improve the photovoltaic performance stability. In the inverted structure of PSCs, nickel oxide (NiO) is one of the most efficient HTL material owing to its wide bandgap, high hole mobility, and appropriate valence band edge. ${ }^{[94,95]}$ Bai et al. demonstrated that surface modification of NiO HTL in inverted type PSC with di-ethanolamine (DEA) molecules can enhance the hole extraction/transport and thus the photovoltaic performance. ${ }^{[96]}$ The enhancement in photovoltaic performance was ascribed to the favourable layer formed by the molecular adsorption and the better interfacial interaction. The molecular adsorption creates a dipole layer, which is favourably oriented for hole extraction resulting in higher device performance (FF: 0.80 and PCE: $15.9 \%)$ for DEA based PSC than the control device (FF: 0.65 and PCE: $11.2 \%)$.

Recently, molecular doping was introduced to modify the solution-derived $\mathrm{NiO}_{\mathrm{x}} \mathrm{HTLs}$ by simply spin-coating an acetonitrile solution of 2,2'-(perfluoronaphthalene-2,6- 


\section{WILEY-VCH}

diylidene)dimalononitrile (F6TCNNQ) onto the bare $\mathrm{NiO}{ }^{[97]}$ This approach helped the molecular dopants to penetrate into the grain boundaries of the bare $\mathrm{NiO}_{\mathrm{x}}$ film, which resulted in a strong $p$-type doping effect, thus leading to a remarkable reduction in contact resistance at the $\mathrm{NiO}_{\mathrm{x}}$-perovskite interface. Moreover, the Fermi level of $\mathrm{NiO}_{\mathrm{x}}$ was increased from $4.63 \mathrm{eV}$ to $5.07 \mathrm{eV}$ after the F6TCNNQ doping, while the valence band maximum (VBM) level was decreased from $5.21 \mathrm{eV}$ to $5.37 \mathrm{eV}$, leading to an increase in $V_{O C}$ and overall PCE in inverted CsFAMAPb(IBr) 3 -based devices, owing to the minimized thermionic losses (Figure 8e and f).

Very recently, low temperature and solution-combustion based method was employed to prepare the $\mathrm{NiO}_{x}$ HTL. ${ }^{[98]}$ The resulting $\mathrm{NiO}_{x}$ exhibited a high film quality, slightly larger bandgap and preferable energy alignment with respect to $\mathrm{MA}_{1-\mathrm{y}} \mathrm{FA}_{\mathrm{y}} \mathrm{PbI}_{3-\mathrm{x}} \mathrm{Cl}_{\mathrm{x}}$ perovskite layer compared to high-temperature sol-gel-processed $\mathrm{NiO}_{x}$. The devices employing combustionderived $\mathrm{NiO}_{x}$ showed that the perovskite films on corresponding HTL had larger grain size with fewer defect states, exhibiting a high $P C E$ of $20.2 \%$ with a remarkable $V O C$ of $1.12 \mathrm{~V}$. The improved $P C E$ and enhanced ambient air storage stability was ascribed to the high quality of perovskite/HTL interface resulting in an enhanced charge transport, extraction, and suppressed charge recombination whereas the enhancement in $V_{O C}$ was attributed to the decreased work function which increases the potential difference between valance band of $\mathrm{NiO} x$ and conduction band of perovskite.

In addition to inorganic $\mathrm{NiO} \mathrm{HTL}$, organic-based poly(3,4-ethylenedioxythiophene): poly(styrene sulfonate) (PEDOT: PSS) is widely used as an HTL material in perovskite devices owing to its low-temperature processability, suitable valance band maximum, and low surface roughness. However, the high acidic nature and large energy barrier between the perovskite/PEDOT: PSS layers limit the hole extraction. To improve the hole extraction properties of PEDOT: PSS HTL, several attempts have been reported. For example, graphene 


\section{WILEY-VCH}

oxide (GO) was doped into PEDOT: PSS HTL and excellent optical and electrical properties including high electrical conductivity, high Fermi level, and high quality of perovskite crystal were reported (Figure 8g). ${ }^{[99]}$ The device employing GO doped PEDOT: PSS facilitated an efficient hole extraction and higher $\operatorname{VOC}(1.02 \mathrm{~V})$ as compared to a control device $(0.97 \mathrm{~V})$. As a result, a $P C E$ of $18.09 \%$ has been obtained with negligible hysteresis.

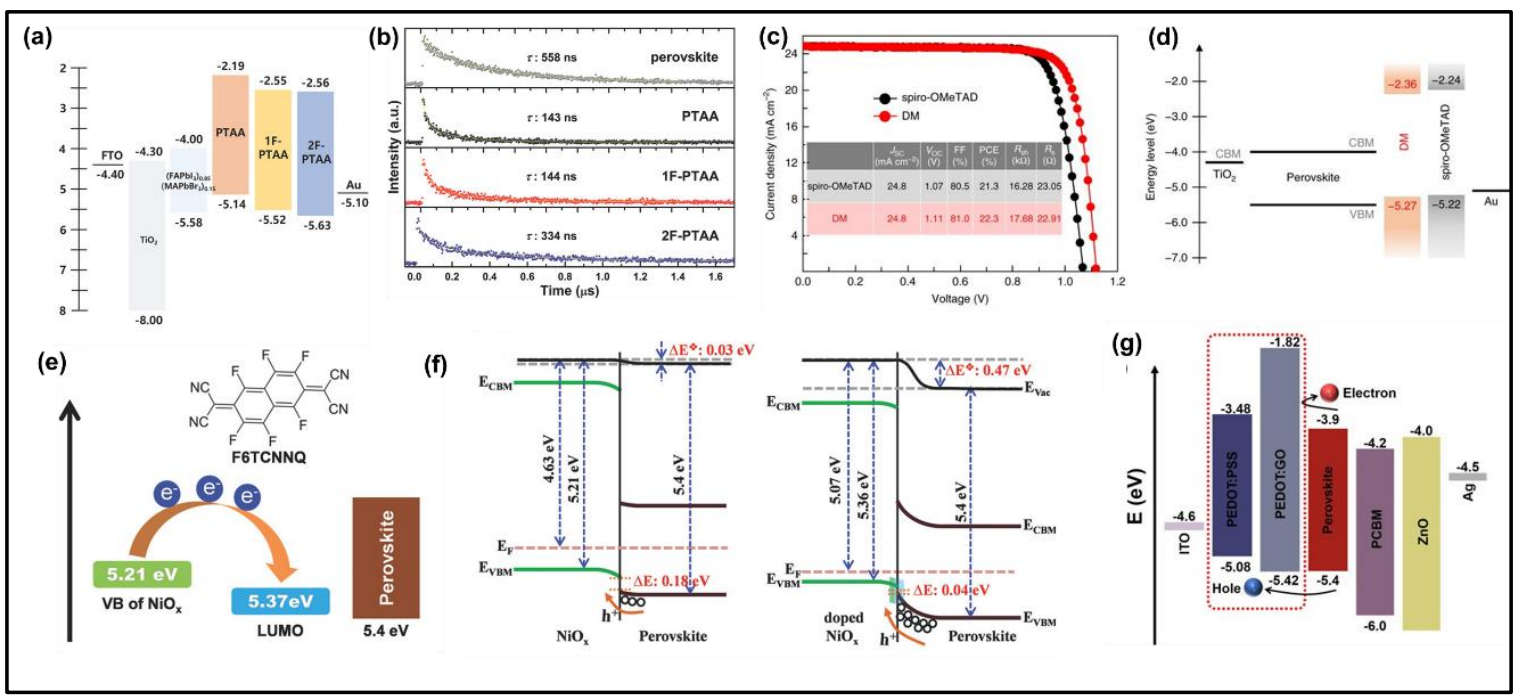

Figure 8. a) Schematic illustration of energy level alignment of perovskite devices with PTAA derivatives as HTLs. Reproduced with permission.[92] Copyright 2018, John Wiley \& Sons. b) TRPL decay curves of pristine perovskite, PTAA, 1F-PTAA, and 2FPTAA deposited on perovskites. Reproduced with permission.[92] Copyright 2018, Wiley. c) $J-V$ curves of the average measured efficiency for the perovskite devices using spiroOMeTAD and DM as HTL, the device using DM showed a higher Voc. Reproduced with permission.[93] Copyright 2018, Nature Publishing Group. d) Energy level diagram of DM and spiro-OMeTAD. Reproduced with permission.[93] Copyright 2018, Nature Publishing Group. e) Chemical structure of molecular dopant F6TCNNQ and energy band alignment of $\mathrm{NiO}_{x}$ and molecular dopants of F6TCNNQ and the chemical structure. Reproduced with permission.[97] Copyright 2018, Wiley. f) Impact of molecular doping of F6TCNNQ on the band bending at p-type doped $\mathrm{NiO}_{x}$-perovskite interface. Reproduced with permission.[97] Copyright 2018, Wiley. g) The relative energy levels of the various device components in the ITO/HTL/perovskite/PCBM/ZnO nanoparticles/Ag perovskite device. Reproduced under the terms of the CC BY-NC 4.0 license.[99] Copyright 2018, Nature Publishing Group.

\subsection{Interface engineering in mixed cation and/or mixed halide perovskites}

In addition to trap-assisted recombination in the perovskite layer, minority carrier recombination at the perovskite/charge transport layer interfaces is another crucial obstacle in 


\section{WILEY-VCH}

PSCs. Stolterfoht et al. investigated non-radiative recombination pathways in planar invertedtype PSCs with undoped organic charge transport layers. ${ }^{[100]}$ The conjugated polyelectrolyte poly[(9,9-bis(30-((N,N-dimethyl)-N-ethylammonium)-propyl)-2,7-fluorene)-alt-2,7-(9,9dioctylfluorene)] dibromide (PFN-P2) and LiF were used as interfacial layers to suppress the recombination losses. Inserting ultrathin interlayers $(<1 \mathrm{~nm})$ between the perovskite absorber and charge transport layers (PTAA/perovskite and perovskite/C60) led to a substantial reduction in the interfacial recombination losses by $65 \mathrm{meV}$ and $35 \mathrm{meV}$ for $p$ - and $n$ contacts, respectively. This approach enabled a dopant-free $1 \mathrm{~cm}^{2}$ PSCs with an efficiency exceeding $20 \%(19.83 \%$ certified $P C E)$ with a remarkable $V_{O C}(1.17 \mathrm{~V})$ and $F F(>0.81)$ (Figure 9a). High-quality $\mathrm{CsPbI}_{0.05}\left[\left(\mathrm{FAPbI}_{3}\right)_{0.89}\left(\mathrm{MAPbBr}_{3}\right)_{0.11}\right]_{0.9}$ perovskite film exhibited a lifetime around $500 \mathrm{~ns}$ while perovskite/transport layer heterojunctions showed fast decay potentially allowing a high $V_{O C}($ Figure $9 b)$. A similar approach was introduced by Peng $e t$ al. applying a double-side polymer poly(methyl methacrylate) (PMMA) at $\mathrm{TiO}_{2} /$ perovskite and perovskite/spiro-OMeTAD interfaces. ${ }^{[101]}$ The remarkable passivation properties of PMMA increased the $V O C$ from $1.10 \pm 0.01 \mathrm{~V}$ for the control device to $1.16 \pm 0.01 \mathrm{~V}$ for perovskite/ETL interface- passivation, and 1.20 $\pm 0.01 \mathrm{~V}$ for double-side passivated devices. As a result, a high PCE of $20.8 \%$ was achieved with a significant $V O C$ of $1.22 \mathrm{~V}$ while using $\sim 1.6 \mathrm{eV}$ bandgap $\mathrm{Cs}_{0.07} \mathrm{Rb}_{0.03} \mathrm{FA}_{0.765} \mathrm{MA}_{0.135} \mathrm{PbI}_{2.55} \mathrm{Br}_{0.45}$ layer (Figure 9c). Photoluminescence imaging and transient spectroscopic measurements showed a lower non-radiative recombination rate (Figure 9d) whereas surface analysis indicated a good filling of pinholes, and unspecified passivation of surface traps/defects, yielding an improved VOC without any significant degradation in $J_{S C}$ or $F F$. The analysis of perovskite-PMMA molecular interactions reveals that the Lewis-base nature of the oxygen atoms in the carbonyl $(\mathrm{C}=\mathrm{O})$ groups (donor electrons) on the PMMA can aid in the reduction of $\mathrm{Pb}^{2+}$ defect ions at the perovskite/ETL and perovskite/HTL interfaces. 


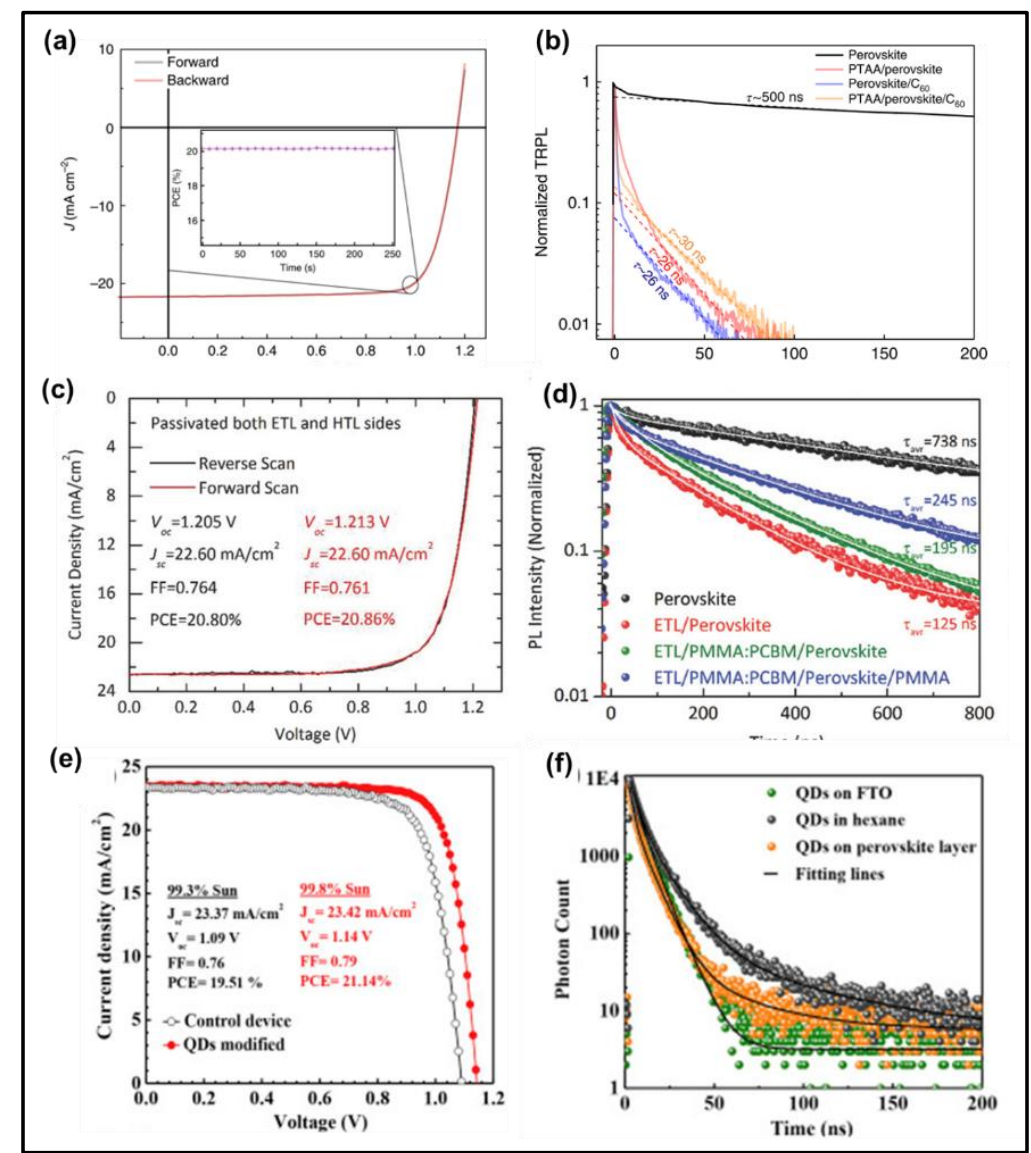

Figure 9. a) $J-V$ curves of the $1 \mathrm{~cm}^{2}$ perovskite cells reaching 20\% PCE using a combination of PFN-P2 and LiF interlayers. Reproduced with permission.[100] Copyright 2018, Nature Publishing Group. b) TRPL decay of a pristine perovskite film showing mono-exponential lifetime ( $\sim 500 \mathrm{~ns})$ and bi-exponential decay for perovskite/charge transport layer heterojunctions. Reproduced with permission.[100] Copyright 2018, Nature Publishing Group. c) $J$ - $V$ curves of the double-side passivated device with an architecture of FTO/c-In$\mathrm{TiO}_{\mathrm{x}} / \mathrm{m} \mathrm{TiO}_{2} / \mathrm{PMMA}$ : PCBM/Perovskite/PMMA/Spiro-OMeTAD/Au. Reproduced with permission.[101] Copyright 2018, Wiley. d) TRPL measurements of ETL only samples (illuminated from the ETL side): perovskite, ETL/perovskite, ETL/PMMA: PCBM/Perovskite and ETL/PMMA: PCBM/Perovskite/PMMA. Reproduced with permission.[101] Copyright 2018, Wiley. e) $J-V$ curves for the champion cells for bare and QDs-10 modified perovskitebased devices. Reproduced with permission.[102] Copyright 2019, Elsevier. f) TRPL decays of the bare and QDs-10 modified perovskite films with and without spiro-OMeTAD layer. Reproduced with permission.[102] Copyright 2019, Elsevier.

In addition to organic passivation materials including fullerene derivatives or PMMA, more recently Akin et al. developed a promising approach to modify the perovskite/HTL interface employing inorganic $\mathrm{Cs} \mathrm{PbBr}_{1.85} \mathrm{I}_{1.15}$ perovskite quantum dots (PQDs) as an interfacial layer. ${ }^{[102]}$ By the insertion of the interfacial layer, $P C E$ of the best-performing 


\section{WILEY-VCH}

device increased from $19.51 \%$ to $21.14 \%$ with a remarkable increase in $F F$ and $V_{O C}$ (Figure 9e). The increase in $F F$ (0.76 to 0.79 ) was attributed to enhanced hole extraction and suppressed carrier recombination at the interfaces and grain boundaries whereas such an increase in $\operatorname{VOC}(1.09 \mathrm{~V}$ to $1.14 \mathrm{~V})$ was ascribed to the photo-induced dipole effect originating from the accumulated charges on the perovskite surface and suitable energy level of PQDs layer. The dipole effect positively shifted the perovskite energy bands whereas PQDs layer hindered the back-flow of electrons towards the HTL, minimizing parasitic charge-carrier recombination (Figure 8f). Table 2 summarizes the recent progress on the photovoltaic performance of mixed cation and/or mixed halide-based perovskite devices. In this section, we have covered the strategies including; 1) solvent/polymer-assisted crystal engineering for fast crystallization resulting in perovskite films of high electronic quality, 2) compositional engineering for example by addition of inorganic cations for perovskite films with low defect density, 3) band alignment engineering using modified charge transport layers such as doped $\mathrm{SnO}_{2}$, modified state-of-the-art HTL spiro-OMeTAD, molecular engineering of perovskite and HTLs, and 4) use of interfacial layers to suppress recombination losses. These studies clearly indicate that the development of strategies to improve performance and stability of mixed cation and/or mixed halide-based PSCs is an important application-driven research topic.

Table 2. VOC and other photovoltaic parameters of mixed cation and/or mixed halide perovskite-based PSCs.

\begin{tabular}{|c|c|c|c|c|c|c|c|}
\hline $\begin{array}{l}\text { Perovskite } \\
\text { composition }\end{array}$ & Device configuration & $\begin{array}{l}\text { Voc } \\
\text { (V) }\end{array}$ & $\begin{array}{l}J s c \\
(\mathrm{~mA} \\
\left.\mathrm{cm}^{-2}\right)\end{array}$ & $F F$ & $\begin{array}{l}P C E \\
(\%)\end{array}$ & $\begin{array}{l}\text { Change } \\
\text { in Voc } \\
(\mathrm{mV})\end{array}$ & Ref. \\
\hline $\mathrm{CsFAMAPb}(\mathrm{I}, \mathrm{Br})_{3}$ & $\begin{array}{l}\mathrm{FTO} / \mathrm{c}-\mathrm{TiO}_{2} / \mathrm{mp} \text { - } \\
\mathrm{TiO}_{2} / \mathrm{Perovskite/Spiro-} \\
\mathrm{OMeTAD} \mathrm{Au}\end{array}$ & 1.13 & 22.69 & 0.75 & 21.10 & +10 & [21] \\
\hline $\mathrm{RbCsFAMAPb}(\mathrm{I}, \mathrm{Br})_{3}$ & $\begin{array}{l}\mathrm{FTO} / \mathrm{c}-\mathrm{TiO}_{2} / \mathrm{mp} \text { - } \\
\mathrm{TiO}_{2} / \mathrm{Perovskite/Spiro-} \\
\mathrm{OMeTAD} / \mathrm{Au}^{-}\end{array}$ & 1.19 & 22.80 & 0.81 & 21.80 & +50 & [22] \\
\hline
\end{tabular}




\begin{tabular}{|c|c|c|c|c|c|c|}
\hline $\mathrm{MAPb}(\mathrm{Br}, \mathrm{I})_{3}$ & $\begin{array}{l}\text { ITO/C } 0_{00}^{-} \\
\text {Phlm/Perovskite/TaTm/Au }\end{array}$ & 1.21 & 10.50 & 0.79 & 10.00 & +110 \\
\hline $\mathrm{MAPb}(\mathrm{Cl}, \mathrm{I})_{3}$ & $\begin{array}{l}\text { ITO/C- } \\
\mathrm{TiO}_{2} / \text { Perovskite:HBr/Spiro- } \\
\text { OMeTAD/Ag }\end{array}$ & 0.94 & 21.71 & 0.77 & 15.76 & +50 \\
\hline $\mathrm{FAMAPbl}_{3}$ & $\begin{array}{l}\mathrm{FTO} / \mathrm{SnO}_{2} / \mathrm{C}_{60^{-}} \\
\mathrm{SAM} / \mathrm{Perovskite}+ \\
\mathrm{Pb}(\mathrm{SCN})_{2} / \text { Spiro-OMeTAD/Au }\end{array}$ & 1.11 & 22.34 & 0.81 & 20.03 & +10 \\
\hline $\mathrm{CsFAPbl}_{3}$ & $\begin{array}{l}\mathrm{FTO} / \mathrm{c}-\mathrm{TiO}_{2} / \mathrm{Sb} \text { doped } \\
\text { Perovskite/Spiro- } \\
\text { OMeTAD/Ag }\end{array}$ & 1.10 & 22.85 & 0.84 & 21.04 & +80 \\
\hline $\mathrm{CsFAPb}(\mathrm{I}, \mathrm{Br})_{3}$ & 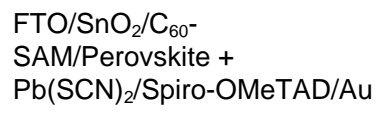 & 1.25 & 18.53 & 0.79 & 18.27 & +80 \\
\hline $\mathrm{CsFAPb}(\mathrm{I}, \mathrm{Br})_{3}$ & $\begin{array}{l}\text { FTO/c-TiO } / \text { Perovskite/Spiro- } \\
\text { OMeTAD/Au }\end{array}$ & 1.07 & 23.30 & 0.72 & 18.02 & +60 \\
\hline $\operatorname{FAMAPb}(\mathrm{I}, \mathrm{Br})_{3}$ & $\begin{array}{l}\mathrm{FTO} / \mathrm{c}-\mathrm{TiO}_{2} / \mathrm{mp}- \\
\mathrm{TiO}_{2} / \mathrm{Perovskite}+ \\
\mathrm{PMMA} / \text { Spiro-OMeTAD/Au }\end{array}$ & 1.14 & 23.70 & 0.78 & 21.60 & +40 \\
\hline $\operatorname{FAMAPb}(\mathrm{I}, \mathrm{Br})_{3}$ & $\begin{array}{l}\mathrm{FTO} / \mathrm{c}-\mathrm{TiO}_{2} / \mathrm{mp}^{-} \\
\mathrm{TiO}_{2} / \mathrm{Perovskite}+ \\
\mathrm{PCBM} / \text { Spiro-OMeTAD/Au }\end{array}$ & 1.13 & 23.95 & 0.74 & 20.80 & +20 \\
\hline $\operatorname{CsFAMAPb}(\mathrm{I}, \mathrm{Br})_{3}$ & $\begin{array}{l}\mathrm{FTO} / \mathrm{c}-\mathrm{TiO}_{2} / \mathrm{mp}- \\
\mathrm{TiO}_{2} / \mathrm{Perovskite}+\text { Gual/Spiro- } \\
\mathrm{OMeTAD} / \mathrm{Au}^{-}\end{array}$ & 1.20 & 23.60 & 0.70 & 20.30 & +70 \\
\hline $\operatorname{CsFAMAPb}(\mathrm{I}, \mathrm{Br})_{3}$ & $\begin{array}{l}\mathrm{FTO} / \mathrm{c}-\mathrm{TiO}_{2} / \mathrm{mp}- \\
\mathrm{TiO}_{2} / \text { Perovskite }+ \\
\mathrm{FAAc} / \text { Spiro-OMeTAD/Au }\end{array}$ & 1.19 & 23.23 & 0.80 & 21.90 & +50 \\
\hline $\mathrm{MAPb}(\mathrm{Cl}, \mathrm{I})_{3}$ & $\begin{array}{l}\text { ITO/PEIE/Y:TiO } / \text { Perovskite/ } \\
\text { Spiro-OMeTAD/Au }\end{array}$ & 1.15 & 22.80 & 0.76 & 19.30 & +110 \\
\hline $\operatorname{RbCsFAMAPb}(\mathrm{I}, \mathrm{Br})_{3}$ & $\begin{array}{l}\mathrm{FTO} / \mathrm{c}-\mathrm{TiO}_{2} / \mathrm{CsBr} \text { treated mp- } \\
\mathrm{TiO}_{2} / \text { Perovskite/Spiro- } \\
\text { OMeTAD/Au }\end{array}$ & 1.14 & 23.20 & 0.80 & 21.40 & +40 \\
\hline FAMAPb $(\mathrm{I}, \mathrm{Br})_{3}$ & $\begin{array}{l}\text { FTO/SnO } / \text { /Perovskite/Spiro- } \\
\text { OMeTAD/Au }\end{array}$ & 1.14 & 21.30 & 0.74 & 18.40 & +70 \\
\hline $\mathrm{CsFAPbl}_{3}$ & $\begin{array}{l}\text { ITO/EDTA-complexed } \\
\mathrm{SnO}_{2} / \text { Perovskite/Spiro- } \\
\text { OMeTAD/Au }\end{array}$ & 1.11 & 24.57 & 0.79 & 21.60 & +30 \\
\hline $\mathrm{FAMAPb}(\mathrm{I}, \mathrm{Br})_{3}$ & $\begin{array}{l}\text { FTO/F:TiO } / \text { /Perovskite/Spiro- } \\
\text { OMeTAD/Au }\end{array}$ & 1.13 & 22.92 & 0.78 & 20.20 & +100 \\
\hline $\mathrm{MAPb}(\mathrm{Cl}, \mathrm{I})_{3}$ & $\begin{array}{l}\text { ITO/SnO } / / \mathrm{LiF} / \text { Perovskite/Spir } \\
\text { o-OMeTAD/Au }\end{array}$ & 1.15 & 21.62 & 0.74 & 18.33 & +70 \\
\hline $\mathrm{MAPb}(\mathrm{Cl}, \mathrm{I})_{3}$ & $\begin{array}{l}\mathrm{ITO} / \mathrm{SnO}_{2} / \mathrm{PbF}_{2} / \text { Perovskite/Sp } \\
\text { iro-OMeTAD/Au }\end{array}$ & 1.14 & 19.05 & 0.71 & 15.50 & +60 \\
\hline $\operatorname{CsFAMAPb}(\mathrm{I}, \mathrm{Br})_{3}$ & $\begin{array}{l}\mathrm{FTO} / \mathrm{Nb}: \mathrm{SnO}_{2} / \text { Perovskite/Spir } \\
\text { o-OMeTAD/Au }\end{array}$ & 1.16 & 22.77 & 0.75 & 20.47 & +20 \\
\hline $\operatorname{CsFAMAPb}(\mathrm{I}, \mathrm{Br})_{3}$ & $\begin{array}{l}\mathrm{FTO} / \mathrm{c}-\mathrm{TiO}_{2} / \mathrm{mp}- \\
\mathrm{TiO}_{2} / \text { Perovskite/ADAHI/Spiro- } \\
\text { OMeTAD/Au }\end{array}$ & 1.17 & 24.30 & 0.77 & 21.90 & +60 \\
\hline FAMAPb $(I, B r)_{3}$ & $\begin{array}{l}\text { ITO/C } 60^{-} \\
\text {SAM/Perovskite/PDCBT/Ta- } \\
\text { WO }_{x} / \mathrm{Au}\end{array}$ & 1.17 & 22.70 & 0.80 & 21.20 & +60 \\
\hline
\end{tabular}




\begin{tabular}{|c|c|c|c|c|c|c|c|}
\hline $\operatorname{FAMAPb}(\mathrm{I}, \mathrm{Br})_{3}$ & $\begin{array}{l}\mathrm{FTO} / \mathrm{c}-\mathrm{TiO}_{2} / \mathrm{mp}- \\
\mathrm{TiO}_{2} / \text { Perovskite/1F-PTAA/Au }\end{array}$ & 1.14 & 23.40 & 0.82 & 22.00 & +40 & [92] \\
\hline FAMAPb $(\mathrm{I}, \mathrm{Br})_{3}$ & $\begin{array}{l}\mathrm{FTO} / \mathrm{c}-\mathrm{TiO}_{2} / \mathrm{mp}- \\
\mathrm{TiO}_{2} / \text { Perovskite/DM/Au }\end{array}$ & 1.14 & 24.91 & 0.81 & 23.20 & +70 & [93] \\
\hline $\mathrm{MAPb}(\mathrm{Cl}, \mathrm{I})_{3}$ & $\begin{array}{l}\text { FTO/NiO/DEA/Perovskite/PC } \\
\text { BM/PN4N/Ag }\end{array}$ & 0.95 & 20.90 & 0.80 & 15.90 & 0 & {$[96]$} \\
\hline CsFAMAPb $(\mathrm{I}, \mathrm{Br})_{3}$ & $\begin{array}{l}\text { ITO/F6TCNNQ:NiO } / \text { /Perovski } \\
\text { te/PCBM/ZrAcac/Ag }\end{array}$ & 1.12 & 23.18 & 0.80 & 20.86 & +50 & [97] \\
\hline $\operatorname{FAMAPb}(\mathrm{I}, \mathrm{Cl})_{3}$ & $\begin{array}{l}\mathrm{FTO} / \mathrm{NiO} / \text { Perovskite/PCBM/B } \\
\mathrm{CP} / \mathrm{Ag}\end{array}$ & 1.12 & 23.70 & 0.76 & 20.20 & +60 & [98] \\
\hline $\mathrm{MAPb}(\mathrm{I}, \mathrm{Br})_{3}$ & $\begin{array}{l}\text { ITO/GO:Pedot/Perovskite/PC } \\
\mathrm{BM} / \mathrm{ZnO} / \mathrm{Ag}\end{array}$ & 1.02 & 21.55 & 0.82 & 18.09 & +50 & [99] \\
\hline CsFAMAPb $(\mathrm{I}, \mathrm{Br})_{3}$ & $\begin{array}{l}\text { ITO/PTAA/PFN- } \\
\text { P2/Perovskite/LiF/C }{ }_{60} / \mathrm{Au}\end{array}$ & 1.17 & 21.70 & 0.79 & 20.30 & +50 & [100] \\
\hline RbCsFAMAPb $(\mathrm{I}, \mathrm{Br})_{3}$ & $\begin{array}{l}\mathrm{FTO} / \mathrm{In}-\mathrm{TiO}_{\mathrm{x}} / \mathrm{mp}- \\
\mathrm{TiO}_{2} / \mathrm{PMMA} / \mathrm{Perovskite} / \mathrm{PMM} \\
\mathrm{A} / \mathrm{Sp} \text { iro-OMeTAD/Au }\end{array}$ & 1.17 & 22.75 & 0.76 & 20.28 & +60 & [101] \\
\hline CsFAMAPb $(\mathrm{I}, \mathrm{Br})_{3}$ & $\begin{array}{l}\mathrm{FTO} / \mathrm{c}-\mathrm{TiO}_{2} / \mathrm{mp}- \\
\mathrm{TiO}_{2} / \text { Perovskite } / \mathrm{CsPb}(\mathrm{Br}, \mathrm{I})_{3} / \mathrm{A} \\
\mathrm{u}\end{array}$ & 1.14 & 23.42 & 0.79 & 21.14 & +50 & [102] \\
\hline CsFAMAPb $(\mathrm{I}, \mathrm{Br})_{3}$ & $\begin{array}{l}\text { FTO/Ru:SnO } / \text { Perovskite/Spir } \\
\text { o-OMeTAD/Au }\end{array}$ & 1.15 & 24.58 & 0.78 & 22.00 & +50 & [103] \\
\hline $\mathrm{MAPb}(\mathrm{Br}, \mathrm{I})_{3}$ & $\begin{array}{l}\text { ITO/PTAA/Perovskite } \\
\text { /PCBM/C } 6 \text { } 6 / \mathrm{BCP} / \mathrm{Al}\end{array}$ & 1.21 & 15.80 & 0.78 & 14.90 & +50 & [104] \\
\hline CsFAMAPb $(\mathrm{I}, \mathrm{Br})_{3}$ & $\begin{array}{l}\text { ITO/Chlorine-capped c- } \\
\mathrm{TiO}_{2} / \text { Perovskite/Spiro- } \\
\text { OMeTAD/Au }\end{array}$ & 1.22 & 21.20 & 0.81 & 20.80 & +50 & [105] \\
\hline CsFAMAPb $(\mathrm{I}, \mathrm{Br})_{3}$ & $\begin{array}{l}\text { ITO/SnO } / \text { /Perovskite:NaF/Spi } \\
\text { ro-OMeTAD/Au }\end{array}$ & 1.13 & 24.23 & 0.80 & 21.92 & +30 & [106] \\
\hline CsFAMAPb $(\mathrm{I}, \mathrm{Br})_{3}$ & $\begin{array}{l}\text { ITO/PTAA/Perovskite/D4TBP } \\
\text { / } \mathrm{C}_{60} / \mathrm{BCP} / \mathrm{Cu}\end{array}$ & 1.16 & 22.51 & 0.80 & 21.40 & +80 & [107] \\
\hline $\mathrm{CsFAPb}(\mathrm{I}, \mathrm{Br})_{3}$ & $\begin{array}{l}\text { ITO/PTAA/Perovskite + } \\
\text { GABr/ }{ }_{60} / \mathrm{BCP} / \mathrm{Ag}\end{array}$ & 1.24 & 21.72 & 0.72 & 18.19 & +120 & [108] \\
\hline $\mathrm{CsFAPb}(\mathrm{I}, \mathrm{Br})_{3}$ & $\begin{array}{l}\text { FTO/SnO } / \text { /PCBM/Perovskite/ } \\
\text { Spiro-OMeTAD/Ag }\end{array}$ & 1.20 & 19.40 & 0.75 & 17.10 & +100 & [109] \\
\hline CsFAMAPb $(\mathrm{I}, \mathrm{Br})_{3}$ & $\begin{array}{l}\text { ITO/TiO }-\mathrm{Cl} / \mathrm{Pbl}_{2} \\
\text { seed/Perovskite/Spiro- } \\
\text { OMeTAD/Au }\end{array}$ & 1.13 & 24.10 & 0.81 & 21.50 & +60 & [110] \\
\hline $\mathrm{FAMAPb}(\mathrm{I}, \mathrm{Br})_{3}$ & $\begin{array}{l}\mathrm{FTO} / \mathrm{c}-\mathrm{TiO}_{2} / \mathrm{mp}- \\
\mathrm{TiO}_{2} / \mathrm{Perovskite} \mathrm{FAPbBr}{ }_{3} \\
\times \mathrm{I}_{x} / \mathrm{Spiro}-\mathrm{OMeTAD} / \mathrm{Au}\end{array}$ & 1.16 & 23.18 & 0.79 & 21.31 & +50 & [111] \\
\hline CsFAMAPb $(\mathrm{I}, \mathrm{Br})_{3}$ & $\begin{array}{l}\mathrm{FTO} / \mathrm{SnO}_{2} / \text { Zwitterion/Perovsk } \\
\text { ite/Spiro-OMeTAD/Au }\end{array}$ & 1.16 & 23.60 & 0.78 & 21.43 & +60 & [112] \\
\hline $\mathrm{FAMAPb}(\mathrm{I}, \mathrm{Br})_{3}$ & 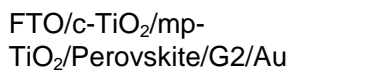 & 1.13 & 23.52 & 0.76 & 20.20 & +50 & [113] \\
\hline
\end{tabular}




\section{WILEY-VCH}

\section{LD/3D-based perovskites}

Low-dimensional $(\mathrm{LD}=1 \mathrm{D}, 2 \mathrm{D})$ perovskites have witnessed a great development in terms of long-term stability under external conditions owing to the effective protection by the hydrophobic organic spacing-ligands. ${ }^{[114,115]}$ However, because of their wide optical bandgaps and anisotropic charge transport properties caused by the long organic spacing-ligand, the $P C E$ of pure LD based PSCs is still far inferior to their 3D analogues. ${ }^{[115,116,117]}$ To marry the desired features of LD perovskites with the excellent light-harvesting properties of 3D perovskite, LD systems have recently emerged as a potential candidate to simultaneously maintain long-term stability and high photovoltaic performance. In the following section, the substantial role of $\mathrm{LD}$ perovskites within a 3D dominant structure either as an additive or as overlayer is discussed.

The confluence of high-efficiency 3D perovskites with superior moisture stability of LD perovskite absorbers has recently ignited quiet interest in the concept of LD-3D heterostructured PSCs. Hu et al. were the first to propose the two-layer approach in 2D/3D $\left((\mathrm{PEA})_{2}(\mathrm{MA})_{4} \mathrm{~Pb}_{5} \mathrm{I}_{16} / \mathrm{MAPbI}_{3}\right)$ heterojunction-based PSCs. ${ }^{[118]}$ Grazing-incidence wide-angle X-ray scattering (GIWAXS) pattern revealed the preferential orientation of the layered 2D perovskite, which is accompanied by a re-organization and re-orientation of the $\mathrm{MAPI}_{3}$ top layer. In the presence of 2D layer, the best-performing devices showed a PCE of $14.94 \%\left(J_{S C}\right.$ $=18.63 \mathrm{~mA} \mathrm{~cm}{ }^{-2}, V_{O C}=1.08 \mathrm{~V}$, and $F F=0.73$ ), whereas pure 3D-based best-performing devices showed a $P C E$ of $13.61 \%\left(J_{S C}=19.82 \mathrm{~mA} \mathrm{~cm}^{-2}, V O C=0.99 \mathrm{~V}\right.$, and $\left.F F=0.70\right)$. The significant increase in $V O C$ and $F F$ was ascribed to reduced recombination losses within the device, inferring the selective charge extraction role of the 2D layer. Such a configuration also provided an additional moisture barrier for the under-3D layer, thus improving the long-term moisture stability owing to the hydrophobic nature of long-chain organic cations. The 2D/3D 


\section{WILEY-VCH}

perovskite devices exhibited a higher average $P C E$ of $11.4 \%$, whereas the 3D perovskite device showed only $6.1 \%$ after 19 days of ageing at $75 \% \mathrm{RH}$.

Following this work, another 2D/3D hybrid structure was reported on the incorporation of $n$-butylammonium (BA) within the cesium-formamidinium lead halide 3D perovskite $\mathrm{FA}_{0.83} \mathrm{Cs}_{0.17} \mathrm{~Pb}\left(\mathrm{I}_{\mathrm{y}} \mathrm{Br}_{1-\mathrm{y}}\right)_{3}$ (Figure 10a). ${ }^{[119]} \mathrm{BA}$ cations facilitated the formation of perpendicularly orientated 2D-phase perovskite crystallites in plate-like morphology embedded between the 3D perovskite grains. This heterostructure enhanced crystallinity and at the same time, interfacial grain boundary passivation remarkably reduced the defect states, leading to an increase in the PL lifetime, higher PCE, minimal current-voltage hysteresis, and improved operational stability. A champion stabilized PCE of $19.5 \%$ and $17.3 \%$ was achieved with a $1.61 \mathrm{eV}$ bandgap perovskite $(\mathrm{y}=0.8)$ and a $1.72 \mathrm{eV}$ bandgap $(\mathrm{y}=0.6)$ perovskite, respectively.

Recently, our group presented a method of depositing 2D material onto a bulk 3D perovskite layer to fabricate exceptionally moisture-resistant PSCs with a record-level PCE exceeding 22\%. ${ }^{[1]}$ In this study, pentafluoro-phenylethylammonium (FEA) lead iodide $\left[(\mathrm{FEA})_{2} \mathrm{PbI}_{4}\right] 2 \mathrm{D}$ perovskite layer was inserted between the 3D perovskite layer and HTM. XPS depth profiling of fluorine $(\mathrm{F})$ confirmed the presence of $\mathrm{FEA}^{+}$in the top 9-nm-thin layer, whereas the EDS mapping showed the conformal and uniform distribution of $\mathrm{FEA}^{+}$ over the 3D film. The perfluorinated benzene unit bestowed an ultra-hydrophobic character to the FEA spacer layer, protecting the perovskite light absorber from ambient moisture while simultaneously inhibiting interlayer ionic diffusion in the device. The 3D/2D fluoroarene bilayer-based champion PSCs achieved a PCE as high as $22.2 \%$ with a $V O C$ of $1.096 \mathrm{~V}, F F$ of 0.79 , and $J_{S C}$ of $25.8 \mathrm{~mA} \mathrm{~cm}^{-2}$ while the reference PSC yielded a $P C E$ of $20.6 \%$ with $V_{O C}$ of $1.045 \mathrm{~V}, F F$ of 0.78 , and $J_{S C}$ of $25.5 \mathrm{~mA} \mathrm{~cm}^{-2}$ (Figure 10b). The $\sim 50 \mathrm{mV}$ increase in $V O C$ was attributed to a two-fold increase in the charge carrier lifetime and faster hole injection into the 


\section{WILEY-VCH}

HTM, implying the suppression of non-radiative carrier recombination at the (3D/2D) perovskite/HTL interface as depicted in Figure 10c. In addition, the operational photostability was also enhanced by applying the 2D treatment.

More recently, different types of ammonium salts, namely ethylammonium iodide (EAI), imidazolium iodide (IAI), and guanidinium iodide (GuaI) have been introduced to reduce the electronic defects at perovskite/HTL interface. ${ }^{[120]}$ This facile strategy thoroughly modified the triple-cation perovskite surface and showed an improvement in $V o c$ by $40 \mathrm{mV}$ (EAI), $70 \mathrm{mV}$ (IAI), and $40 \mathrm{mV}$ (GuaI), leading to the realization of PCEs as high as $22.4 \%$, $22.1 \%$, and $21.0 \%$ for EAI, IAI, and GuaI employed perovskite devices, respectively. The increase in PL intensity for all treated perovskite films further confirmed the reduction of the non-radiative recombination losses that could be explained by defect passivation induced by cation exchange and filling of iodide vacancies at the absorber surface.

In addition to identifying new $L D$ perovskite materials for their integration onto 3D perovskite film, equally important is the preparation of LD perovskite materials. Yoo et al. investigated the role of polar protic solvent isopropyl alcohol (IPA) in surface treatments and reported a selective precursor dissolution (SPD) strategy using $n$-butylammonium bromide/chloroform combination for depositing LD layered perovskite onto a 3D perovskite film. ${ }^{[121]}$ It was observed that IPA solvent can dissolve the 3D perovskite in a short time (> 2 s) due to its highly polar nature and its tendency to form hydrogen bonds while nonhygroscopic chloroform showed no change in optical profile. Through this approach, a champion PCE of $23.4 \%$ (a certified PCE of $22.6 \%$ ) with a $V O C$ loss of only $~ 340 \mathrm{mV}$ was achieved. The improved $P C E$ was ascribed to the effective passivation of interfaces and grain boundary defects. Apart from the stack-by-stack method, the hybridization is another way to prepare LD/3D PSCs. Zhou et al. demonstrated that 2-thiophenemethylammonium (ThMA) as the spacer cations can be successfully embedded into the FAI and MAI based 3D 


\section{WILEY-VCH}

perovskite (Figure 11a). ${ }^{[122]}$ The incorporation of ThMA spacer cation into 3D perovskite, forming a 2D/3D hybrid structure accelerated crystalline growth and orientation with enlarged grain size, resulting in prolonged carrier life-time and decreased recombination losses. The 2D/3D hybrid perovskite-based device exhibited a $P C E$ of $21.49 \%$ with a high $V O C$ of $1.16 \mathrm{~V}$ and a significant $F F$ of 0.81 . This outstanding $F F$ was attributed to more balanced charge mobility whereas improved crystallinity, leading an efficient charge collection can explain relatively higher $V_{O C}$.

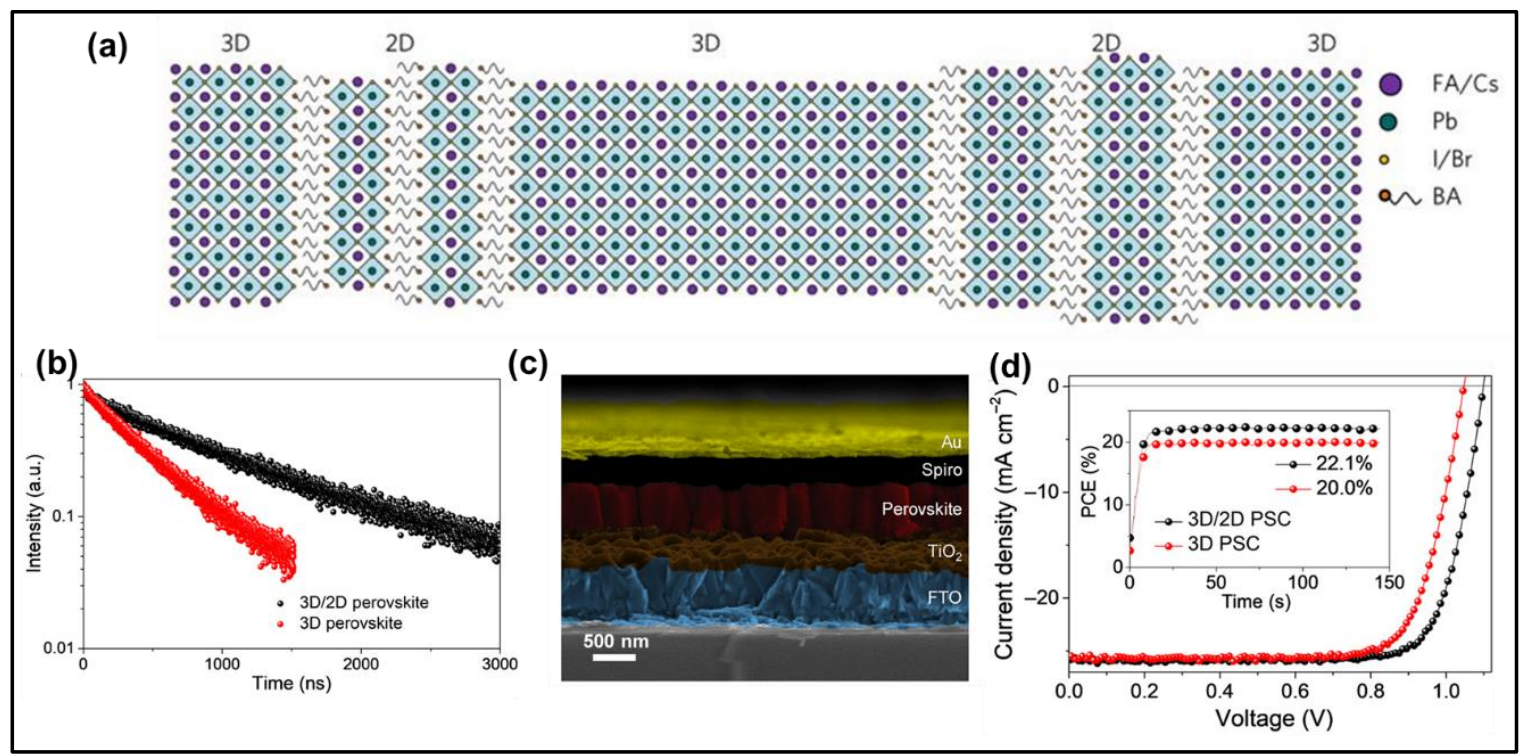

Figure 10. a) Schematic illustration of the proposed self-assembled BA 0.09 (FA0.83 $\left.\mathrm{Cs}_{0.17}\right)_{0.91} \mathrm{~Pb}\left(\mathrm{I}_{0.6} \mathrm{Br}_{0.4}\right)_{3}, 2 \mathrm{D}-3 \mathrm{D}$ crystal interface. Reproduced with permission.[119] Copyright 2017, Nature Publishing Group. b) TRPL decay traces recorded from the $3 \mathrm{D}$ and $3 \mathrm{D} / 2 \mathrm{D}$ perovskite films showing more than twofold increase in the charge carrier lifetime by applying the $2 \mathrm{D}$ surface treatment $\left[t_{10}(3 \mathrm{D} / 2 \mathrm{D})=2550 \mathrm{~ns}\right.$ and $t_{10}(3 \mathrm{D})=950$ ns]. Reproduced under the terms of the CC-BY-NC 4.0 license [1] Copyright 2019, American Association for the Advancement of Science. c) Cross-sectional SEM of a fully assembled 3D/2D PSC. Reproduced under the terms of the CC-BY-NC 4.0 license [1] Copyright 2019, American Association for the Advancement of Science. d) J-V curves of 3D PSC and 3D/2D PSCs recorded under standard AM $1.5 \mathrm{G}$ illumination $\left(100 \mathrm{~mW} \mathrm{~cm}^{-2}\right)$, with inset showing MPP tracking. Reproduced under the terms of the CC BY-NC 4.0 license [1] Copyright 2019, American Association for the Advancement of Science.

Along this direction, 1-year stable PSCs have been developed by engineering a multidimensional junction made of 2D/3D $\left(\mathrm{HOOC}\left(\mathrm{CH}_{2}\right)_{4} \mathrm{NH}_{3}\right)_{2} \mathrm{PbI}_{4} / \mathrm{MAPbI}_{3}$ 


\section{WILEY-VCH}

perovskites. ${ }^{[123]}$ The 2D/3D structure was formed by mixing at different molar ratios of aminovaleric acid iodide $\left(\mathrm{COOH}\left(\mathrm{CH}_{2}\right)_{4} \mathrm{NH}_{3} \mathrm{I}\right)$, AVAI: $\left.\mathrm{PbI}_{2}\right)$ and $\left(\mathrm{CH}_{3} \mathrm{NH}_{3} \mathrm{I}: \mathrm{PbI}_{2}\right)$ precursors. Both small area cells $\left(0.64 \mathrm{~cm}^{2}\right)$ and larger area modules $\left(10 \times 10 \mathrm{~cm}^{2}\right)$ were fabricated. For the small area devices, the perovskite employing 3\% AVAI formed a gradually-organized multi-dimensional interface that allowed to obtain $12.9 \%$ efficiency in a carbon-based architecture and $14.6 \%$ in mesoporous device architecture. The module of $100 \mathrm{~cm}^{2}$ (active area of around $50 \mathrm{~cm}^{2}$ ) retained a remarkable air-stability by maintaining a PCE of $11.2 \%$ over $10000 \mathrm{~h}(\approx 1$ year $)$ with zero loss at a stabilized temperature of $55^{\circ} \mathrm{C}$ under AM $1.5 \mathrm{G}$ conditions under short-circuit conditions.

2D perovskite approach has been also explored in the inverted PSCs with planar architecture using solvent engineering method. Bai et al. developed a solution process based in situ growth route to form a $2 \mathrm{D}$ capping layer together with $3 \mathrm{D}$ perovskite. ${ }^{[124]}$ In this method, phenethylammonium iodide (PEAI) dissolved in toluene solution was used as antisolvent instead of pure toluene which allowed the formation of 2D capping layer together with 3D perovskite. A 3D-2D ( $\left.\mathrm{MAPbI}_{3}-\mathrm{PEA}_{2} \mathrm{~Pb}_{2} \mathrm{I}_{4}\right)$ graded perovskite layer improved interfacial charge transfer as a result of the modified interface energy level and reduced charge-carrier recombination at the perovskite/PCBM interface (Figure 11b). It was described that this graded layer not only enhanced the moisture stability by abating water penetration but also improved the thermal stability by suppressing the ion migration across the interfaces.

In another interesting study, Luo et al. described a simple solution-processed secondary growth (SSG) technique to reduce the non-radiative recombination for the inverted devices. ${ }^{[125]}$ This method comprises two sequential steps: the preparation of perovskite films by solution processing and the secondary growth with the assistance of guanidinium bromide (SSG-G). This strategy produced a more $n$-type perovskite film with a wider bandgap top 


\section{WILEY-VCH}

layer achieving a high $V_{O C}$ of $1.21 \mathrm{~V}$, which was attributed to reduced non-radiative recombination for the $\left(\mathrm{FA}_{0.95} \mathrm{PbI}_{2.95}\right)_{0.85}\left(\mathrm{MAPbBr}_{3}\right)_{0.15}$ based inverted devices (Figure 11c).

The presence of guanidinium bromide throughout the films and at the surfaces inhibited undesired trap-assisted recombination at the heterojunctions by trap passivation and considerable improvements in film quality and electronic nature facilitated to obtain a stabilized PCE close to $21 \%$.

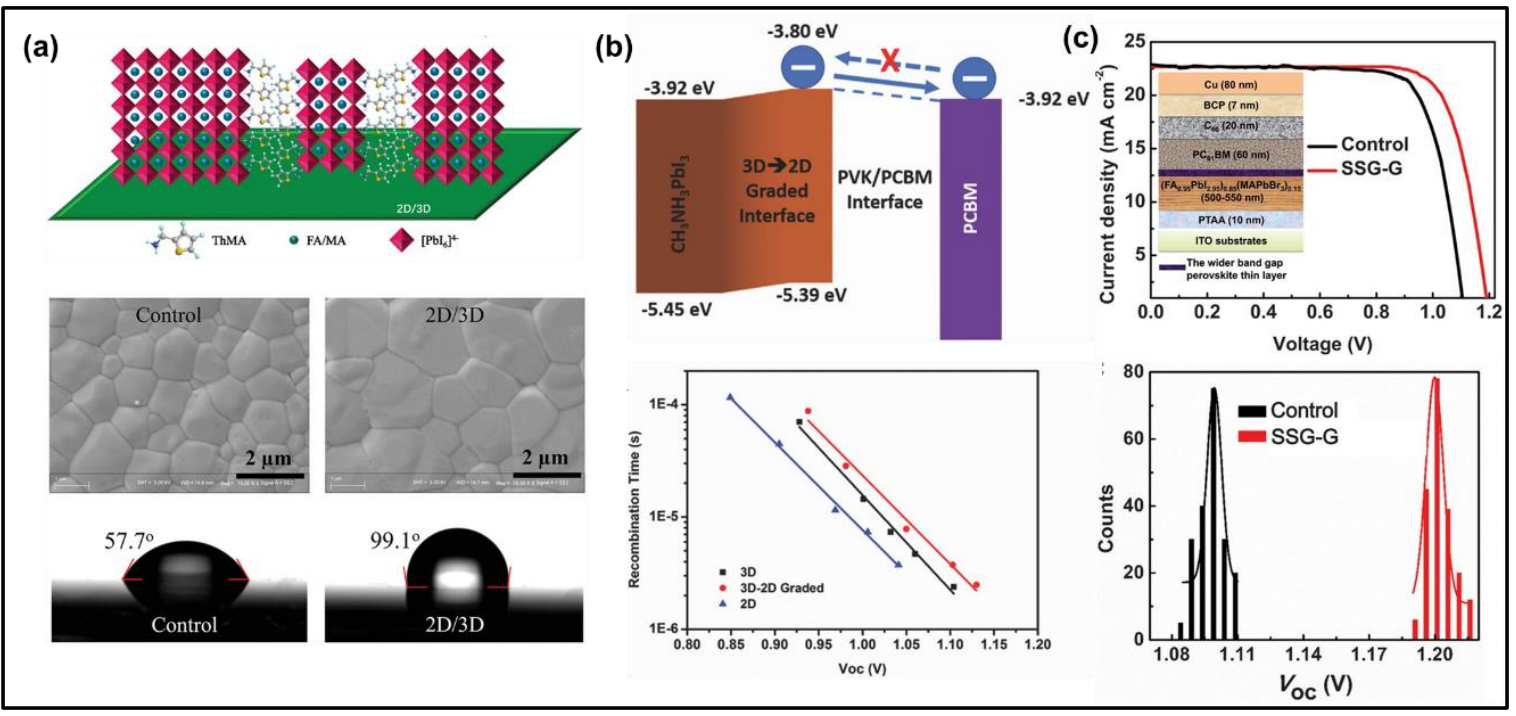

Figure 11. a) Schematic illustration of the proposed 2D/3D perovskite structure, showing the incorporation of large organic cation, ThMAI into the 3D perovskite and formation of 2D layer aligned perpendicular to the substrates, SEM images of the 2D/3D perovskite film on the glass $/ \mathrm{SnO}_{2}$ substrate, and water droplet contact angles on surfaces of the control and the 2D/3D perovskite films. Reproduced with permission.[122] Copyright 2019, John Wiley \& Sons. b) Schematic illustration of energy level alignment at 3D-2D graded perovskite and PCBM interface and voltage-dependence of recombination lifetime for the different devices. Reproduced with permission.[124] Copyright 2017, John Wiley \& Sons .c) $J-V$ curves of the inverted planar heterojunction control and SSG-G PSCs (reverse scans under simulated AM $1.5 \mathrm{G}$ illumination at $100 \mathrm{~mW} \mathrm{~cm}^{-2}$ ) and histograms of the $V_{o c}$ for 200 control and 200 SSG-G devices, the average $V_{\text {oc }}$ of the control devices was about $1.10 \mathrm{~V}$ and $1.20 \mathrm{~V}$ for the SSG-G devices, with a record value of $1.21 \mathrm{~V}$. Reproduced with permission.[125] Copyright 2018, American Association for the Advancement of Science.

Table 3 summarizes the recent progress on the photovoltaic performance of LD/3Dbased perovskite devices. This field is less matured than the field of pure 3D perovskites, and retaining PCEs comparable to 3D-absorber based PSCs while achieving high operational 
stability is still a challenge. Nevertheless, this field is on an interesting trajectory, which is expected to play a substantial role towards stable and efficient devices for industrial applications.

Table 3. VOC and other photovoltaic parameters of LD/3D-based PSCs.

\begin{tabular}{|c|c|c|c|c|c|c|c|}
\hline 3D perovskite composition & Device configuration & $\begin{array}{l}\text { Voc } \\
\text { (V) }\end{array}$ & $\begin{array}{l}J s c \\
(\mathrm{~mA} \\
\left.\mathrm{cm}^{-2}\right)\end{array}$ & $F F$ & $\begin{array}{l}P C E \\
(\%)\end{array}$ & $\begin{array}{l}\text { Chan } \\
\text { ge in } \\
\text { Voc } \\
(\mathrm{mV})\end{array}$ & Ref. \\
\hline $\mathrm{Cs}_{0.05}\left(\mathrm{FA}_{0.10} \mathrm{MA}_{0.90}\right)_{0.95} \mathrm{Pbl}_{3}$ & $\begin{array}{l}\mathrm{FTO} / \mathrm{c}-\mathrm{TiO}_{2} / \mathrm{mp}- \\
\mathrm{TiO}_{2} / 3 \mathrm{D} /(\mathrm{FEAl})_{2} \mathrm{Pbl}_{4} / \text { Spiro- } \\
\text { OMeTAD/Au/MgF } 2\end{array}$ & 1.10 & 25.79 & 0.79 & 22.16 & +50 & [1] \\
\hline $\mathrm{MAPbl}_{3}$ & $\begin{array}{l}\mathrm{FTO} / \mathrm{c}-\mathrm{TiO}_{2} / 3 \mathrm{D} / \\
(\mathrm{PEA})_{2}(\mathrm{MA})_{4} \mathrm{~Pb}_{5} \mathrm{l}_{16} / \text { Spiro- } \\
\text { OMeTAD/Au }\end{array}$ & 1.08 & 18.63 & 0.73 & 14.94 & +90 & [118] \\
\hline $\mathrm{FA}_{0.83} \mathrm{Cs}_{0.17} \mathrm{~Pb}\left(\mathrm{I}_{0.8} \mathrm{Br}_{0.2)_{3}}\right.$ & $\begin{array}{l}\mathrm{FTO} / \mathrm{SnO}_{2} / \mathrm{PC}_{61} \mathrm{BM} / 3 \mathrm{D}+\mathrm{BAl} / \mathrm{Spiro-} \\
\mathrm{OMeTAD} / \mathrm{Au}\end{array}$ & 1.14 & 22.70 & 0.80 & 20.60 & 0 & [119] \\
\hline $\mathrm{FA}_{0.83} \mathrm{Cs}_{0.17} \mathrm{~Pb}\left(\mathrm{I}_{0.6} \mathrm{Br}_{0.4)_{3}}\right.$ & $\begin{array}{l}\mathrm{FTO} / \mathrm{SnO}_{2} / \mathrm{PC}_{61} \mathrm{BM} / 3 \mathrm{D}+\mathrm{BAI} / \mathrm{Spiro-} \\
\mathrm{OMeTAD} / \mathrm{Au}\end{array}$ & 1.18 & 19.80 & 0.73 & 17.20 & +40 & [119] \\
\hline$\left(\mathrm{FAPbl}_{3}\right)_{0.92}\left(\mathrm{MAPbBr}_{3}\right)_{0.08}$ & $\begin{array}{l}\mathrm{FTO} / \mathrm{c}-\mathrm{TiO}_{2} / \mathrm{mp}^{-} \\
\mathrm{TiO}_{2} / 3 \mathrm{D} /\left(\mathrm{C}_{6} \mathrm{H}_{13} \mathrm{NH}_{3}\right)_{2} \mathrm{PbBr}_{2} \mathrm{l}_{2} / \text { Spiro- } \\
\text { OMeTAD/Au }\end{array}$ & 1.16 & 24.50 & 0.82 & 23.40 & +50 & [121] \\
\hline $\mathrm{FA}_{0.83} \mathrm{MA}_{0.17} \mathrm{~Pb}\left(\mathrm{I}_{0.8} \mathrm{Cl}_{0.2}\right)_{3}$ & $\begin{array}{l}\text { ITO/SnO } / 3 \mathrm{D}+\mathrm{ThMAl} / \text { Spiro- } \\
\text { OMeTAD } / \mathrm{MoO}_{3} / \mathrm{Ag}\end{array}$ & 1.16 & 22.88 & 0.81 & 21.49 & +70 & [122] \\
\hline $\mathrm{MAPbl}_{3}$ & $\begin{array}{l}\mathrm{FTO} / \mathrm{c}-\mathrm{TiO}_{2} / \mathrm{mp}-\mathrm{TiO}_{2} / 3 \mathrm{D}+ \\
\mathrm{AVAl} / \mathrm{Sp} \text { iro-OMeTAD/Au }\end{array}$ & 1.03 & 18.84 & 0.76 & 14.60 & -30 & [123] \\
\hline $\mathrm{MAPbl}_{3}$ & $\begin{array}{l}\mathrm{FTO} / \mathrm{NiO} / 3 \mathrm{D}+\mathrm{PEA}_{2} \mathrm{~Pb}_{2} \mathrm{I}_{4} / \mathrm{PCBM} / \mathrm{PN} \\
4 \mathrm{~N} / \mathrm{Ag}\end{array}$ & 1.17 & 21.80 & 0.78 & 19.89 & +70 & [124] \\
\hline$\left(\mathrm{FA}_{0.95} \mathrm{Pbl}_{2.95}\right)_{0.85}\left(\mathrm{MAPbBr}_{3}\right)_{0.15}$ & $\begin{array}{l}\text { ITO/PTAA/3D/Gua } \mathrm{PbBr}_{4} / \mathrm{PCBM} / \mathrm{C}_{60} \\
\text { /BCP/Cu }\end{array}$ & 1.18 & 21.86 & 0.81 & 20.90 & +100 & [125] \\
\hline $\mathrm{Cs}_{0.1} \mathrm{FA}_{0.74} \mathrm{MA}_{0.13} \mathrm{Pbl}_{2.48} \mathrm{Br}_{0.39}$ & $\begin{array}{l}\mathrm{FTO} / \mathrm{c}-\mathrm{TiO}_{2} / \mathrm{mp}- \\
\mathrm{TiO}_{2} / 3 \mathrm{DD} / \mathrm{A} 43_{2} \mathrm{Pbl}_{4} / \text { Spiro- } \\
\text { OMeTAD } / \mathrm{Au}\end{array}$ & 1.13 & 22.85 & 0.78 & 20.00 & +15 & [126] \\
\hline $\mathrm{FA}_{0.9} \mathrm{Cs}_{0.07} \mathrm{MA}_{0.03} \mathrm{~Pb}\left(\mathrm{I}_{0.92} \mathrm{Br}_{0.08}\right)_{3}$ & $\begin{array}{l}\mathrm{FTO} / \mathrm{c}-\mathrm{TiO}_{2} / \mathrm{mp}-\mathrm{TiO}_{2} / 3 \mathrm{D} / \mathrm{EAI} / \text { Spiro- } \\
\text { OMeTAD/Au }\end{array}$ & 1.12 & 24.14 & 0.81 & 22.40 & +40 & [120] \\
\hline $\mathrm{FA}_{0.9} \mathrm{Cs}_{0.07} \mathrm{MA}_{0.03} \mathrm{~Pb}\left(\mathrm{I}_{0.92} \mathrm{Br}_{0.08}\right)_{3}$ & $\begin{array}{l}\mathrm{FTO} / \mathrm{c}-\mathrm{TiO}_{2} / \mathrm{mp}-\mathrm{TiO}_{2} / 3 \mathrm{D} / \mathrm{IAl} / \text { Spiro- } \\
\text { OMeTAD/Au }\end{array}$ & 1.15 & 23.85 & 0.79 & 22.11 & +70 & [120] \\
\hline $\mathrm{FA}_{0.9} \mathrm{Cs}_{0.07} \mathrm{MA}_{0.03} \mathrm{~Pb}\left(\mathrm{I}_{0.92} \mathrm{Br}_{0.08}\right)_{3}$ & 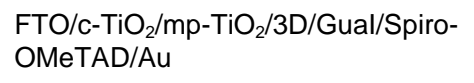 & 1.12 & 24.50 & 0.75 & 21.00 & +40 & [120] \\
\hline $\mathrm{MA}_{0.9} \mathrm{FA}_{0.1} \mathrm{Pbl}_{3}$ & $\begin{array}{l}\mathrm{FTO} / \mathrm{c}-\mathrm{TiO}_{2} / \mathrm{mp}^{-\mathrm{TiO}_{2}} / 3 \mathrm{DD}+ \\
\mathrm{A} 43_{2} \mathrm{~S} \text { Spiro-OMeTAD/Au }\end{array}$ & 1.11 & 22.87 & 0.79 & 20.13 & +70 & [126] \\
\hline $\mathrm{FA}_{0.98} \mathrm{Cs}_{0.02} \mathrm{Pbl}_{3}$ & $\begin{array}{l}\mathrm{ITO} / \mathrm{SnO}_{2} / 3 \mathrm{D}+\mathrm{PEAI} / \mathrm{Spiro-} \\
\mathrm{OMeTAD} / \mathrm{Ag}\end{array}$ & 1.13 & 24.44 & 0.77 & 21.06 & +80 & [127] \\
\hline
\end{tabular}




\begin{tabular}{|c|c|c|c|c|c|c|c|}
\hline $\mathrm{Cs}_{0.1} \mathrm{FA}_{0.74} \mathrm{MA}_{0.13} \mathrm{Pbl}_{2.48} \mathrm{Br}_{0.39}$ & $\begin{array}{l}\mathrm{FTO} / \mathrm{c}-\mathrm{TiO}_{2} / \mathrm{mp}^{-} \\
\mathrm{TiO}_{2} / 3 \mathrm{D} / \mathrm{PEA} \mathrm{Pbl}_{4} / \text { Spiro- } \\
\text { OMeTAD/Au }\end{array}$ & 1.15 & 22.73 & 0.79 & 20.75 & +50 & {$[128]$} \\
\hline $\mathrm{FA}_{0.83} \mathrm{Cs}_{0.17} \mathrm{~Pb}\left(\mathrm{I}_{0.6} \mathrm{Br}_{0.4}\right)_{3}$ & $\begin{array}{l}\text { ITO/SnO }{ }_{2} / 3 \mathrm{D} / \mathrm{BA}_{2} \mathrm{PbBr}_{4} / \text { Spiro- } \\
\text { OMeTAD/Au }\end{array}$ & 1.31 & 18.40 & 0.78 & 19.40 & +80 & {$[130]$} \\
\hline $\begin{array}{l}\mathrm{Cs}_{0.05}\left(\mathrm{FA}_{0.83} \mathrm{MA}_{0.17}\right)_{0.95} \mathrm{~Pb}\left(\mathrm{I}_{0.83} \mathrm{~B}\right. \\
\left.\mathrm{r}_{0.17}\right)_{3}\end{array}$ & $\begin{array}{l}\mathrm{FTO} / \mathrm{c}-\mathrm{TiO}_{2} / \mathrm{mp}-\mathrm{TiO}_{2} / 3 \mathrm{D} / \\
\mathrm{PEA}_{2} \mathrm{Pbl}_{4} / \text { Spiro-OMeTAD/Au }\end{array}$ & 1.11 & 22.89 & 0.73 & 18.51 & +60 & [131] \\
\hline $\mathrm{MAPbl}_{3}$ & $\begin{array}{l}\text { ITO/PTAA } / 3 \mathrm{D} /(\mathrm{BA})_{2} \mathrm{Pbl}_{4} / \mathrm{PCBM} / \mathrm{C}_{60} / \\
\mathrm{BCP} / \mathrm{Cu}\end{array}$ & 1.11 & 22.49 & 0.78 & 19.56 & +30 & [132] \\
\hline
\end{tabular}

\section{Long-term Stability}

Besides efficiency, long-term stability is warranted for up-scaling of perovskite technology. The stability of perovskite devices strongly depends on the stability of individual components within the device architecture such as the absorber layer, charge transporting layers, and metal contacts. Therefore, the stability of each component and interfaces is of great importance for commercialization. Thus far, PSC research has bloomed into a race to develop not only efficient but also long-term stable device components. In the following section, the recent advances towards limiting the extrinsic (environmental) and intrinsic factors affecting the device stability have been summarized.

\subsection{Operational stability}

Among all the promising techniques, additive engineering has been widely applied as an effective and feasible approach to obtaining high-quality perovskite films, thereby leading to enhanced stability of PSCs.

Cesium cation $\left(\mathrm{Cs}^{+}\right)$employing triple-cation perovskite-based devices have displayed improved stability under the operational conditions with an output power of $18 \%$ after $250 \mathrm{~h}$ while Cs-free perovskite-based devices showed less stable behaviour. ${ }^{[21]}$ In addition to appropriate Goldschmidt tolerance factor, reduced defect states, and the critical role of $\mathrm{Cs}^{+}$to mitigate phase separation; the strong interaction of $\mathrm{Cs}^{+}$with the lead iodide (or bromide) 


\section{WILEY-VCH}

octahedral framework greatly improved the photo-stability. ${ }^{[133]}$ Consequently, the incorporation of small and oxidation-stable rubidium cation $\left(\mathrm{Rb}^{+}\right)$into perovskite has further improved the performance and stability of PSCs. ${ }^{[22]}$

Very recently, a great enhancement in the long-term device stability of inverted type PSCs was reported by the incorporation of ionic liquid, 1-butyl-3-methylimidazolium tetrafluoroborate $\left(\mathrm{BMIMBF}_{4}\right)$ into the perovskite film. ${ }^{[134]}$ Interestingly, as shown in Figure 12a, the encapsulated cells based on $\mathrm{BMIMBF}_{4}$-incorporated perovskite film showed less degradation $(<5 \%)$ in comparison to solar cells based on $\mathrm{BMIMBF}_{4}$ at the perovskite/NiO interface, which degraded at a similar rate to the control cells under full solar spectrum after aging at the elevated temperature $\left(70-75^{\circ} \mathrm{C}\right)$. It was envisaged that improved stability originates from the presence of $[\mathrm{BMIM}]^{+}$cations, that binds to the surface sites and evading degradation.

In the same direction, the formation of thin and compact lead oxysalt on the metal halide perovskite surface was demonstrated by in situ reaction of perovskite with inorganic anions. ${ }^{[135]}$ Such water-insoluble wide-bandgap lead oxysalt thin layers improved the moisture resistance of the perovskite films by forming strong chemical bonds and reducing defectnucleating sites on the perovskite surface by passivating undercoordinated lead centers. A $P C E$ of $21.1 \%$ was achieved as a result of the increased carrier recombination lifetime by the formation of lead oxysalt layer as a result encapsulated devices retained $96.8 \%$ of their initial efficiency after operation at MPP tracking under continuous illumination for $1200 \mathrm{~h}$ at $65^{\circ} \mathrm{C}$. Under the same ageing conditions, encapsulated control device degraded rapidly from $18.2 \%$ to $8.54 \%$ merely in $\sim 470 \mathrm{~h}$. More recently, another solution-processing strategy to stabilize the perovskite heterostructure was reported via the formation of strong $\mathrm{Pb}-\mathrm{Cl}$ and $\mathrm{Pb}-\mathrm{O}$ chemical bonds in a $\left[\mathrm{CH}\left(\mathrm{NH}_{2}\right)_{2}\right]_{x}\left[\mathrm{CH}_{3} \mathrm{NH}_{3}\right]_{1-\mathrm{x}} \mathrm{Pb}_{1+\mathrm{y}} \mathrm{I}_{3}$ perovskite film with a $\mathrm{Pb}$-rich surface and a chlorinated graphene oxide $(\mathrm{Cl}-\mathrm{GO})$ layer. ${ }^{[136]}$ A reduction in charge recombination and 


\section{WILEY-VCH}

more-efficient charge extraction in the perovskite/Cl-GO/PTAA heterostructure was revealed by transient photocurrent decay and photovoltage decay measurements. The PSC with the heterostructure of perovskite/Cl-GO maintained $90 \%$ of its initial efficiency of $21 \%$ at the MPP under AM1.5G solar light at $60^{\circ} \mathrm{C}$ after $1000 \mathrm{~h}$.

A major bottleneck delaying the further commercialization of PSCs is interfacial losses within the devices. In order to minimize these losses in PSCs, it is essential to decrease the energy barriers within charge-transporting interfaces. Hou et al. showed that tantalumdoped tungsten oxide $\left(\mathrm{Ta}^{-} \mathrm{WO}_{\mathrm{x}}\right)$ interlayer can form almost ohmic contacts with polythiophene derivative conjugated polymer multilayers to create an HTL with a small interface barrier. ${ }^{[91]} \mathrm{Ta}-\mathrm{WO} \times \mathrm{PDCBT}$ (poly[5,5'-bis(2-butyloctyl)-(2,2'-bithiophene)-4,4'dicarboxylate-alt-5,5'-2,2'-bithiophene]) multilayer based ionic dopant-free approach showed a stabilized $P C E$ of $21.2 \%$ and almost $95 \%$ of its initial efficiency was retained over $1000 \mathrm{~h}$ under continuous illumination as depicted in Figure 11b.

The poor device stability of traditional HTL of spiro-OMeTAD mainly comes from the highly hydrophilic bis(trifluoromethylsulfonyl)imide (Li-TFSI) dopant, which is indispensable in the case of spiro-OMeTAD owing to its intrinsically low hole mobility. Seo et al. introduced a new $p$-type material, namely $\mathrm{Zn}$-TFSI 2 , to combat the instability issue of spiro-OMeTAD ${ }^{[89]}$ As compared to Li-TFSI, the utilization of Zn-TFSI 2 dopant into spiroOMeTAD increased the hole mobility of HTL. Besides outstanding efficiency (stabilized $P C E$ of $22.0 \%$ ), the devices employing Zn-TFSI2 exhibited superb photo-stability, showing even a $2 \%$ increase in the $P C E$ after $600 \mathrm{~h}$ of light soaking under continuous illumination at the MPP, while the Li-TFSI based control device degraded severely under similar conditions. $\mathrm{Zn}$-TFSI $I_{2}$ also demonstrated a stable behaviour even under the thermal stress at $50^{\circ} \mathrm{C}$ and in a humid environment (relative humidity of 40-50\%). The approved stability was ascribed to the 


\section{WILEY-VCH}

non-migration behaviour of zinc ions in the HTL and induced strong electrostatic interaction within the spiro-OMeTAD matrix that suppressed perovskite degradation.

Another promising solution for stabilizing PSCs is the appropriate choice of inorganic based HTLs. Removing the organic HTLs has already been demonstrated to be a very effective approach towards prolonged device stability. Among the various inorganic based HTLs, copper thiocyanate ( $\mathrm{CuSCN})$ has been actively pursued by researchers. Improvement of the photovoltaic performance from $12.4 \%$ to the very recent achievement over $20 \%$ was reported for $\mathrm{CuSCN}$ based PSCs. ${ }^{[137,138]}$

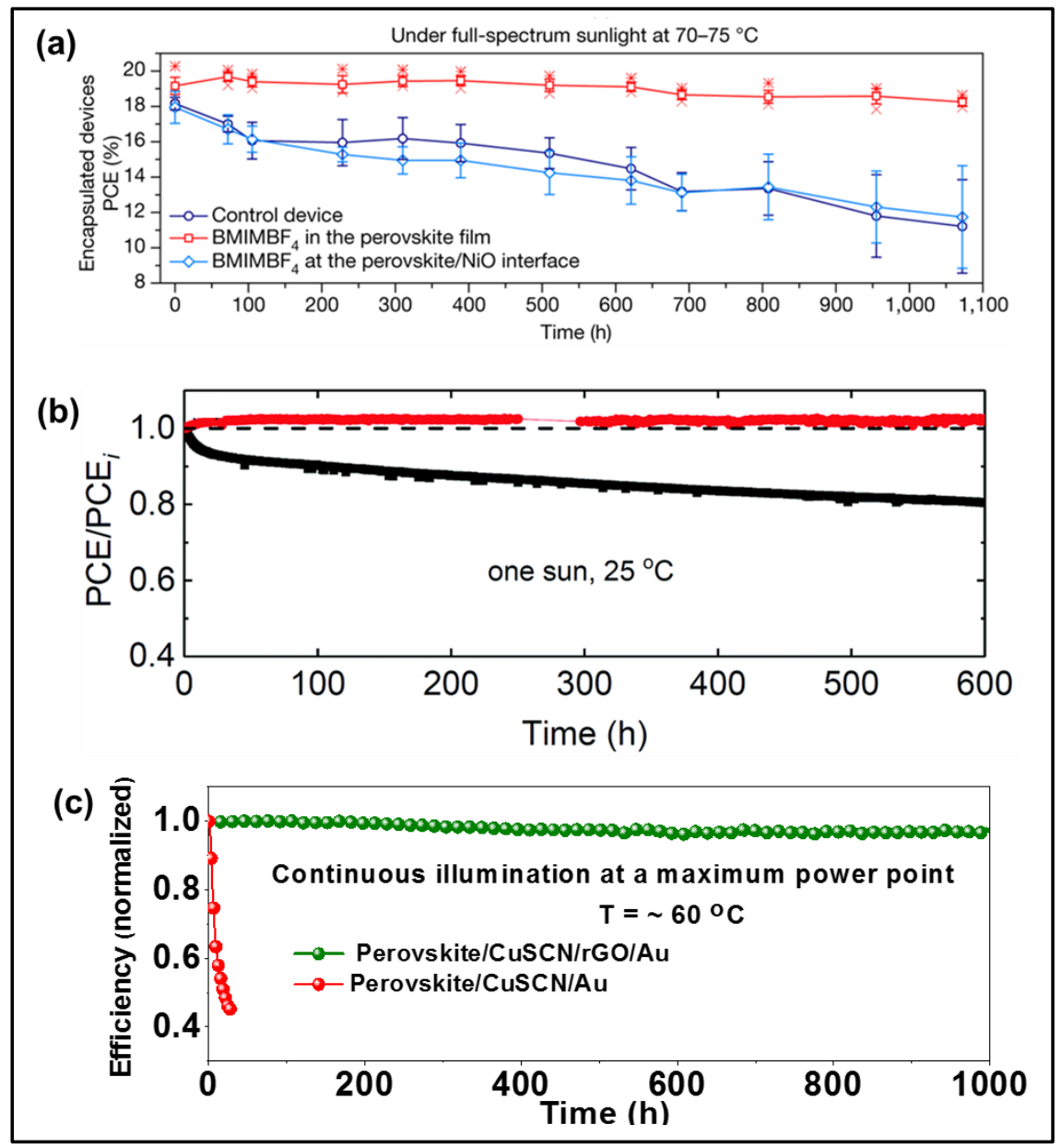

Figure 12. a) Evolution of device stability of the encapsulated control device and a device with $\mathrm{BMIMBF}_{4}$ in the perovskite film and at the perovskite/ $\mathrm{NiO}$ interface under full-spectrum sunlight at $70-75^{\circ} \mathrm{C}$. Reproduced with permission.[134] Copyright 2019, Nature Publishing Group. b) Long-term stability of devices with respect to the dopant for spiro-OMeTAD in the presence of Li-TFSI (black) and Zn-TFSI 2 (red) kept at the MPP under continuous one sun illumination $\left(100 \mathrm{~mW} \mathrm{~cm}{ }^{2}\right)$ in an inert atmosphere $\left(\mathrm{N}_{2}\right)$ at $25^{\circ} \mathrm{C}$. Reproduced with 


\section{WILEY-VCH}

permission.[89] Copyright 2018, Royal Society of Chemistry. (c) Operational stability of an unencapsulated $\mathrm{CuSCN}$-based device with and without a thin layer of $\mathrm{GGO}$, examined at MPP under continuous illumination at $60^{\circ} \mathrm{C}$. Reproduced with permission.[139] Copyright 2017, American Association for the Advancement of Science.

Recently, our group demonstrated a stabilized PCE exceeding $20 \%$ for CuSCN-based devices using a regular architecture. ${ }^{[139]}$ For the first time, it was demonstrated that the instability of PSCs is not associated with the degradation of $\mathrm{CuSCN} /$ perovskite interface, but rather arises mainly from the $\mathrm{CuSCN} / \mathrm{Au}$ contact. By using reduced graphene oxide (rGO) spacer layer between $\mathrm{CuSCN}$ and top metal contact, ${ }^{[140]}$ the devices showed a remarkable long-term operational stability retaining $>95 \%$ of the initial PCE after $1000 \mathrm{~h}$ under continuous illumination at MPP tracking $\left(\mathrm{T} \sim 60^{\circ} \mathrm{C}\right)$ (Figure 12c). More recently, a facile and low-cost device architecture employing dopant-free $\mathrm{TiO}_{2}$ ETL and CuSCN HTL was introduced in which a graphitic carbon (C) layer deposited at room temperature serves as the back electrical contact. ${ }^{[141]}$ The resulting hysteresis-free PSCs reached efficiencies exceeding $18 \%$ under standard AM 1.5 solar illumination and retained $~ 95 \%$ of their initial efficiencies after $>2000 \mathrm{~h}$ at the MPP tracking under full-sun illumination at $60{ }^{\circ} \mathrm{C}$. Moreover, the CuSCN/C-based devices demonstrated a promising UV stability under irradiance for $>1000 \mathrm{~h}$ while the standard spiro-OMeTAD/Au based devices degraded severely under similar conditions.

\subsection{Thermal stability}

In addition to the photo-stability, thermal stability is another factor limiting the commercialization of PSCs. As is well known, thermal instability mainly originates from the stability issue of organic molecules, which are necessary to obtain high efficiency.

Choi et al. reported a zwitterion-modified $\mathrm{SnO}_{2} \mathrm{ETL}$ for achieving thermally stable and highly efficient planar type PSCs in an inverted architecture. ${ }^{[12]}$ This modification resulted in the formation of interfacial dipoles, shifted the work function of the $\mathrm{SnO}_{2}$, and 


\section{WILEY-VCH}

suppressed charge recombination of $\mathrm{SnO}_{2}$ ETL as depicted in Figure 13a. Moreover, the zwitterion passivated the $\mathrm{Pb}-\mathrm{I}$ antisite traps of the perovskite owing to its positively charged atoms improving the thermal stability of devices. Thermal stability tests were mainly performed in the presence of dopant-free asy-PBTBDT polymer HTL, due to high thermal and moisture sensitivity of doped spiro-OMeTAD. The corresponding devices maintained $82 \%$ of their initial $P C E$ at $85{ }^{\circ} \mathrm{C}$ and under $85 \%$ relative humidity conditions.

In another study, fluorene-terminated N2,N2',N7,N7'-tetrakis(9,9-dimethyl-9Hfluoren-2-yl)-N2,N2',N7,N7'-tetrakis(4-methoxyphenyl)-,9'-spirobi[fluorene]-2,2',7,7'tetraamine (abbreviated as DM) has been reported as a promising HTL material. ${ }^{[93]}$ The resultant device showed remarkable thermal stability as compared to spiro-OMeTAD employing device, maintaining almost $95 \%$ of its initial $P C E$ over $500 \mathrm{~h}$ thermal annealing at $60^{\circ} \mathrm{C}$. Under identical conditions, the device with spiro-OMeTAD degraded rapidly merely after $50 \mathrm{~h}$ (Figure 13b). This outstanding thermal stability was attributed to the high glass transition temperature $\left(\sim 160^{\circ} \mathrm{C}\right)$ of the DM material.

As is well known, $\mathrm{I}^{-}$can be easily oxidized to $\mathrm{I}^{0}$ and $\mathrm{Pb}^{2+}$ is prone to be reduced to metallic $\mathrm{Pb}^{0}$ upon heating or under illumination and such defects serve not only as recombination centers to deteriorate device performance but also act as degradation initiators to impede the life cycle during the operation. Very recently, Wang et al., demonstrated the concurrent oxidation of lead $(\mathrm{Pb})^{0}$ and reduction of iodine $(\mathrm{I})^{0}$ defects by rare earth europium ion pair $\mathrm{Eu}^{3+}-\mathrm{Eu}^{2+}$ acting as the "redox shuttle" in a cyclical transition. ${ }^{[142]}$ In this study, the redox shuttle transferred electrons from $\mathrm{Pb}^{0}$ to $\mathrm{I}^{0}$ defects in a cyclic manner, wherein the $\mathrm{Eu}^{3+}$ oxidized $\mathrm{Pb}^{0}$ to $\mathrm{Pb}^{2+}$ and the formed $\mathrm{Eu}^{2+}$ simultaneously reduced $\mathrm{I}^{0}$ to $\mathrm{I}^{-}$. As a result, a considerable $P C E$ of $21.5 \%$ was obtained with negligible hysteresis. More importantly, the devices retained $92 \%$ and $89 \%$ of their initial PCEs, respectivcely, under the light and thermal stress (at $85^{\circ} \mathrm{C}$ ) for 1500 hours. 


\section{WILEY-VCH}

\subsection{Moisture stability}

The degradation of perovskite devices under a humid environment is still a big

challenge. ${ }^{[143,144,145]}$ The moisture stability issue, which originates from the hygroscopic nature of methylamine salt and $\mathrm{Pb}-\mathrm{X}$ framework gets further accelerated in the presence of hygroscopic dopants in HTL material. In recent years, 2D perovskite structures have gained considerable attention owing to their outstanding moisture resistance. Adding a precise amount of 2D material into 3D perovskite or stacking as 2D/3D structure not only improves moisture stability but also suppresses the non-radiative recombination by passivating the surface defect and/or bulk traps of the 3D perovskite.

A 3D/2D hybrid structure using $n$-butylammonium (BA) 2D material within $\mathrm{FA}_{0.83} \mathrm{Cs}_{0.17} \mathrm{~Pb}\left(\mathrm{I}_{\mathrm{y}} \mathrm{Br}_{1-\mathrm{y}}\right)_{3} 3 \mathrm{D}$ perovskite was reported. ${ }^{[119]}$ This hybrid structure exhibited enhanced moisture stability in comparison to the control device. The unencapsulated devices were strongly stable at $40 \%$ relative humidity over $1000 \mathrm{~h}$ and encapsulated devices demonstrated similar features over $3880 \mathrm{~h}$. Very recently, our group reported 2D perovskite layer using pentafluorophenylethylammonium (FEA) as a fluoroarene cation inserted between 3D perovskite and spiro-OMeTAD. Figure 13c shows that unsealed 3D/2D PSC retained $90 \%$ of its initial efficiency during the photovoltaic operation for $1000 \mathrm{~h}$ in humid air under simulated sunlight. In addition to operational stability, we also demonstrated that FEA-based 3D/2D PSC exhibited superior stability in a high relative humidity up to $90 \%$. The excellent moisture resistance of 3D/2D bilayer-based PSCs was attributed to the ultra-hydrophobic character of the perfluorinated 2D perovskite layer.

In addition to the 2D layer, surface modification of the perovskite layer by a functionalized molecule or polymer is another novel strategy to achieve long-term stability against moisture. Hou et al. passivated the perovskite surface by introducing oleylammonium 


\section{WILEY-VCH}

polysulfides (OPs) using dipping treatment to prevent the perovskite layer from erosion by water molecules as shown in Figure 13d. ${ }^{[146]}$ The resultant unencapsulated device retained more than $70 \%$ of its initial efficiency after 14 days at a relative humidity of $40 \pm 10 \%$. The enhanced moisture stability was ascribed to the bulky alkyl chain in OPs assembled by forming $\mathrm{Pb}-\mathrm{S}$ bond and hydrogen bond, which tighten the OPs-perovskite connection, thus, prevents the perovskite layer from interacting with water molecules. Table 4 summarizes the recent progress on stability based on different device configurations.

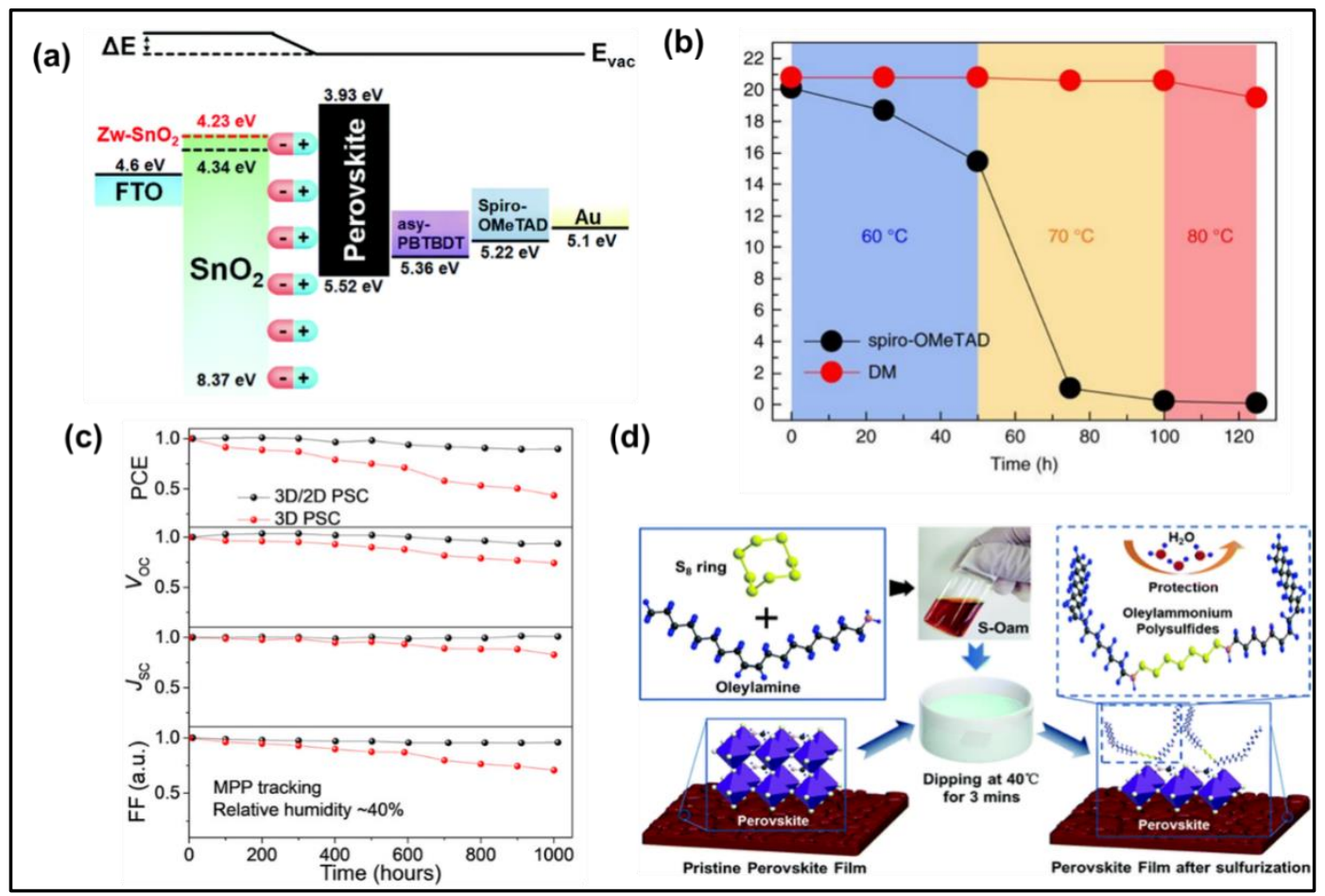

Figure 13. a) Energy diagram of zwitterion (3-(1-pyridinio)-1-propanesulfonate)-modified $\mathrm{SnO}_{2}$ electron transport layer-based perovskite device. Reproduced with permission.[112] Copyright 2018, Royal Society of Chemistry. b) Stability of the devices stressed at different temperatures of 60,70 and $80^{\circ} \mathrm{C}$ in air $(\sim 25 \% \mathrm{RH})$ with $\left(N^{2}, N^{2^{\prime}}, N^{7}, N^{7^{\prime}}\right.$-tetrakis(9,9-dimethyl9H-fluoren-2-yl)- $N^{2}, N^{2^{\prime}}, N^{7}, N^{7^{\prime}}$-tetrakis(4-methoxyphenyl)-9,9'-spirobi[fluorene]-2,2',7,7'tetraamine) (DM) and spiro-OMeTAD. Reproduced with permission.[93] Copyright 2018, Nature Publishing Group. c) Operational stability of the nonencapsulated devices at the MPP under 1 sun irradiation in ambient condition with a prevalent humidity of 40\% for 3D and 3D/2D PSCs. Reproduced under the terms of the CC BY-NC 4.0 license [1] Copyright 2019, American Association for the Advancement of Science. d) Schematic representation of the surface modification process with sulfur-oleylamine ( $\mathrm{S}-\mathrm{Oam}$ ) solution by $\mathrm{H}_{2} \mathrm{~S}$ etching and Oleylammonium polysulfides (Ops) assembling on the perovskite surface. Reproduced with permission.[146] Copyright 2019, Royal Society of Chemistry. 
These highlighted reports as summarized in Table 4 show that increasing the device lifetime is a key to the performance of PSCs. It is evident that the aforementioned treatments focusing either on fully assembled -devices (e.g., encapsulation) or on individual components/interfaces within the device have been developed and adopted for PSCs based on different architectures to greatly improve the device longevity. Furthermore, in-depth understanding of the degradation mechanisms is essential for realizing the complete potential of PSCs.

Table 4. VOC and other photovoltaic parameters of highly stable PSCs based on different device configurations.

\begin{tabular}{|c|c|c|c|c|c|c|c|c|}
\hline $\begin{array}{l}\text { Measurement } \\
\text { conditions }\end{array}$ & Device configuration & $\begin{array}{l}\text { Voc } \\
\text { (V) }\end{array}$ & $\begin{array}{l}J s c \\
(\mathrm{~mA} \\
\left.\mathrm{cm}^{-2}\right)\end{array}$ & $F F$ & $\begin{array}{l}P C E \\
(\%)\end{array}$ & $\begin{array}{l}\text { Change } \\
\text { in Voc } \\
(\mathrm{mV})\end{array}$ & $\begin{array}{l}\text { Degradatio } \\
\text { n rate }(\%)\end{array}$ & Ref. \\
\hline $\begin{array}{l}\text { at MPP, under } \\
\text { illumination, } \\
\text { humidity of } 40 \% \text {, } \\
1000 \mathrm{~h}\end{array}$ & $\begin{array}{l}\mathrm{FTO} / \mathrm{c}-\mathrm{TiO}_{2} / \mathrm{mp}^{-} \\
\mathrm{TiO}_{2} / \mathrm{CsFAMAPbI}{ }_{3} \\
/(\mathrm{FEAI})_{2} \mathrm{Pbl}_{4} / \mathrm{spiro} \\
\text { OMeTAD/Au/MgF }\end{array}$ & 1.10 & 25.79 & 0.79 & 22.16 & +50 & -10 & {$[1]$} \\
\hline $\begin{array}{l}\text { under ambient } \\
\text { conditions, } 90 \% \\
\text { humidity, } 960 \mathrm{~h}\end{array}$ & $\begin{array}{l}\mathrm{FTO} / \mathrm{c}-\mathrm{TiO}_{2} / \mathrm{mp}- \\
\mathrm{TiO}_{2} / \mathrm{CsFAMAPbl} /(\mathrm{FEAI})_{2} \mathrm{Pbl}_{4} / \mathrm{s} \\
\text { piro-OMeTAD } / \mathrm{Au} / \mathrm{MgF}_{2}\end{array}$ & 1.10 & 25.79 & 0.79 & 22.16 & +50 & -30 & [1] \\
\hline $\begin{array}{l}\text { at } 85^{\circ} \mathrm{C} \text {, in a dry } \\
\text { box, dark } \\
\text { conditions, } 60 \mathrm{~h}\end{array}$ & $\begin{array}{l}\mathrm{FTO} / \mathrm{c}-\mathrm{TiO}_{2} / \mathrm{mp}^{-} \\
\mathrm{TiO}_{2} / \mathrm{CsFAMAPbl} / /(\mathrm{FEAl})_{2} \mathrm{Pbl}_{4} / \mathrm{s} \\
\text { piro-OMeTAD/Au/MgF}\end{array}$ & 1.10 & 25.79 & 0.79 & 22.16 & +50 & -10 & {$[1]$} \\
\hline $\begin{array}{l}\text { at MPP, under } \\
\text { illumination, } 250 \mathrm{~h}\end{array}$ & $\begin{array}{l}\mathrm{FTO} / \mathrm{c}-\mathrm{TiO}_{2} / \mathrm{mp}- \\
\mathrm{TiO}_{2} / \mathrm{CsFAMAPb}(\mathrm{I}, \mathrm{Br})_{3} / \text { spiro- } \\
\text { OMeTAD/Au }\end{array}$ & 1.13 & 22.69 & 0.75 & 21.10 & +10 & -15 & [21] \\
\hline $\begin{array}{l}\text { under ambient } \\
\text { conditions, } 20-25 \% \\
\text { humidity, } 1000 \mathrm{~h}\end{array}$ & 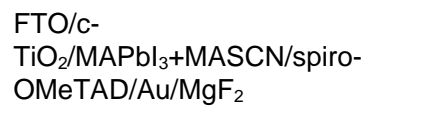 & 1.06 & 22.29 & 0.77 & 18.22 & +450 & -10 & [38] \\
\hline $\begin{array}{l}\text { in ambient } \\
\text { atmosphere, after } \\
2880 \mathrm{~h}\end{array}$ & $\begin{array}{l}\text { ITO/EDTA-complexed } \\
\mathrm{SnO}_{2} / \mathrm{CsFAPb} \mathrm{I}_{3} / \text { spiro- } \\
\mathrm{OMeTAD} / \mathrm{Au}^{\text {MMeTA }}\end{array}$ & 1.11 & 24.57 & 0.79 & 21.60 & +30 & -8 & [82] \\
\hline $\begin{array}{l}\text { under illumination, } \\
120 \mathrm{~h}\end{array}$ & $\begin{array}{l}\text { ITO/EDTA-complexed } \\
\mathrm{SnO}_{2} / \mathrm{CsFAPbl} / \mathrm{sp}_{3} \text { spiro- } \\
\mathrm{OMeTAD} / \mathrm{Au}^{-}\end{array}$ & 1.11 & 24.57 & 0.79 & 21.60 & +30 & -14 & [82] \\
\hline $\begin{array}{l}\text { at MPP, under } \\
\text { illumination, at } 60 \\
{ }^{\circ} \mathrm{C}, 500 \mathrm{~h}\end{array}$ & $\begin{array}{l}\mathrm{FTO} / \mathrm{c}-\mathrm{TiO}_{2} / \mathrm{mp}- \\
\mathrm{TiO}_{2} / \mathrm{FAMAPb}(\mathrm{I}, \mathrm{Br})_{3} / \mathrm{DM} / \mathrm{Au}\end{array}$ & 1.14 & 24.91 & 0.81 & 23.20 & +70 & -5 & [93] \\
\hline $\begin{array}{l}\text { at MPP, under } \\
\text { illumination, } 600 \mathrm{~h}\end{array}$ & 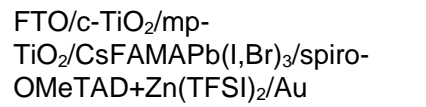 & 1.15 & 23.90 & 0.79 & 21.50 & +50 & +2 & [89] \\
\hline
\end{tabular}




\begin{tabular}{|c|c|c|c|c|c|c|c|c|}
\hline $\begin{array}{l}\text { at MPP, under } \\
\text { illumination, } 1000 \mathrm{~h}\end{array}$ & $\begin{array}{l}\text { ITO/C } 60^{-} \\
\text {SAM/FAMAPb(I,Br) })_{3} / \mathrm{PDCBT} / \mathrm{Ta} \text { : } \\
\text { WOx/Au }\end{array}$ & 1.17 & 22.70 & 0.80 & 21.20 & +60 & -5 & [91] \\
\hline $\begin{array}{l}\text { at } 85^{\circ} \mathrm{C}, 85 \% \\
\text { humidity, } 140 \mathrm{~h}\end{array}$ & $\begin{array}{l}\text { FTO/SnO } / \text { /Zwitterion/CsFAMAP } \\
\mathrm{b}(\mathrm{I}, \mathrm{Br})_{3} / \text { spiro-OMeTAD/Au }\end{array}$ & 1.16 & 23.60 & 0.78 & 21.43 & +60 & -25 & [112] \\
\hline $\begin{array}{l}\text { at } 85^{\circ} \mathrm{C}, 85 \% \\
\text { humidity, } 140 \mathrm{~h}\end{array}$ & $\begin{array}{l}\mathrm{FTO} / \mathrm{SnO}_{2} / \text { Zwitterion/CsFAMAP } \\
\mathrm{b}(\mathrm{I}, \mathrm{Br})_{3} / \mathrm{PBTBDT} / \mathrm{Au}\end{array}$ & 1.14 & 22.90 & 0.78 & 20.50 & +40 & -5 & [112] \\
\hline $\begin{array}{l}\text { at MPP, under } \\
\text { illumination, } 45 \% \\
\text { relative humidity, } \\
1000 \mathrm{~h}\end{array}$ & $\begin{array}{l}\mathrm{FTO} / \mathrm{SnO}_{2} / \mathrm{PC}_{61} \mathrm{BM} / \mathrm{CsFAPb}(\mathrm{I}, \mathrm{Br}) \\
{ }_{3}+\mathrm{BAI} / \mathrm{Spiro}-\mathrm{OMeTAD} / \mathrm{Au}\end{array}$ & 1.18 & 19.80 & 0.73 & 17.20 & +40 & -20 & [119] \\
\hline $\begin{array}{l}\text { at MPP, under } \\
\text { illumination, } 45 \% \\
\text { relative humidity, } \\
3880 \mathrm{~h} \text {, } \\
\text { encapsulated }\end{array}$ & $\begin{array}{l}\mathrm{FTO} / \mathrm{SnO}_{2} / \mathrm{PC}_{61} \mathrm{BM} / \mathrm{FACsPb}(\mathrm{I}, \mathrm{Br}) \\
{ }_{3}+\mathrm{BAI} / \mathrm{Spiro}-\mathrm{OMeTAD} / \mathrm{Au}\end{array}$ & 1.18 & 19.80 & 0.73 & 17.20 & +40 & -20 & [119] \\
\hline $\begin{array}{l}\text { under illumination, } \\
580 \mathrm{~h}\end{array}$ & $\begin{array}{l}\text { ITO/SnO } / \mathrm{FA}_{0.83} \mathrm{MA}_{0.17} \mathrm{~Pb}\left(\mathrm{I}_{0.8} \mathrm{Cl}_{0.2}\right) \\
\text { 3+ThMA/spiro- } \\
\text { OMeTAD/MoO } / \mathrm{Ag}\end{array}$ & 1.16 & 22.88 & 0.81 & 21.49 & +70 & -6 & [122] \\
\hline $\begin{array}{l}\text { at } 70-75^{\circ} \mathrm{C}, \text { under } \\
\text { illumination, } 1800 \mathrm{~h}\end{array}$ & $\begin{array}{l}\mathrm{FTO} / \mathrm{NiO} / \mathrm{MAPbl}_{3}+\mathrm{BMIMBF}_{4} / \mathrm{PC} \\
\mathrm{BM} / \mathrm{C}_{60} / \mathrm{Cr}_{2} \mathrm{O}_{3} / \mathrm{Au}\end{array}$ & 1.08 & 23.80 & 0.81 & 19.80 & +60 & -15 & [134] \\
\hline $\begin{array}{l}\text { encapsulated, } \\
\text { under illumination, } \\
\sim 60 \pm 10 \% \\
\text { humidity, at } 65^{\circ} \mathrm{C} \text {, } \\
1200 \mathrm{~h}\end{array}$ & $\begin{array}{l}\text { ITO/PTAA/CsFAMAPb }(\mathrm{I}, \mathrm{Br})_{3} / \mathrm{C}_{60} / \\
\mathrm{BCP} / \mathrm{Cu}\end{array}$ & 1.16 & 22.63 & 0.80 & 21.10 & +90 & -3 & [135] \\
\hline $\begin{array}{l}\text { at MPP, under } \\
\text { illumination, at } 60 \\
{ }^{\circ} \mathrm{C}, 1000 \mathrm{~h}\end{array}$ & $\begin{array}{l}\text { ITO/SnO } / \mathrm{FAMAPb}_{1+\mathrm{y}} \mathrm{l}_{3} / \mathrm{Cl}- \\
\mathrm{GO} / \mathrm{PTAA} / \mathrm{Au}\end{array}$ & 1.12 & 23.82 & 0.79 & 21.08 & +30 & -10 & [136] \\
\hline $\begin{array}{l}\text { at MPP, under } \\
\text { illumination, at } 60 \\
{ }^{\circ} \mathrm{C}, 1000 \mathrm{~h}\end{array}$ & $\begin{array}{l}\mathrm{FTO} / \mathrm{c}-\mathrm{TiO}_{2} / \mathrm{mp}- \\
\mathrm{TiO}_{2} / \mathrm{CsFAMAPb}(\mathrm{I}, \mathrm{Br})_{3} / \mathrm{CuSCN} / \mathrm{r} \\
\mathrm{GO} / \mathrm{Au}\end{array}$ & 1.11 & 23.24 & 0.78 & 20.40 & -20 & -5 & [139] \\
\hline at $85^{\circ} \mathrm{C}, 1500 \mathrm{~h}$ & $\begin{array}{l}\mathrm{ITO} / \mathrm{c}-\mathrm{TiO}_{2} / \mathrm{CsFAMAPb}(\mathrm{I}, \mathrm{Br}, \mathrm{Cl})_{3} \\
+\mathrm{Eu}^{3+}-\mathrm{Eu}^{2+} / \text { spiro-OMeTAD/Au }\end{array}$ & 1.15 & 23.53 & 0.81 & 21.89 & $\mathrm{~N} / \mathrm{A}$ & -11 & [142] \\
\hline $\begin{array}{l}\text { under ambient } \\
\text { conditions, } 30-50 \% \\
\text { humidity, } 14 \text { days }\end{array}$ & $\begin{array}{l}\mathrm{FTO} / \mathrm{c}-\mathrm{TiO}_{2} / \mathrm{MAPbl}_{3} / \mathrm{OPs} / \text { spiro- } \\
\text { OMeTAD/Ag }\end{array}$ & 1.04 & 21.90 & 0.69 & 15.71 & +10 & -30 & [146] \\
\hline $\begin{array}{l}\text { under illumination, } \\
150 \mathrm{~h}\end{array}$ & $\begin{array}{l}\mathrm{FTO} / \mathrm{c}- \\
\mathrm{TiO}_{2} / \mathrm{MAPbl}_{3} / \text { pyridine+spiro- } \\
\mathrm{OMeTAD} / \mathrm{Au}\end{array}$ & 1.03 & 20.89 & 0.69 & 14.82 & +30 & -14 & [148] \\
\hline $\begin{array}{l}\text { under ambient } \\
\text { conditions, } 1500 \mathrm{~h}\end{array}$ & $\begin{array}{l}\mathrm{FTO} / \mathrm{C}-\mathrm{TiO}_{2} / \mathrm{FAMAPbl}_{3} / \text { thiazole } \\
\text { ammonium } \mathrm{Pbl} / \mathrm{s}_{3} / \text { spiro- }^{-} \\
\text {OMeTAD/Au }\end{array}$ & 1.08 & 22.81 & 0.77 & 18.97 & +50 & -8 & [147] \\
\hline $\begin{array}{l}\text { in a dry box, dark } \\
\text { conditions, } 900 \mathrm{~h}\end{array}$ & $\begin{array}{l}\mathrm{FTO} / \mathrm{c}- \\
\mathrm{TiO}_{2} / \mathrm{MAPbl} /{ }_{3} / \text { pyridine+spiro- } \\
\mathrm{OMeTAD} / \mathrm{Au}^{-}\end{array}$ & 1.03 & 20.89 & 0.69 & 14.82 & +30 & 0 & [148] \\
\hline $\begin{array}{l}\text { under ambient } \\
\text { conditions, dark } \\
\text { storage, } 50-\end{array}$ & $\begin{array}{l}\mathrm{FTO} / \mathrm{c}-\mathrm{TiO}_{2} / \mathrm{MAPbl}_{3} / \\
\mathrm{F} 4 \mathrm{TCNQ} / \text { spiro-OMeTAD/Au }\end{array}$ & 1.06 & 20.30 & 0.75 & 16.40 & +20 & -40 & [149] \\
\hline
\end{tabular}


$70 \%$ humidity, 960

$\mathrm{h}$

\begin{tabular}{|c|c|c|c|c|c|c|c|c|}
\hline $\begin{array}{l}\text { at MPP, under } \\
\text { illumination, } 1500 \mathrm{~h}\end{array}$ & $\begin{array}{l}\mathrm{FTO} / \mathrm{c}-\mathrm{TiO}_{2} / \mathrm{mp}- \\
\mathrm{TiO}_{2} / \mathrm{CsFAMAPb}(\mathrm{I}, \mathrm{Br})_{3} / \mathrm{X} 44 / \mathrm{Au}\end{array}$ & 1.08 & 21.04 & 0.67 & 15.20 & 0 & -10 & [150] \\
\hline $\begin{array}{l}\text { dark storage, } 50 \% \\
\text { humidity, } 7 \text { months }\end{array}$ & $\begin{array}{l}\mathrm{FTO} / \mathrm{c}-\mathrm{TiO}_{2} / \mathrm{mp}- \\
\mathrm{TiO}_{2} / \mathrm{FAMAPb}(\mathrm{I}, \mathrm{Br})_{3} / \mathrm{BMPyTFSI} \\
\text { doped spiro-OMeTAD/Au }\end{array}$ & 1.02 & 21.17 & 0.65 & 14.06 & +70 & -20 & [151] \\
\hline $\begin{array}{l}\text { encapsulated, } 40 \% \\
\text { humidity, under } \\
\text { illumination, } 500 \mathrm{~h}\end{array}$ & $\begin{array}{l}\mathrm{FTO} / \mathrm{C}_{60} / \mathrm{MAPbl}_{3} /\left[\mathrm{Li}^{+} @ \mathrm{C}_{60}\right] \mathrm{TFSI}^{-} \\
\text {doped spiro-OMeTAD/Au }\end{array}$ & 0.89 & 23.00 & 0.63 & 13.10 & -80 & -20 & [152] \\
\hline $\begin{array}{l}\text { under ambient } \\
\text { conditions, dark } \\
\text { storage, } 40 \% \\
\text { humidity, } 120 \text { day }\end{array}$ & $\begin{array}{l}\text { ITO/SnO } / \text { ODAl modified } \\
\text { FAPbl }_{3} / \text { spiro-OMeTAD/Au }^{-O M}\end{array}$ & 1.13 & 24.90 & 0.75 & 21.18 & +90 & -8 & [153] \\
\hline $\begin{array}{l}\text { under ambient } \\
\text { conditions, dark } \\
\text { storage, } 95 \% \\
\text { humidity, } 3 \text { months }\end{array}$ & $\begin{array}{l}\mathrm{FTO} / \mathrm{c}-\mathrm{TiO}_{2} / \mathrm{mp}- \\
\mathrm{TiO}_{2} / \mathrm{FAMAPb}(\mathrm{I}, \mathrm{Br})_{3} / \text { spiro- } \\
\text { OMeTAD/Au }\end{array}$ & 1.09 & 23.23 & 0.74 & 18.67 & +20 & -5 & [154] \\
\hline
\end{tabular}

\section{Conclusions and Future Outlook}

PSCs hold great promise for the future of solar energy. Although striking progress has been made on the device performance, high requirements with respect to the stability are still a challenge and major efforts are currently directed towards addressing these problems. The primary requirement to achieve remarkably stable efficiencies is to understand in great depth the photo-physics of PSCs. Not only the degradation mechanism of individual layers is important but the optoelectronic loss mechanisms within the device architecture also need to be understood. One of the ways to overcome the current challenges involves the investigation of various engineering approaches such as additive/composition engineering, charge transporting layer engineering, and interface engineering. As discussed above, composition/additive engineering plays a substantial role in obtaining high-efficiency. As compared to single cation-based traditional $\left(\mathrm{MAPbI}_{3}\right)$ perovskites, multi cation and/or multi halide-based perovskite structures exhibit much desired optoelectronic properties which translate into high device performance. However, the presence of trap states and/or ionic defects still limit the potential of PSC technology. 


\section{WILEY-VCH}

The meticulous defect healing can be an important strategy to push the efficiency of PSCs to the theoretical limit, as well as to stabilize perovskite-based materials and devices. The design of new molecules to fully passivate the defects on the surface and/or at grain boundaries requires a thorough understanding of the nature, concentration, and distribution of the defects in perovskite devices. Otherwise, defect assisted non-radiative recombination will limit the $V_{O C}$ parameter, thereby, amplify the hysteresis and affect the long-term stability. Furthermore, the mitigation of both non-radiative losses and photoinduced ion migration in perovskite films is vital to obtain higher performance. Towards this direction, interfacial engineering can play a substantial role in reducing the recombination centres and suppressing the ion migration, by decorating the surfaces and grain boundaries with passivating molecules. In addition to suppression of ion migration in the device, the interfacial layer can also prevent the structural phase transitions caused by the degradation induced by moisture, heat, and light.

Another attractive straightforward engineering approach to minimize defects could be the formation of suitable band alignment between high-quality charge-transporting layers and perovskite layer. The rational selection of both ETL and HTL materials can spontaneously eliminate the optoelectronic losses in the devices by transferring the photo-generated charges effectively. Besides, a high-quality charge transporting layer can provide better long-term stability when exposed to moisture, oxygen, thermal stress, UV-light, and forward bias. Furthermore, to boost efficiency and improve the long-term stability beyond the state-of-theart can be realized by employing stable multi-dimensional hybrid perovskites. The incorporation of an ultra-hydrophobic 2D perovskite materials between hydrophilic 3D perovskite and HTL or ETL could easily mitigate the detrimental charge collection losses. Considering the overall assessment, although device engineering plays a great role to improve efficiency and long-term stability, further investigations are required to reach the 


\section{WILEY-VCH}

commercialization goals. The innovative engineering approaches to overcome the abovementioned challenges have been thoroughly summarized and discussed.

\section{Acknowledgements}

M.I.D acknowledges financial support from the Swiss National Science Foundation under the project number P300P2_174471. N.A. and R.H.F. thank EPSRC project 'Strategic University Network to Revolutionize Indian Solar Energy-SUNRISE (EP/P032591/1).

Received: ((will be filled in by the editorial staff))

Revised: ((will be filled in by the editorial staff)) Published online: ((will be filled in by the editorial staff))

References

[1] Y. Liu, S. Akin, L. Pan, R. Uchida, N. Arora, J. V. Milić, A. Hinderhofer, F. Schreiber, A.

R. Uhl, S. M. Zakeeruddin, A. Hagfeldt, M. I. Dar, M. Grätzel, M. Sci Adv. 2019, 5, eaaw2543.

[2] W. S. Yang, B.-W. Park, E. H. Jung, N. J. Jeon, Y. C. Kim, D. U. Lee, S. S. Shin, J. Seo,

E. K. Kim, J. H. Noh, S. I. Seok, Science. 2017, 356, 1376-1379.

[3] E. H. Jung, N. J. Jeon, E. Y. Park, C. S. Moon, T. J. Shin, T.-Y. Yang, J. H. Noh, J. Seo, Nature. 2019, 567, 511-515.

[4] H.-S. Kim, C.-R. Lee, J.-H. Im, K.-B. Lee, T. Moehl, A. Marchioro, S.-J. Moon, R. Humphry-Baker, J.-H. Yum, J. E. Moser, M. Grätzel, N.-G. Park, Sci Rep- 2012, 2, 591.

[5] M. Abdi-Jalebi, M. Ibrahim Dar, S. P. Senanayak, A. Sadhanala, Z. Andaji-Garmaroudi,

L. M. Pazos-Outón, J. M. Richter, A. J. Pearson, H. Sirringhaus, M. Grätzel, R. H. Friend, Sci. Adv. 2019, 5, eaav2012.

[6] M. M. Lee, J. Teuscher, T. Miyasaka, T. N. Murakami, H. J. Snaith, Science 2012, 338, 643. 


\section{WILEY-VCH}

[7] S. De Wolf, J. Holovsky, S.-J. Moon, P. Löper, B. Niesen, M. Ledinsky, F.-J. Haug, J.-H. Yum, C. Ballif, J Phys Chem Lett. 2014, 5, 1035-1039.

[8] M. I. Dar, G. Jacopin, S. Meloni, A. Mattoni, N. Arora, A. Boziki, S. M. Zakeeruddin, U. Rothlisberger, M. Grätzel,M. Sci Adv. 2016, 2, e1601156.

[9] G. Xing, N. Mathews, S. Sun, S. S. Lim, Y. M. Lam, M. Grätzel, S. Mhaisalkar, T. C. Sum, Science. 2013, 342, 344-347.

[10] A. Kojima, K. Teshima, Y. Shirai, T. Miyasaka, J Am Chem Soc. 2009, 131, 6050-6051.

[11] National Renewable Energy Laboratory (NREL). https://www.nrel.gov/pv/cellefficiency.html. (accessed August 2019)

[12] T. S. Sherkar, C. Momblona, L. Gil-Escrig, J. Ávila, M. Sessolo, H. J. Bolink, L. J. A. Koster, ACS Energy Lett. 2017, 2, 1214-1222.

[13] J. Shi, Y. Li, Y. Li, D. Li, Y. Luo, H. Wu, Q. Meng, Joule. 2018, 2, 879-901.

[14] M. I. Dar, M. Franckevičius, N. Arora, K. Redeckas, M. Vengris, V. Gulbinas, S. M. Zakeeruddin, M. Grätzel, Chem. Phys. Lett. 2017, 683, 211-215.

[15] A. K. Chandiran, M. Abdi-Jalebi, A. Yella, M. I. Dar, C. Yi, S. A. Shivashankar, M. K. Nazeeruddin, M. Grätzel, Nano Lett. 2014, 14, 1190-1195.

[16] M. I. Dar, A. Hinderhofer, G. Jacopin, V. Belova, N. Arora, S. M. Zakeeruddin, F. Schreiber, M. Grätzel, Adv. Funct. Mater. 2017, 27, 1701433.

[17] M. I. Dar, G. Jacopin, M. Hezam, N. Arora, S. M. Zakeeruddin, B. Deveaud, M. K. Nazeeruddin, M. Gratzel, Acs Photonics. 2016, 3, 947-952.

[18] A. Greco, A. Hinderhofer, M. I. Dar, N. Arora, J. Hagenlocher, A. Chumakov, M. Gratzel, F. Schreiber, J Phys Chem Lett 2018, 9, 6750-6754.

[19] J.-W. Lee, D.-H. Kim, H.-S. Kim, S.-W. Seo, S. M. Cho, N.-G. Park, Adv Energy Mater. $\mathbf{2 0 1 5}, 5,1501310$. 


\section{WILEY-VCH}

[20] D. W. Ferdani, S. R. Pering, D. Ghosh, P. Kubiak, A. B. Walker, S. E. Lewis, A. L.

Johnson, P. J. Baker, M. S. Islam, P. J. Cameron, Energ Environ Sci. 2019, 12, 2264-2272.

[21] M. Saliba, T. Matsui, J.-Y. Seo, K. Domanski, J.-P. Correa-Baena, M. K. Nazeeruddin,

S. M. Zakeeruddin, W. Tress, A. Abate, A. Hagfeldt, M. Grätzel, M. Energ Environ Sci. 2016, 9, 1989-1997.

[22] M. Saliba, T. Matsui, K. Domanski, J.-Y. Seo, A. Ummadisingu, S. M. Zakeeruddin, J.-

P. Correa-Baena, W. R. Tress, A. Abate, A. Hagfeldt, M. Grätzel, Science 2016, 354, 206.

[23] F. Zheng, W. Chen, T. Bu, K. P. Ghiggino, F. Huang, Y. Cheng, P. Tapping, T. W. Kee, B. Jia, X. Wen, Adv Energy Mater. 2019, 9 , 1901016.

[24] a) W. Zhang, J. Xiong, J. Li, W. A. Daoud,. J Mater Chem A. 2019, 7 , 9486-9496. b) M. H. Alotaibi, Y. A. Alzahrani, N. Arora, A. Alyamani, A. Albadri, H. Albrithen, I. H. AlLehyani, S. M. Alenzi, A. Z. Alanzi, F. S. Alghamdi, S. M. Zakeeruddin, S. Meloni, M. I. Dar, M. Graetzel, Solar RRL 2019, 0, 1900234.c) M. Abdi-Jalebi, M. I. Dar, A. Sadhanala, S. P. Senanayak, M. Franckevičius, N. Arora, Y. Hu, M. K. Nazeeruddin, S. M. Zakeeruddin, M. Grätzel, R. H. Friend, Adv Energy Mater. 2016, 6, 1502472.

[25] Y. Yang, H. Peng, C. Liu, Z. Arain, Y. Ding, S. Ma, X. Liu, T. Hayat, A. Alsaedi, S. Dai, J Mater Chem A. 2019, 7 , 6450-6458.

[26] W. Xiang, Z. Wang, D. J. Kubicki, W. Tress, J. Luo, D. Prochowicz, S. Akin, L. Emsley, J. Zhou, G. Dietler, M. Grätzel, A. Hagfeldt, Joule. 2019, 3, 205-214.

[27] G. Yang, C. Wang, H. Lei, X. Zheng, P. Qin, L. Xiong, X. Zhao, Y. Yan, G. Fang, J Mater Chem A. 2017, 5, 1658-1666.

[28] Y. Bai, X. Meng, S. Yang, Adv Energy Mater. 2018, 8, 1701883.

[29] L. Yan, Q. Xue, M. Liu, Z. Zhu, J. Tian, Z. Li, Z. Chen, Z. Chen, H. Yan, H.-L. Yip, Y. Cao, Adv Mater. 2018, 30, 1802509. 


\section{WILEY-VCH}

[30] Cheng, B.; Li, T. Y.; Wei, P. C.; Yin, J.; Ho, K. T.; Retamal, J. R. D.; Mohammed, O. F.; He, J. H Nat Commun. 2018, 9, 5196.

[31] Li, H.; Wang, X. K.; Zhang, T.; Gong, X.; Sun, Q.; Pan, H.; Shen, Y.; Ahmad, S.; Wang, M. K. Adv Funct Mater. 2019, 29, 1903293.

[32] Koh, T. M.; Shanmugam, V.; Schlipf, J.; Oesinghaus, L.; Muller-Buschbaum, P.;

Ramakrishnan, N.; Swamy, V.; Mathews, N.; Boix, P. P.; Mhaisalkar, S. G. Adv Mater. 2016, $28,3653-3661$.

[33] C. Roldan-Carmona, C.; Gratia, P.; Zimmermann, I.; Grancini, G.; Gao, P.; Graetzel, M.; Nazeeruddin, M. K. Energ Environ Sci. 2015, 8, 3550-3556.

[34] F. Li, W. Zhu, C. Bao, T. Yu, Y. Wang, X. Zhou, Z. Zou,. Chem Commun. 2016, 52 (31), 5394-5397.

[35] X. P. Zheng, B. Chen, J. Dai, Y. J. Fang, Y. Bai, Y. Z. Lin, H. T. Wei, X. C. Zeng, J. S. Huang, Nat Energy. 2017, 2, 17102.

[36] C. G. Wu, C. H. Chiang, Z. L. Tseng, M. K. Nazeeruddin, A. Hagfeldt, M. Gratzel, Energ Environ Sci. 2015, 8 , 2725-2733.

[37] J. B. You, Y. M. Yang, Z. R. Hong, T. B. Song, L. Meng, Y. S. Liu, C. Y. Jiang, H. P. Zhou, W. H. Chang, G. Li, Y. Yang, Appl Phys Lett. 2014, 105, 183902.

[38] Q. W. Han, Y. S. Bai, J. Liu, K. Z. Du, T. Y. Li, D. Ji, Y. H. Zhou, C. Y. Cao, D. Shin, J. Ding, A. D. Franklin, J. T. Glass, J. S. Hu, M. J. Therien, J. Liu, D. B. Mitzi, Energ Environ Sci. 2017, 10 (11), 2365-2371.

[39] W. R. Zhou, D. Li, Z. G. Xiao, Z. L. Wen, M. M. Zhang, W. P. Hu, X. J. Wu, M. T. Wang, W. H. Zhang, Y. L. Lu, S. H. Yang, S. F. Yang,. Adv Funct Mater. 2019, 29, 1901026. [40] Z. F. Liu, L. Kruckemeier, B. Krogmeier, B. Klingebiel, J. A. Marquez, S. Levcenko, S. Oz, S. Mathur, U. Rau, T. Unold, T. Kirchartz, Acs Energy Lett. 2019, 4 , 110-117. 


\section{WILEY-VCH}

[41] M. Abdi-Jalebi, M. Pazoki, B. Philippe, M. I. Dar, M. Alsari, A. Sadhanala, G. Diyitini,

R. Imani, S. Lilliu, J. Kullgren, H. Rensmo, M. Gratzel, R. H. Friend, Acs Nano. 2018, 12 , 7301-7311.

[42] M. Abdi-Jalebi, M. I. Dar, A. Sadhanala, S. P. Senanayak, M. Grätzel, R. H. Friend, JoVE 2017, e55307.

[43] R. Uchida, S. Binet, N. Arora, G. Jacopin, M. H. Alotaibi, A. Taubert, S. M.

Zakeeruddin, M. I. Dar, M. Graetzel, Small 2018, 14, 1802033.

[44] M. T. Klug, A. Osherov, A. A. Haghighirad, S. D. Stranks, P. R. Brown, S. Bai, J. T. W. Wang, X. Dang, V. Bulović, H. J. Snaith, A. M. Belcher, Energ Environ Sci. 2017, 10, 236246.

[45] M. Abdi-Jalebi, M. I. Dar, A. Sadhanala, S. P. Senanayak, F. Giordano, S. M.

Zakeeruddin, M. Grätzel, R. H. Friend, Impact of a Mesoporous Titania-Perovskite Interface on the Performance of Hybrid Organic-Inorganic Perovskite Solar Cells. J Phys Chem Lett. 2016, 7, 3264-3269.

[46] Y. Dong, W. Li, X. Zhang, Q. Xu, Q. Liu, C. Li, Z. Bo, Small. 2016, 12, 1098-1104.

[47] A. Kogo, Y. Sanehira, Y. Numata, M. Ikegami, T. Miyasaka, Acs Appl Mater Inter. 2018, 10, 2224-2229.

[48] R. Azmi, W. T. Hadmojo, S. Sinaga, C.-L. Lee, S. C. Yoon, I. H. Jung, S.-Y. Jang, Adv Energy Mater. 2018, 8, 1701683.

[49] Y. Wang, S. Wang, X. Chen, Z. Li, J. Wang, T. Li, X. Deng, J Mater Chem A. 2018, 6 (11), 4860-4867.

[50] S. Wang, H. Chen, J. Zhang, G. Xu, W. Chen, R. Xue, M. Zhang, Y. Li, Y. Li, Adv Mater. 2019, 31, 1903691.

[51] C. Bi, Q. Wang, Y. Shao, Y. Yuan, Z. Xiao, J. Huang, Nat Commun. 2015, 6, 7747. 


\section{WILEY-VCH}

[52] H. D. Pham, T. T. Do, J. Kim, C. Charbonneau, S. Manzhos, K. Feron, W. C. Tsoi, J. R.

Durrant, S. M. Jain, P. Sonar, Adv Energy Mater. 2018, 8 , 1703007.

[53] C. M. Wolff, F. Zu, A. Paulke, L. P. Toro, N. Koch, D. Neher, Adv Mater. 2017, 29 , 1700159.

[54] M. Zhong, Y. Liang, J. Zhang, Z. Wei, Q. Li, D. Xu, J Mater Chem A. 2019, 7 (12), 6659-6664.

[55] Z. Liu, S. Li, X. Wang, Y. Cui, Y. Qin, S. Leng, Y.-x. Xu, K. Yao, H. Huang, Nano Energy. 2019, 62, 734-744.

[56] J. Huang, S. Xiang, J. Yu, C.-Z. Li, Energ Environ Sci. 2019, 12, 929-937.

[57] G. Xu, R. Xue, W. Chen, J. Zhang, M. Zhang, H. Chen, C. Cui, H. Li, Y. Li, Y. Li, Adv. Mater. Energy 2018, 8, 1703054.

[58] G. Han, F. Wang, C. Jia, Y. Chen, M. Guan, H. Liu, Q. Zhang, Mater Chem Phys. 2018, $219,90-95$.

[59] D. Saranin, P. Gostischev, D. Tatarinov, I. Ermanova, V. Mazov, D. Muratov, A. Tameev, D. Kuznetsov, S. Didenko, A. Di Carlo, Materials. 2019, 12 , 1406.

[60] N. Pellet, P. Gao, G. Gregori, T. Y. Yang, M. K. Nazeeruddin, J. Maier, M. Gratzel, Angew Chem Int Edit. 2014, 53, 3151-3157

[61] N. J. Jeon, J. H. Noh, Y. C. Kim, W. S. Yang, S. Ryu, S. I. Seok, Nat Mater. 2014, 13, 897-903.

[62] M. I. Dar, N. Arora, P. Gao, S. Ahmad, M. Gratzel, M. K. Nazeeruddin, Nano Lett. 2014, 14, 6991-6996.

[63] M. I. Dar, M. Abdi-Jalebi, N. Arora, T. Moehl, M. Gratzel, M. K. Nazeeruddin, Adv Mater. 2015, 27, 7221-7228.

[64] M. I. Dar, M. Abdi-Jalebi, N. Arora, M. Gratzel, M. K. Nazeeruddin, Adv Energy Mater. 2016, 6,1501358 . 


\section{WILEY-VCH}

[65] G. Longo, C. Momblona, M. G. La-Placa, L. Gil-Escrig, M. Sessolo, H. J. Bolink, Acs Energy Lett. 2018, 3, 214-219.

[66] a)C. Huang, P. Lin, N. Q. Fu, C. Liu, B. M. Xu, K. W. Sun, D. Y. Wang, X. R. Zeng, S. M. Ke, Chem Commun. 2019, 55 , 2777-2780. b) J. Huang, M. Wang, L. Ding, Z. Yang, K. Zhang, RSC Adv 2016, 6, 55720-55725.

[67] Y. Wang, M. I. Dar, L. K. Ono, T. Y. Zhang, M. Kan, Y. W. Li, L. J. Zhang, X. T.

Wang, Y. G. Yang, X. Y. Gao, Y. B. Qi, M. Gratzel, Y. X. Zhao, Science. 2019, 36, 591-595.

[68] C. L. Wang, D. W. Zhao, Y. Yu, N. Shrestha, C. R. Grice, W. Q. Liao, A. J. Cimaroli, J. Chen, R. J. Ellingson, X. Z. Zhao, Y. F. Yan, Nano Energy. 2017, 35, 223-232.

[69] H. W. Qiao, S. Yang, Y. Wang, X. Chen, T. Y. Wen, L. J. Tang, Q. L. Cheng, Y. Hou, H. J. Zhao, H. G. Yang, Adv Mater. 2019, 31 , 1804217.

[70] C. Y. Yi, J. S. Luo, S. Meloni, A. Boziki, N. Ashari-Astani, C. Gratzel, S. M.

Zakeeruddin, U. Rothlisberger, M. Gratzel, Energ Environ Sci. 2016, 9 (2), 656-662.

[71] N. J. Jeon, J. H. Noh, W. S. Yang, Y. C. Kim, S. Ryu, J. Seo, S. I. Seok, Nature. 2015, $517,476-480$.

[72] Y. Yu, C. L. Wang, C. R. Grice, N. Shrestha, D. W. Zhao, W. Q. Liao, L. Guan, R. A. Awni, W. W. Meng, A. J. Cimaroli, K. Zhu, R. J. Ellingson, Y. F. Yan, Acs Energy Lett. 2017, 2, 1177-1182.

[73] D. Q. Bi, C. Y. Yi, J. S. Luo, J. D. Decoppet, F. Zhang, S. M. Zakeeruddin, X. Li, A. Hagfeldt, M. Gratzel, Nat Energy. 2016, 1, 16142.

[74] F. Zhang, W. D. Shi, J. S. Luo, N. Pellet, C. Y. Yi, X. Li, X. M. Zhao, T. J. S. Dennis, X. G. Li, S. R. Wang, Y. Xiao, S. M. Zakeeruddin, D. Q. Bi, M. Gratzel, Adv Mater. 2017, 29, 1606806.

[75] A. Albadri, P. Yadav, M. Alotaibi, N. Arora, A. Alyamani, H. Albrithen, M. I. Dar, S. M. Zakeeruddin, M. Gratzel, J Phys Chem C. 2017 121, 24903-24908. 


\section{WILEY-VCH}

[76] P. Yadav, M. I. Dar, N. Arora, E. A. Alharbi, F. Giordano, S. M. Zakeeruddin, M.

Gratzel, Adv Mater. 2017, 29, 1701077.

[77] E. A. Alharbi, M. I. Dar, N. Arora, M. Alotaibi, Y. A. Alzhrani, P. Yadav, W. Tress, A. Alyamani, A. Albadri, S. M. Zakeeruddin, M. Grätzel, Research. 2019, 2019, 8474698.

[78] R. Fu, Y. C. Zhao, W. K. Zhou, Q. Li, Y. Zhao, Q. Zhao, J Mater Chem A. 2018, 6, $14387-14391$.

[79] H. P. Zhou, Q. Chen, G. Li, S. Luo, T. B. Song, H. S. Duan, Z. R. Hong, J. B. You, Y. S. Liu, Y. Yang, Science. 2014, 345, 542-546.

[80] J. Y. Seo, R. Uchida, H. S. Kim, Y. Saygili, J. S. Luo, C. Moore, J. Kerrod, A. Wagstaff, M. Eklund, R. McIntyre, N. Pellet, S. M. Zakeeruddin, A. Hagfeldt, M. Gratzel, Adv Funct Mater. 2018, 28, 1705763.

[81] J. P. C. Baena, L. Steier, W. Tress, M. Saliba, S. Neutzner, T. Matsui, F. Giordano, T. J. Jacobsson, A. R. S. Kandada, S. M. Zakeeruddin, A. Petrozza, A. Abate, M. K. Nazeeruddin, M. Gratzel, A. Hagfeldt, Energ Environ Sci. 2015, 8, 2928-2934

[82] D. Yang, R. X. Yang, K. Wang, C. C. Wu, X. J. Zhu, J. S. Feng, X. D. Ren, G. J. Fang, S. Priya, S. Z. Liu, Nat Commun. 2018, 9, 3239.

[83] X. Gong, Q. Sun, S. S. Liu, P. Z. Liao, Y. Shen, C. Gratzel, S. M. Zakeeruddin, M. Gratzel, M. K. Wang, Nano Lett. 2018, 18, 3969-3977.

[84] S. J. Yuan, J. Wang, K. L. Yang, P. F. Wang, X. Zhang, Y. Q. Zhan, L. R. Zheng, Nanoscale. 2018, 10, 18909-18914.

[85] E. H. Anaraki, A. Kermanpur, M. T. Mayer, L. Steier, T. Ahmed, S. H. Turren-Cruz, J. Y. Seo, J. S. Luo, S. M. Zakeeruddin, W. R. Tress, T. Edvinsson, M. Gratzel, A. Hagfeldt, J. P. Correa-Baena, Acs Energy Lett. 2018, 3, 773-778.

[86] H. S. Kim, J. Y. Seo, S. Akin, E. Simon, M. Fleischer, S. M. Zakeeruddin, M. Gratzel, A. Hagfeldt, Nano Energy. 2019, 61, 126-131. 


\section{WILEY-VCH}

[87] S. Akin, Y. H. Liu, M. I. Dar, S. M. Zakeeruddin, M. Gratzel, S. Turan, S. Sonmezoglu, J Mater Chem A. 2018, 6, 20327-20337.

[88] J. P. Correa-Baena, W. Tress, K. Domanski, E. H. Anaraki, S. H. Turren-Cruz, B. Roose, P. P. Boix, M. Gratzel, M. Saliba, A. Abate, A. Hagfeldt, Energ Environ Sci. 2017, 10, $1207-$ 1212.

[89] J. Y. Seo, H. S. Kim, S. Akin, M. Stojanovic, E. Simon, M. Fleischer, A. Hagfeldt, S. M. Zakeeruddin, M. Gratzel, Energ Environ Sci. 2018, 11, 2985-2992.

[90] M. M. Tavakoli, W. Tress, J. V. Milic, D. Kubicki, L. Emsley, M. Gratzel, Energ Environ Sci. 2018, 11, 3310-3320.

[91] Y. Hou, X. Y. Du, S. Scheiner, D. P. McMeekin, Z. P. Wang, N. Li, M. S. Killian, H. W. Chen, M. Richter, I. Levchuk, N. Schrenker, E. Spiecker, T. Stubhan, N. A. Luechinger, A. Hirsch, P. Schmuki, H. P. Steinruck, R. H. Fink, M. Halik, H. J. Snaith, C. J. Brabec, Science. 2017, $358,1192-1197$.

[92] Y. Kim, E. H. Jung, G. Kim, D. Kim, B. J. Kim, J. Seo, Adv Energy Mater. 2018, 8, 1801668.

[93] N. J. Jeon, H. Na, E. H. Jung, T. Y. Yang, Y. G. Lee, G. Kim, H. W. Shin, S. I. Seok, J. Lee, J. Seo, Nat Energy. 2018, 3, 682-689.

[94] W. Chen, Y. H. Wu, J. Fan, A. B. Djurisic, F. Z. Liu, H. W. Tam, A. Ng, C. Surya, W. K. Chan, D. Wang, Z. B. He, Adv Energy Mater. 2018, 8, 1703519.

[95] S. S. Mali, H. J. Kim, S. E. Shim, C. K. Hong, Nanoscale. 2016, 8, 19189-19194.

[96] Y. Bai, H. N. Chen, S. Xiao, Q. F. Xue, T. Zhang, Z. L. Zhu, Q. Li, C. Hu, Y. Yang, Z. C. Hu, F. Huang, K. S. Wong, H. L. Yip, S. H. Yang, Adv Funct Mater. 2016, 26, 2950-2958. [97] W. Chen, Y. C. Zhou, L. J. Wang, Y. H. Wu, B. Tu, B. B. Yu, F. Z. Liu, H. W. Tam, G. Wang, A. B. Djurisic, L. Huang, Z. B. He, Adv Mater. 2018, 30, 1800515. 


\section{WILEY-VCH}

[98] Z. Y. Liu, J. J. Chang, Z. H. Lin, L. Zhou, Z. Yang, D. Z. Chen, C. F. Zhang, S. Z. Liu, Y. Hao,Adv Energy Mater. 2018, 8, 1703432.

[99] J. C. Yu, J. A. Hong, E. D. Jung, D. Bin Kim, S. M. Baek, S. Lee, S. Cho, S. S. Park, K. J. Choi, M. H. Song, Sci Rep 2018, 8, 1070.

[100] M. Stolterfoht, C. M. Wolff, J. A. Marquez, S. S. Zhang, C. J. Hages, D. Rothhardt, S. Albrecht, P. L. Burn, P. Meredith, T. Unold, D. Neher, Nat Energy. 2018, 3, 847-854.

[101] J. Peng, J. I. Khan, W. Z. Liu, E. Ugur, T. Duong, Y. L. Wu, H. P. Shen, K. Wang, H. Dang, E. Aydin, X. B. Yang, Y. M. Wan, K. J. Weber, K. R. Catchpole, F. Laquai, S. De Wolf, T. P. White, Adv Energy Mater. 2018, 8, 1801208.

[102] S. Akin, Y. Altintas, E. Mutlugun, S. Sonmezoglu, Nano Energy. 2019, 60, 557-566.

[103] S. Akin, ACS Appl. Mater. Interfaces 2019, DOI: 10.1021/acsami.9b13876.

[104] M. Hu, C. Bi, Y. B. Yuan, Y. Bai, J. S. Huang, Adv Sci. 2016, 3, 1500301.

[105] H. R. Tan, F. L. Che, M. Y. Wei, Y. C. Zhao, M. I. Saidaminov, P. Todorovic, D.

Broberg, G. Walters, F. R. Tan, T. T. Zhuang, B. Sun, Z. Q. Liang, H. F. Yuan, E. Fron, J.

Kim, Z. Y. Yang, O. Voznyy, M. Asta, E. H. Sargent, Nat Commun. 2018, 9, 3100.

[106] N. Li, S. Tao, Y. Chen, X. Niu, C. K. Onwudinanti, C. Hu, Z. Qiu, Z. Xu, G. Zheng, L. Wang, Y. Zhang, L. Li, H. Liu, Y. Lun, J. Hong, X. Wang, Y. Liu, H. Xie, Y. Gao, Y. Bai, S. Yang, G. Brocks, Q. Chen, H. Zhou, Nat. Energy 2019, 4, 408-415.

[107] S. Yang, J. Dai, Z. Yu, Y. Shao, Y. Zhou, X. Xiao, X. C. Zeng, J. Huang, J Am Chem Soc. 2019, 141, 5781-5787.

[108] C. Chen, Z. N. Song, C. X. Xiao, D. W. Zhao, N. Shrestha, C. W. Li, G. Yang, F. Yao, X. L. Zheng, R. J. Ellingson, C. S. Jiang, M. Al-Jassim, K. Zhu, G. J. Fang, Y. F. Yan, Nano Energy. 2019, 61, 141-147. 


\section{WILEY-VCH}

[109] D. P. McMeekin, G. Sadoughi, W. Rehman, G. E. Eperon, M. Saliba, M. T. Horantner,

A. Haghighirad, N. Sakai, L. Korte, B. Rech, M. B. Johnston, L. M. Herz, H. J. Snaith, Science. 2016, 351, 151-155.

[110] Y. C. Zhao, H. R. Tan, H. F. Yuan, Z. Y. Yang, J. Z. Fan, J. Kim, O. Voznyy, X. W.

Gong, L. N. Quan, C. S. Tan, J. Hofkens, D. P. Yu, Q. Zhao, E. H. Sargent, Nat Commun. 2018, 9, 1607.

[111] K. T. Cho, S. Paek, G. Grancini, C. Roldan-Carmona, P. Gao, Y. H. Lee, M. K. Nazeeruddin, Energ Environ Sci. 2017, 10, 621-627.

[112] K. Choi, J. Lee, H. I. Kim, C. W. Park, G. W. Kim, H. Choi, S. Park, S. A. Park, T. Park, Energ Environ Sci. 2018, 11 , 3238-3247.

[113] K. Gao, B. Xu, C. S. Hong, X. L. Shi, H. B. Liu, X. S. Li, L. H. Xie, A. K. Y. Jen, Adv Energy Mater. 2018, 8, 1800809.

[114] N. Chen, Y. Sun, J. J. Peng, W. Zhang, X. J. Su, K. B. Zheng, T. Pullerits, Z. Q. Liang, Adv Energy Mater. 2017, 7, 1700162.

[115] H. H. Tsai, W. Y. Nie, J. C. Blancon, C. C. S. Toumpos, R. Asadpour, B. Harutyunyan, A. J. Neukirch, R. Verduzco, J. J. Crochet, S. Tretiak, L. Pedesseau, J. Even, M. A. Alam, G. Gupta, J. Lou, P. M. Ajayan, M. J. Bedzyk, M. G. Kanatzidis, A. D. Nature. 2016, 536, 312316.

[116] L. Etgar, Energ Environ Sci. 2018, 11, 234-242.

[117] S. Yang, Y. Wang, P. R. Liu, Y. B. Cheng, H. J. Zhao, H. G. Yang, Nat Energy. 2016, $1,15016$.

[118] Y. H. Hu, J. Schlipf, M. Wussler, M. L. Petrus, W. Jaegermann, T. Bein, P. MullerBuschbaum, P. Docampo, Acs Nano. 2016, 10, 5999-6007.

[119] Z. P. Wang, Q. Q. Lin, F. P. Chmiel, N. Sakai, L. M. Herz, H. J. Snaith, Nat Energy. 2017, 2, 17135. 


\section{WILEY-VCH}

[120] E. A. Alharbi, A. Y. Alyamani, D. J. Kubicki, A. R. Uhl, B. J. Walder, A. Q. Alanazi, J.

Luo, A. Burgos-Caminal, A. Albadri, H. Albrithen, M. H. Alotaibi, J.-E. Moser, S. M.

Zakeeruddin, F. Giordano, L. Emsley, M. Grätzel, Nat. Commun. 2019, 10, 3008.

[121] J. J. Yoo, S. Wieghold, M. C. Sponseller, M. R. Chua, S. N. Bertram, N. T. P. Hartono,

J. S. Tresback, E. C. Hansen, J. P. Correa-Baena, V. Bulovic, T. Buonassisi, S. S. Shin, M. G.

Bawendi, Energ Environ Sci. 2019, 12, 2192-2199.

[122] T. Zhou, H. Lai, T. Liu, D. Lu, X. Wan, X. Zhang, Y. Liu, Y. Chen, Adv Mater. 2019, 31,1901242

[123] G. Grancini, C. Roldan-Carmona, I. Zimmermann, E. Mosconi, X. Lee, D. Martineau,

S. Narbey, F. Oswald, F. De Angelis, M. Graetzel, M. K. Nazeeruddin, Nat Commun. 2017, 8, 15684.

[124] Y. Bai, S. Xiao, C. Hu, T. Zhang, X. Y. Meng, H. Lin, Y. L. Yang, S. H. Yang, Adv Energy Mater. 2017, 7, 1701038.

[125] D. Y. Luo, W. Q. Yang, Z. P. Wang, A. Sadhanala, Q. Hu, R. Su, R. Shivanna, G. F. Trindade, J. F. Watts, Z. J. Xu, T. H. Liu, K. Chen, F. J. Ye, P. Wu, L. C. Zhao, J. Wu, Y. G. Tu, Y. F. Zhang, X. Y. Yang, W. Zhang, R. H. Friend, Q. H. Gong, H. J. Snaith, R. Zhu, Science. 2018, 360, 1442-1446.

[126] K. T. Cho, Y. Zhang, S. Orlandi, M. Cavazzini, I. Zimmermann, A. Lesch, N. Tabet, G. Pozzi, G. Grancini, M. K. Nazeeruddin, Nano Lett. 2018, 18, 5467-5474.

[127] J. W. Lee, Z. H. Dai, T. H. Han, C. Choi, S. Y. Chang, S. J. Lee, N. De Marco, H. X. Zhao, P. Y. Sun, Y. Huang, Y. Yang,Nat Commun. 2018, 9, 3021.

[128] K. T. Cho, G. Grancini, Y. Lee, E. Oveisi, J. Ryu, O. Almora, M. Tschumi, P. A. Schouwink, G. Seo, S. Heo, J. Park, J. Jang, S. Paek, G. Garcia-Belmonte, M. K. Nazeeruddin, Energ Environ Sci. 2018, 11, 952-959. 


\section{WILEY-VCH}

[129] Y. Zhou, F. Wang, Y. Cao, J. P. Wang, H. H. Fang, M. A. Loi, N. Zhao, C. P. Wong, Adv Energy Mater. 2017, 7, 1701048.

[130] S. Gharibzadeh, B. A. Nejand, M. Jakoby, T. Abzieher, D. Hauschild, S.

Moghadamzadeh, J. A. Schwenzer, P. Brenner, R. Schmager, A. A. Haghighirad, L.

Weinhardt, U. Lemmer, B. S. Richards, I. A. Howard, U. W. Paetzold, Adv Energy Mater. 2019, 9, 1803699.

[131] P. Chen, Y. Bai, S. C. Wang, M. Q. Lyu, J. H. Yun, L. Z. Wang, Adv Funct Mater. 2018, 28, 1706923.

[132] Y. Lin, Y. Bai, Y. J. Fang, Z. L. Chen, S. Yang, X. P. Zheng, S. Tang, Y. Liu, J. J.

Zhao, J. S. Huang, J Phys Chem Lett. 2018, 9, 654-658.

[133] L. Chen, Y. Y. Tan, Z. X. Chen, T. Wang, S. Hu, Z. A. Nan, L. Q. Xie, Y. Hui, J. X. Huang, C. Zhan, S. H. Wang, J. Z. Zhou, J. W. Yan, B. W. Mao, Z. Q. Tian, J. Am. Chem Soc. 2019, 141, 1665-1671.

[134] S. Bai, P. M. Da, C. Li, Z. P. Wang, Z. C. Yuan, F. Fu, M. Kawecki, X. J. Liu, N. Sakai, J. T. W. Wang, S. Huettner, S. Buecheler, M. Fahlman, F. Gao, H. J. Snaith, Nature. 2019, $571,245-250$.

[135] S. Yang, S. Chen, E. Mosconi, Y. Fang, X. Xiao, C. Wang, Y. Zhou, Z. Yu, J. Zhao, Y. Gao, F. De Angelis, J. Huang, Science 2019, 365, 473-478.

[136] Y. Wang, T. Wu, J. Barbaud, W. Kong, D. Cui, H. Chen, X. Yang, L. Han, Science 2019, 365, 687-691.

[137] P. Qin, S. Tanaka, S. Ito, N. Tetreault, K. Manabe, H. Nishino, M. K. Nazeeruddin, M. Gratzel, Nat Commun. 2014, 5, 3834.

[138] L. Kavan, Z. V. Zivcova, P. Hubik, N. Arora, M. I. Dar, S. M. Zakeeruddin, M. Gratzel, ACS Appl. Energy Mater. 2019, 2, 4264-4273. 


\section{WILEY-VCH}

[139] N. Arora, M. I. Dar, A. Hinderhofer, N. Pellet, F. Schreiber, S. M. Zakeeruddin, M. Gratzel, Science. 2017, 358, 768-771.

[140] J. V. Milic, N. Arora, M. I. Dar, S. M. Zakeeruddin, M. Gratzel, Adv. Mater Interfaces. 2018, 5, 1800416.

[141] N. Arora, M. I. Dar, S. Akin, R. Uchida, T. Baumeler, Y. Liu, S. M. Zakeeruddin, M. Gratzel Small, 2019, DOI: 10.1002/smll.201904746.

[142] L. Wang, H. Zhou, J. Hu, B. Huang, M. Sun, B. Dong, G. Zheng, Y. Huang, Y. Chen, L. Li, Z. Xu, N. Li, Z. Liu, Q. Chen, L.-D. Sun, C.-H. Yan, Science 2019, 363, 265-270.

[143] S. G. Hashmi, D. Martineau, X. Li, M. Ozkan, A. Tiihonen, M. I. Dar, T. Sarikka, S. M. Zakeeruddin, J. Paltakari, P. D. Lund, M. Grätzel, Adv. Mater. Technol. 2017, 2, 1600183. [144] S. G. Hashmi, D. Martineau, M. I. Dar, T. T. T. Myllymäki, T. Sarikka, V. Ulla, S. M. Zakeeruddin, M. Grätzel, J. Mater. Chem. A 2017, 5, 12060-12067.

[145] D. Di Girolamo, M. I. Dar, D. Dini, L. Gontrani, R. Caminiti, A. Mattoni, M. Graetzel, S. Meloni, J. Mater. Chem. A 2019, 7, 12292-12302.

[146] Y. Hou, Z. R. Zhou, T. Y. Wen, H. W. Qiao, Z. Q. Lin, B. Ge, H. G. Yang, Nanoscale Horiz. 2019, 4, 208-213.

[147] L. L. Gao, I. Spanopoulos, W. J. Ke, S. Huang, I. Hadar, L. Chen, X. L. Li, G. J. Yang, M. G. Kanatzidis, Acs Energy Lett. 2019, 4, 1763-1769.

[148] Y. F. Yue, N. Salim, Y. Z. Wu, X. D. Yang, A. Islam, W. Chen, J. Liu, E. B. Bi, F. X. Xie, M. L. Cai, L. Y. Han, Adv Mater. 2016, 28, 10738-10743.

[149] D. D. Song, D. Wei, P. Cui, M. C. Li, Z. Q. Duan, T. Y. Wang, J. Ji, Y. Y. Li, J. M. Mbengue, Y. F. Li, Y. He, M. Trevor, N. G. Park, J Mater Chem A. 2016, 4, 6091-6097. [150] J. B. Zhang, B. Xu, L. Yang, A. Mingorance, C. Q. Ruan, Y. Hua, L. Q. Wang, N. Vlachopoulos, M. Lira-Cantu, G. Boschloo, A. Hagfeldt, L. C. Sun, E. M. J. Johansson, Adv Energy Mater. 2017, 7, 1602736. 


\section{WILEY-VCH}

[151] L. Calio, M. Salado, S. Kazim, S. Ahmad, Joule. 2018, 2, 1800-1815.

[152] I. Jeon, H. Ueno, S. Seo, K. Aitola, R. Nishikubo, A. Saeki, H. Okada, G. Boschloo, S. Maruyama, Y. Matsuo, Angew. Chem., Int. Ed.. 2018, 57, 4607-4611.

[153] W. Luo, C. C. Wu, D. Wang, Y. Q. Zhang, Z. H. Zhang, X. Qi, N. Zhu, X. Guo, B. Qu, L. X. Xiao, Z. J. Chen, Acs Appl Mater Inter. 2019, 11, 9149-9155.

[154] F. Bella, G. Griffini, J. P. Correa-Baena, G. Saracco, M. Gratzel, A. Hagfeldt, S. Turri, C. Gerbaldi, Science. 2016, 354, 203-206. 


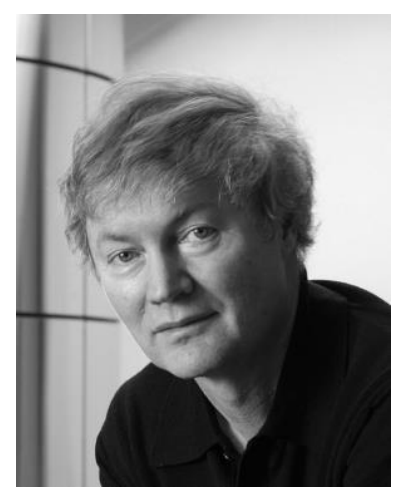

Michael Graetzel is a Professor at the Ecole Polytechnique Fédérale de Lausanne (EPFL). He directs there the Laboratory of Photonics and Interfaces. He pioneered research on energy and electron transfer reactions in mesoscopic systems and their use to generate electricity and fuels from sunlight. He is credited with moving the solar cell field beyond the principle of light absorption via diodes to the molecular level exploiting the sensitization of 3D nanoparticle networks of semiconductors oxides by dyes, pigments, or quantum dots for light energy harvesting.

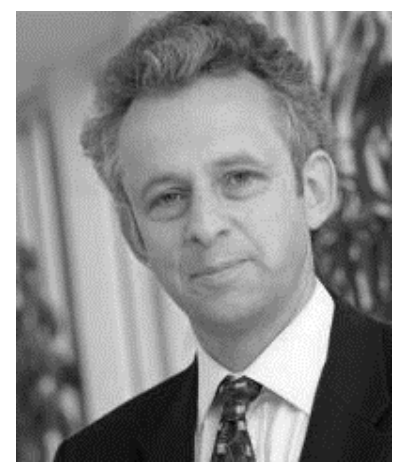

Richard Friend holds the Cavendish Professorship of Physics at the University of Cambridge. His research encompasses the physics, materials science and engineering of semiconductor devices made with carbon-based semiconductors, particularly polymers. His research advances have shown that carbon-based semiconductors have significant applications in lightemitting devices, solar cells, lasers, and electronics. These have been developed and exploited through a number of spin-off companies. His current research interests are directed to novel schemes to improve the performance and cost of solar cells.

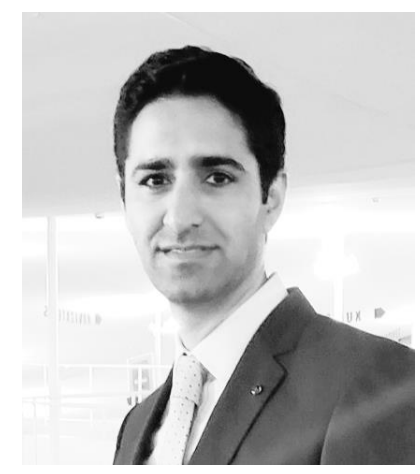

M. Ibrahim Dar is an Advanced Swiss National Science Foundation Fellow working in collaboration with Prof. Sir Richard Friend at the Cavendish Laboratory, the University of 


\section{WILEY-VCH}

Cambridge. From 2014-2018, he worked as a Post-Doctoral Scientist with Prof. Michael Graetzel at EPFL, Switzerland. He received his $\mathrm{PhD}$ in Nanoscience at Indian Institute of Science, Bangalore, India in 2014. During this period, he was also awarded the Swiss Government Excellence Research Scholarship to work as a guest PhD scholar in Prof. Graetzel group at EPFL. His current research focuses on understanding structural, compositional and optoelectronic properties of materials for their application in lightharnessing and light-emitting devices. 


\section{WILEY-VCH}

\section{The table of contents entry}

Despite the record efficiency exceeding $25 \%$, the long-term operational stability of perovskite solar cells is limited by the degradation mechanisims accelerated by the presence of vacancies and defects. In this review, recent engineering strategies ranging from grains to interfaces that mitigate degradation and improve efficincies are discussed.

Keyword (perovskite solar cells, defects, passivation, efficiency, mixed-cation-halide, 2D$3 \mathrm{D}$, engineering, stability)

Seckin Akin, Neha Arora*, Shaik M. Zakeeruddin, Michael Grätzel, Richard H. Friend, M. Ibrahim Dar*

New Passivation Strategies for High-Efficiency and Stable Perovskite Solar Cells

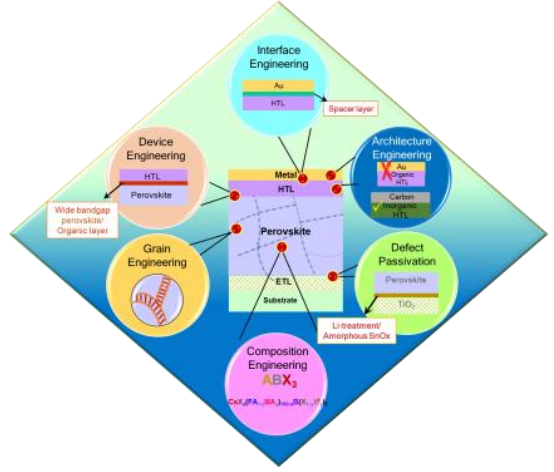

